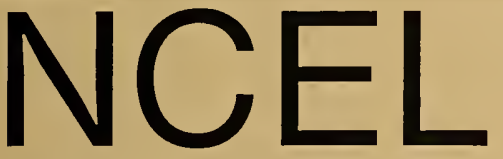

Technical Report
November 1989

By John F. Peel Brahtz, Ph. D Sponsored By Naval Civil Engineering Laboratory

\title{
MODULARIZED OCEAN BASING SYSTEM - A UNITED STATES OPTION IN A STRATEGY OF DISCRIMINATE DETERRENCE (Circa 2000)
}

ABSTRACT This report investigates the feasibility of employing MOBS, the Modularized Ocean Basing System, as an alternative to fixed land basing overseas. MOBS is a concept for floating bases that could serve to project United States power as part of a U.S. forward strategy of "Discriminate Deterrence". The requirement for such an alternative to land basing becomes increasingly likely in a typical Third World scenario of growing nationalism and denial of extraterritorial rights to the U.S. This trend is likely_to become amplified following recent changes in the political attitude of Gom= munist Block nations and the Soviet Union.

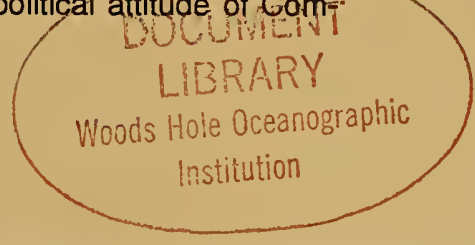

IVAL CIVIL ENGINEERING LABORATORY PORT HUENEME CALIFORNIA 93043-5003 


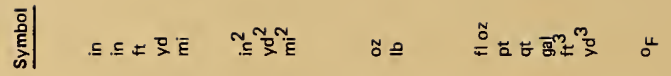

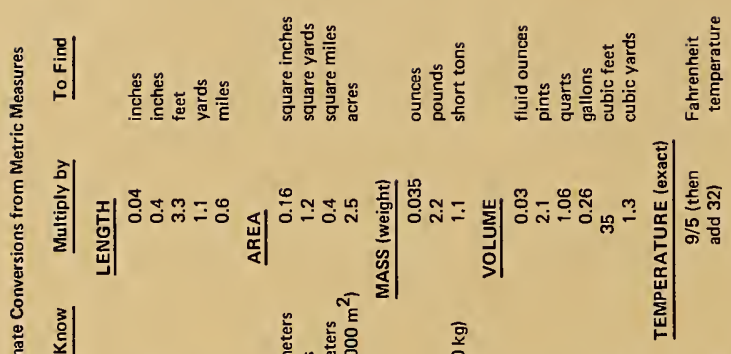

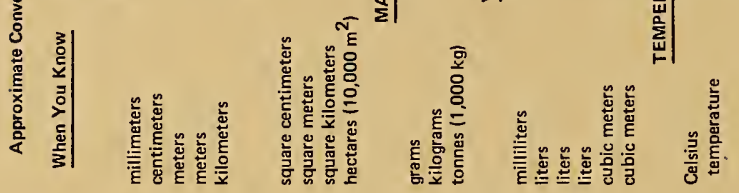

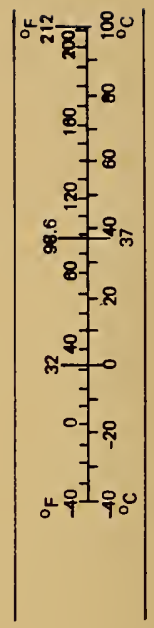

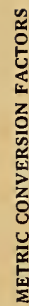

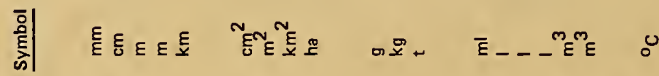

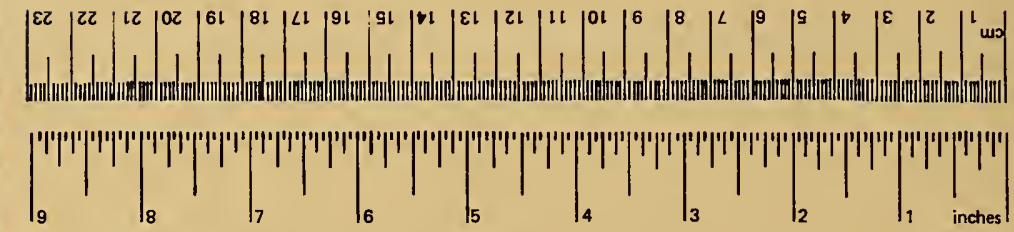

总

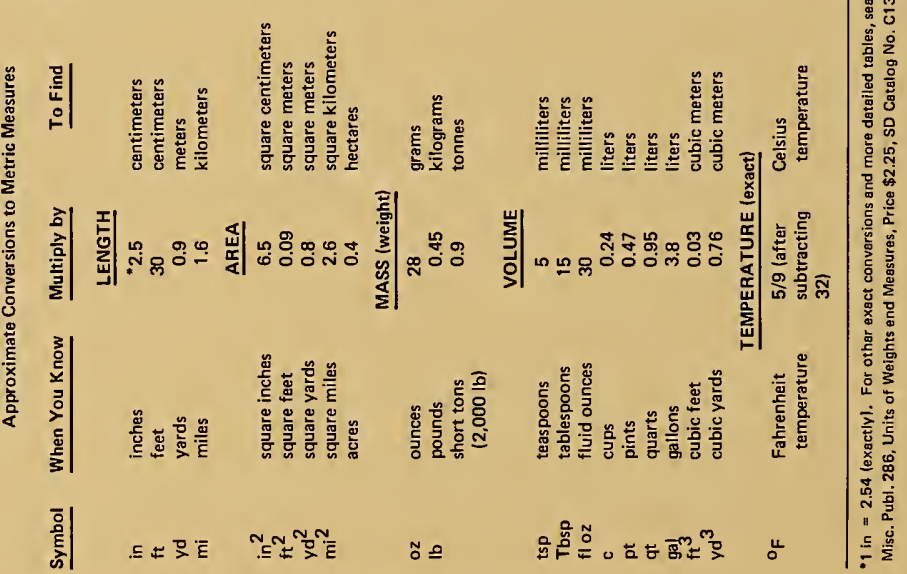




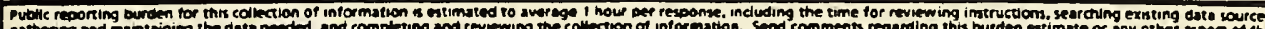

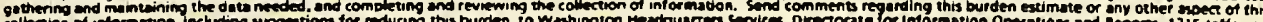

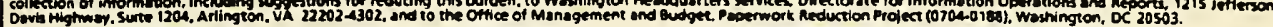

\begin{tabular}{|c|c|c|}
\hline 1. AGENC USE ONLY (Leave b/ank) & $\begin{array}{c}\text { 2. REPORT DATE } \\
\text { NOV } 1989\end{array}$ & $\begin{array}{c}\text { 3. REPORT TYPE AND DATES COVERED } \\
\text { Final; Jan 1989- Nov } 1989\end{array}$ \\
\hline
\end{tabular}

4. TITE AND SUBTTEL

MODULARIZED OCEAN BASING SYSTEM - A UNITED STATES OPTION IN A STRATEGY OF DISCRIMINATE DETERRENCE (Circa 2000)

6. AUTHOA(S)

John F. Peel Brahtz

\section{FUNDING MUMBERS}

N/A

Sponsoring: Naval Civil Engineering Laboratory, Port Hueneme,

10. SPONSORING/MONITORING

8. PEAFORMING ORGANIZATION

7. PERFORMING ORGANIZATION HAME(S) AND ADDRESS(ES)

Naval Civil Engineering Laboratory

Port Hueneme, CA 93043-5003

TR-928 CA 93043

Monitoring: Naval Postgraduate School, National Security Affairs

11. SUPPLE MENTARY MOTES

12a. DISTRIBUTION/AVALAGILITY STATEMENT

12b. DISTRIBUTION CODE

Approved for public release; distribution is unlimited.

\section{ABSTRACT (Maximum 200 words)}

This report investigates the feasibility of employing MOBS, the Modularized Ocean Basing System, as an alternative to fixed land basing overseas. MOBS is a concept for floating bases that could serve to project United States power as part of a U.S. forward strategy of "Discriminate Deterrence". The requirement for such an alternative to land basing becomes increasingly likely in a typical Third World scenario of growing nationalism and denial of extraterritorial rights to the U.S. This trend is likely to become amplified following recent changes in the political attitude of Communist Block nations and the Soviet Union.

1L. SUEAEC TERMS

MOBS; modularized ocean basing systems; U.S. power projection, circa 2000; forward basing; deployable basing systems; future basing alternatives; multi-senvice ioint logistic support stmucture

17. SECURITY CLASSIFICATION 18. SECURITY CLASSIFICATION OF REPORT

Unclassified
15. NUMBER OF PAGES

101

16. PRICE CODE

20. LIMITATION OF ABSTRACT
19. SECURITY CLASSIFICATION
OF ABSTRACT Unclassified
UL 



\section{EXECUTIVE SUIMARY}

\section{Introduction}

This report is being submitted as an NCEL contribution to the OP603 sponsored project, "Relationship of War-at-Sea to Warfare Ashore," for the National Security Affairs Department at the Naval Postgraduate School. Investigation centers on feasibility of floating bases as a viable alternative to diminishing U.S. foreign basing assets. The study is based in part on the 1988 report of the President's Commission on Integrated Long-Term Strategy, "Discriminate Deterrence." The CILTS report provides strategic factors and threat criteria from which to determine effective basing needs and the future security environment as context for the problem situation.

Early studies at NCEL (1970-71) into the feasibility of large buoyant platforms, were identified by the acronym, MOBS, to indicate "Mobile Ocean Basing System." Now, to emphasize design flexibility and system optimization through modularity in the present investigation, this report designates "MOBS" as "Modularized Ocean Basing System."

In parallel with the current MOBS study, NCEL draws upon the same laboratory resources to prepare an information package for OP-403 (Logistics). This package is intended specifically for briefing the Chief of Naval Operations in anticipation of a scheduled executive decision conference as described in the CNO letter dated 22 May 1989 (Appendix A). This effort, in cooperation with other activities, is identified as "Ocean Station Project" (OSP).

\section{Objectives and Rationale}

The following study objectives define the thrust of this investigation: 
- Isolate effective basing needs and define related functional requirements for a unified logistic support structure for joint multi-service military operations, considering future U.S. forward strategy.

- Describe a range of MOBS concepts that satisfy the necessary and sufficient requirements for war-fighting support structure in consonance with a national security strategy of Discriminate Deterrence.

- Determine the performance and technical feasibility of selected MOBS concepts.

- Assess performance capabilities of selected MOBS concepts compared to a most likely alternative within the context of a typical Third World scenario, circa 2000.

- Assess financial feasibility of the MOBS concept in comparison to a most likely alternative.

Reasoning applied in carrying objectives through to final conclusions consists of two parallel and ordered decision sets, both stemming from analysis of the future security environment as depicted by CILTS (Appendix B). One set includes Analysis of Basing Needs, System Identification, Formulation of Concepts, and Physical Viability Analysis, ordered as stated. Similarly, a second set includes Analysis of Threat Situation, Synthesis of Scenarios, and Gaming Comparison of Alternative Systems. Combined output of the two sets is Basing System I (with MOBS) and Basing System II (without MOBS). The two alternative basing systems, both having been determined to be technically and operationally viable, are compared for relative performance effectiveness in terms of useful timewise avallability of cumulative logistic throughput. This single functional measure of effectiveness is selected out of 21 recognized forward Navy base functions as being the most significant in the context 
of a typical Third World crisis situation wherein immediate and visible U.S. response with large scale force projection would be essential for deterring Soviet reaction while proximate U.S. foreign basing assets are lacking.

Establishing comparative cost-effectiveness for the two basing systems will require definitive cost analysis including weighted application of an appropriate measure of effectiveness for each of the several significant basing functions. Therefore, in the interest of timeliness and maximizing benefit deriving from this phase of the system development process, detailed cost-benefit evaluation, however essential to the ultimate decision process, is necessarily expected to be treated in a later phase.

\section{Conclusions}

In relating to the study objectives, the following conclusions and observations characterize the feasibility of modularized ocean basing systems as an alternative to diminished foreign basing assets in the year 2000 time frame:

- Conclusion: The U.S. will remain committed to a forward strategy of Discriminate Deterrence for the long term (20 years).

Observation: It would appear incredible to contemplate any U.S. military posture other than total national commitment to a forward strategy pending abandonment by the Soviet Union of its aggressive military aims and objectives. The CILTS report confirms this conclusion. Therefore, it serves as a basic assumption to the rationale for system concept development in this study.

- Conclusion: In support of a forward strategy the U.S. must anticipate future diminished foreign basing assets by seeking to develop viable alternatives. 
Observation: As recently as mid-1989, The Association of South East Asian Nation's Inter-Parliamentary Organization has called for the closure of all foreign military bases as a step toward regional neutrality. This is typical of positions now being assumed by Third World nations having welcomed the protective presence of U.S. military forces in years past since WW II. Between the present time and 1994, the United States will renegotiate base access agreements with Spain, Portugal, Morocco, the Philippines, Kenya, Oman, Greece, and Turkey. Moreover, in anticipation of future basing needs for its developing nuclear navy, India has indicated claim for access to Diego Garcia in the Indian Ocean. Currently Diego Garcia is a prime prepositioning node within the U.S. basing network in the Middle East and Indian Ocean territory.

- Conclusion: The most viable concept for addressing effective basing needs in the year 2000 time frame is a large scale floating structure with specified ancillary facilities.

Observation: The RAND Corporation, in its 1984 report, "A Comparison of Methods for Improving U.S. Capability to Project Ground Forces to Southwest Asia in the 1990s" assesses a range of plausible alternatives. RAND's conclusion is: "A Mobile Operational Large Island (MOLI) floating airbase is a promising prepositioning platform.... Prepositioning on MOLIs could out perform any other system we investigate and would avoid the risks of land prepositioning." The 1971 NCEL study of MOBS, including model tests, supports the above conclusion as to the technical viability of large floating bases (Appendix C). In referring to "specified ancillary facilities," as stated in the conclusion, these are seen to include the Floating Deployable Waterfront as demonstrated and analyzed in the crisis response scenarios (Appendix $D$ and Section 4.2.0). 
- Conclusion: The technology of enduring and sustainable marine structures indicates a modularized floating platform of large scale, constructed primarily of prestressed concrete elements and configured for hydrodynamic stability within a critical range of sea states.

Observation: Structural engineering literature is rife with evidence of the suitability of reinforced concrete as a durable and economical construction material for the ocean environment. This has become particularly evident with the developing technology of prestressed concrete. Eberhard Lemcke of Bechtel Civil Inc., in his report of design studies on the technical feasibility of floating structures suitable for aircraft operations and industrial uses, such as for warehousing or fishing industries, found prestressed concrete to be a superior alternative (Item 11, Appendix E). Lemcke's analysis of alternative steel and concrete decks supported on buoyant cylindrical concrete columns favored the concept of stee 1 decks for load bearing, weight distribution and economical considerations. Bechtel was given the assignment to perform their study in August 1984 by Kumagai Gumi Co., Ltd. of Tokyo in anticipation of placing a single-point moored commercial airstrip in Tokyo Bay.

- Conclusion: Performance of modularized ocean basing systems can be demonstrated as significantly superior in terms of cumulative logistic throughput on a daily basis over that of present U.S. capabilities for projecting military force assuming a dearth of proximate foreign basing assets.

Observation: In terms of daily useful availability of Cumulative Logistic Throughput, the superiority of MOBS over Basing System II (without MOBS) varies between 20\% and 28\% during the 90-day ramping-up period. This is depicted in the Third-World 
crisis scenario analysed in this investigation (Figure 7 in Section 4.2.3). This quantified comparison has been viewed as highly conservative due to advantages of prepositioning with MOBS. Basing System II will require multiple sorties of critically scheduled long range airlift and will risk equipment breakdown and weather contingencies.

- Conclusion: The cost of a modularized ocean basing system, pending definitive cost studies, is of the same order of magnitude as the access costs attributable to foreign bases in the year 2000 .

Observation: According to a 1988 study by the BDM Corporation of McLean, Virginia for The Defense Advanced Rearch Projects Agency, it is determined that U.S. overseas basing costs in 1990 will approximate $\$ 8.5$ billion, of which $\$ 5.5$ billion will be for access including leasing and providing economic assistance to host nations. Corresponding figures for the year 2000 could reach $\$ 11$ billion with $\$ 7.5$ billion of that amount attributable to access costs. A preliminary construction cost estimate for the MOBS with 2 decks and 46 million square feet of usable deck space including a 9,900-foot long airstrip as depicted in Figure 5 , indicates a total cost of $\$ 9.43$ billion for the structure in place (Unit cost for usable deck space is estimated at $\$ 205$ per square foot).

- Conclusion: Financing a MOBS could be viewed as effectiveiy transferring the displaced funds for foreign base leasing and access thereby, eliminating added financial burden to the U.S.

Observation: It is readily conceivable that financing the construction of MOBS platforms designed to replace high-cost foreign bases can be aided by scheduling the construction program so as to benefit from released foreign basing funds. 
Moreover, those host nations with stable economies and which have reluctantly tolerated U.S. presence except for the benefits of military defense, may be induced to share the financial burden of a MOBS in their territorial waters. In this vein, a report by the U.S. General Accounting Office has said that if Japan assumed additional yen-based costs related to U.S. forces in Japan, such as maintenance, ship repair, local salaries and utilities, U.S. spending could be reduced by at least $\$ 600$ million annually. These costs are currently paid by the U.S. in yen.

- Conclusion: Significant technical issues, although considered readily tractable within the normal RDT\&E process, will need to be addressed in near-term budget programming in order to realize system development and acquisition of the MOBS concept in a timely and realistic manner.

Observation: Two significant technical issues emerge for early consideration in design development of the MOBS. One involves the area of construction technology and management including fabrication and transfer of concrete elements for final platform assembly on site. The other relates to station keeping and operational positioning of the MOBS platform. As is normally expected, numerous design problems will emerge as development proceeds from feasibility analysis into preliminary design of the system.

This MOBS study along with the efforts put into the Ocean Station Project indicate technical and economic feasibility for the use of modularized ocean basing systems as an alternative to foreign basing assets. The analytical data and information utilized to come to this conclusion is presented in detail. 


\section{ACKNOWLEDGMENTS}

NCEL wishes to acknowledge invaluable inputs to this investigation provided by the following individuals who generously gave of their time and effort in discussions with the investigator:

P.M. Dadant, The RAND CORPORATION, Santa Monica

Commander James J. Tritten, USN (Ret)

(Currently Associate Professor in National Security Affairs at the Naval Postgraduate School, Monterey)

Major John Brusca, USMC

(Currently Liaison Officer to the Naval Civil Engineering

Laboratory, Port Hueneme)

Lieutenant Colonel Michael D. Armstrong, USA

(Currently Director of Plans, Training and Mobilization at

Headquarters, 7th Infantry Division (Light) and Fort Ord)

Lieutenant Commander James L. Gustafson, CEC, USN

(Currently Operations Officer, Thirty-First Naval Construction

Regiment, Construction Battalion Center, Port Hueneme)

Lieutenant Richard Crompton, CEC, USN

(Currently on duty with the Thirty-First Naval Construction

Regiment, Construction Battalion Center, Port Hueneme)

Mr. James L. Malone, J.D.

(Former special representative of the President of the United States to Third United Nations Conference on Law of the Sea)

NAVAL RESERVE NAVAL SEA SYSTEMS COMMAND DETACHMENT 222 participated with NCEL staff in a two-day workshop for evaluating assumptions and analysis applied in the MOBS investigation. The following members of that detachment provided numerous suggestions for which the investigators wish to express appreciation:

Captain Ernst J. Bitten, USNR

Captain Michael J. Kolar, USNR

Captain Richard H. Evans, USNR

Captain John F. Kittel1, USNR

Captain Ronald P. Ernst, USNR

Captain Ronald M. Krel1, USNR

Captain Ronald J. Stryer, USNR

Commander Russell C. Johnson, USNR

Commander Stephen J. Szender, USNR 
Finally, the author is truly grateful to his NCEL associates for their many constructive and significant suggestions that contributed substantially to the final presentation of the report. 
1.0. INTRODUCTION ...................... 1

1.1. Background ............... . . 1

1.2. Purpose of the Investigation . . . . . . . . . 3

1.3. Approach ................... 4

1.4. Organization of Report . . . . . . . . . . 5

1.5 Project Organization ........... 6

2.0. ANALYSIS ................... . . 7

2.1.0. Security Environment Factors . . . . . . . . 7

2.1.1. Political and Strategic ............ . . 7

2.1.2. Technical and Physical . . . . . . . . . . 10

2.1.3. Cost and Financial ............ . . 11

2.2.0. Strategic Problem Definition .......... 11

2.2.1. Effective Needs . . . . . . . . . . . . . . . 13

2.2.2. Applied Value System . . . . . . . . . . . . 14

2.2.3. System Objectives . . . . . . . . . . . . . . 15

2.2.4. System Boundary Conditions . . . . . . . . . 17

3.0. SYNTHESIS . . . . . . . . . . . . . . 18

3.1.0. Generalized Situation Scenario ......... 19

BASING SYSTEM I (MOBS) . . . . . . . . . . . 20

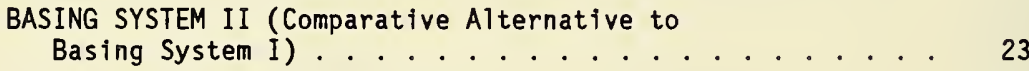

3.2.0. Formulation of Concepts . . . . . . . . . 25

3.2.1. Modularized Ocean Basing Systems (MOBS) . . . . . . 25

Indicated MOBS Characteristics . . . . . . . . . . 25

4.0. COMPARATIVE EVALUATION ..................... 29

4.1.0. Physical Viability .............. 29

4.2.0. Performance Effectiveness . . . . . . . . 36

4.2.1. Crisis Response: Basing System I (With MOBS) . . . 36

Crisis Response-Event Matrix - Basing System I . . . . . . 37

Matrix Event Descriptions: Basing System I (With MOBS) . . 38

4.2.2 Crisis Response: Basing System II (Without MOBS) . . 42

Crisis Response-Event Matrix - Basing System II . . . . . 42

Matrix Event Descriptions: Basing System II (Without MOBS) . 43 


\section{Table of Contents (cont'd)}

Page

4.2.3 Crisis Response Comparison: Basing Systems

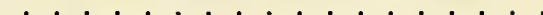

4.3.0 Cost . . . . . . . . . . . . . . 46

4.4.0 Financial Feasibility............. 46

5.0 CONCLUSIONS . . . . . . . . . . . . . . . . . 52 APPENDICES -

A. Supporting Exhibits . . . . . . . . . . . . . A-1

B. System Feasibility Logic . . . . . . . . . . . . B-1

C. Mobile Ocean Basing System .............. C-1

D. System Requirements and Design Criteria for Floating

Deployable Waterfront Facilities on Exposed Coastlines . D-1

E. Bibliography .................. E-1

F. Abridged Account of Events Relating to the Joint NCEL/NSA Feasibility Study of a Modularized Ocean

Basing System.................. F-1

G. Definitions of Forward Naval Base Functions . . . . . . G-1

H. Glossary of Terminology . . . . . . . . . . . . H-1 



\subsection{INTRODUCTION}

This is a report of investigation into the feasibility of floating bases as an alternative to diminishing United States foreign basing assets. The Modularized Ocean Basing System (MOBS) platform is the central concept in an integrated scheme for future forward basing infrastructure. The investigation is structured within the context of a long range national security strategy of "Discriminate Deterrence," circa year 2000, as set forth by the President's Commission on Integrated Long Term Strategy (CILTS). The study provides a hypothetical comparison of the integrity of MOBS to that of an alternative support structure normally reliant on fixed land bases to which access is denied in a typical Third World scenario.

The Naval Civil Engineering Laboratory (NCEL), Port Hueneme and the National Security Affairs Department (NSAD) of the Naval Postgraduate School, Monterey, are joint participants in this investigation. NCEL and NSAD/NPS recognize the potential for significant benefits to the Department of Defense and the Navy by combining the unique assets and complementary capabilities of the Laboratory and the School in this and other studies.

\subsection{Background}

The President's Commission On Integrated Long-Term Strategy (CILTS), in its report of January 1988, Discriminate Deterrence (Appendix E, Item 6), recognizes our diminishing ability to gain agreement for timely access, including bases, to areas threatened by Soviet aggression. The CILTS report emphasizes the continued need for bases to deter or defeat aggressors at distant points overseas.

Accepting the assumptions of the CILTS report, the Chief of Naval Operations (CNO) directed the Center for Naval Warfare Studies, Naval 
War College to study the issues and key implications for the Navy (Appendix E, Item 4). In the same vein of strategic awareness, the Department of National Security Affairs at the Naval Postgraduate School has been directed by Chief of Naval Operations through the Long Range Strategic Planning Branch $(\mathrm{OP}-603)$ to undertake an extensive research project: "The Relationship of War at Sea to Warfare Ashore."

The present investigation including analysis, synthesis and evaluation of alternative basing systems, has been structured to be compatible with the strategic decision environment depicted in the CILTS report and recent CNO studies including that cited above. This report is submitted as part of the $\mathrm{OP}-603$ project via its director within the National Security Affairs Department at the Naval Postgraduate School. It is being included as part of the OP- 603 project for the following significant reasons:

- The concept of a large scale modularized ocean basing system, in contrast to fixed foreign land bases, offers unprecedented opportunity for introducing major strategic innovation with operational, fiscal and economic advantages. Operational advantage is partly vested in the potential for unified logistic support to joint multi-service operations in which "war at sea" becomes fully integrated with "warfare ashore."

- Deployable and uniquely configured components of logistic support infrastructure including modularized floating off-shore bases complemented by transportable waterfront facilities could be optimally positioned in advanced operating areas.

- Such an innovation could serve specified and integrated air, land and sea operations within the context of a broadened and unified approach to multi-service Warfare Systems Architecture and Engineering (WSA\&E).

Further, this investigation recognizes that various groups within the defense community (Government as well as the private sector) favor 
the concept of floating forward bases for early investigation. Appendix $F$ provides an abridged account of background events selected for their significance to MOBS. This includes data from interests within the private sector who view floating facilities as an innovative and favorable extension of the nation's infrastructure for industrial development and environmental preservation.

\subsection{Purpose of the Investigation}

The purpose of this investigation is to evaluate modularized ocean basing as an alternative to a war-fighting support structure dependent on access to foreign land bases, assuming a U.S. forward strategy of "Discriminate Deterrence," circa year 2000.

The following "study objectives" (in contrast to "system objectives" to be discussed later) have been adopted for this investigation:

- Study Objective (a): Isolate effective basing needs and define related functional requirements for a unified logistic support structure for joint multi-service military operations, assuming continued emphasis on forward strategy by the U.S. in the future.

- Study Objective (b): Describe a range of MOBS concepts that satisfy the necessary and sufficient requirements for warfighting support structure in consonance with a national security strategy of "Discriminate Deterrence," circa year 2000 .

- Study Objective (c): Determine the performance and technical feasibility of selected MOBS concepts.

- Study Objective (d): Assess performance capabilities of selected MOBS concepts compared to a most likely existing alternative within the context of a typical Third World scenario. 
- Study Objective (e): Assess financial feasibility of the MOBS concept in comparison to an existing alternative.

\subsection{Approach}

The morphology of large scale engineering system development provides the approach for this study. The logic in this approach for determining the feasibility of MOBS and comparing its performance with a likely alternative basing system is represented graphically in Appendix B. Accordingly, the following sequence of specified tasks was executed in order to satisfy the purpose of the investigation:

Task (a): In conformance with the CILTS security assessment and other related strategic studies, identify an envelope of security environment factors (Section 2.0) which serve as descriptors for characterizing a threat profile and simulating a generalized typical Third World crisis situation, circa year 2000.

In parallel with the crisis simulation, those same strategic descriptors enable identification of effective basing needs within the context of the projected security environment and specifically, the crisis scenario. The effective basing needs are to be accommodated by the modularized ocean basing system or its most likely alternative. Further, in order to demonstrate the full range of identified basing needs and define related functional requirements within the scenario, the U.S. response is executed in a combined operation of land, sea, and air forces with a single unified support structure. As a result, the logistic support can be treated as a large-scale system optimized for cost-effectiveness within constraints of joint multi-service Warfare Systems Architecture and Engineering in the year 2000 time frame. Finally, this same scenario, which confirms functional basing requirements, aiso serves as the context for evaluating MOBS and comparing it with a most likely existing alternative.

Task (b): Resolve previously identified effective basing needs by defining system performance objectives including conditions at the 
boundary of a hypothetical "black box" (undefined large scale basing system). This "black box" represents an engineering system expected to provide sustaining and flexible support for the war-fighting activities of each of the participating military services. In addition, this task will demonstrate compatibility of derived system characteristics within established Navy war-fighting support requirements vis-a-vis Top Level Warfare Requirements (TLWR) and Warfare Systems Architecture and Engineering (WSA\&E). This portion of the study enables preliminary consideration of advance technological assets as inputs to formulation of basing system concepts symbolized by the "black box."

Task (c): Describe plausible modularized ocean basing concepts and a most likely aiternative serving the required system performance characteristics for support structure in the crisis situation.

Task (d): Analyze the most favorable MOBS concept for its performance effectiveness, cost, and financial feasibility in comparison with the most likely alternative forward basing system.

\subsection{Organization of Report}

This report is organized in five basic parts; Introduction, Analysis, Synthesis, Evaluation, and Conclusions. The investigation parallels the morphology of large scale system design/development.

1. Introduction: (1.0) provides background for the subject of investigation and description of the rationale to be applied (Appendix B).

2. Analysis: (2.0) provides assessment of basing needs and characterization of engineering systems deriving from analysis of the future security environment with included strategic factors. 
3. Synthesis: (3.0) provides conceptualization of candidate large scale systems in response to the needs and the engineering problem situation. This part of the study also provides formulation of a generalized threat scenario within which to compare alternative systems.

4. Evaluation: (4.0) provides physical viability, operational performance, limited economic and financial comparisons of alternative forward basing systems.

5. Conclusions: (5.0) offers conclusions reached through this investigation bearing on the feasibility of modular ocean basing systems as an alternative to currently diminishing U.S. foreign basing assets.

\subsection{Project Organization}

The project is organized to enable effective treatment of likely alternatives to the U.S. forward basing situation by seeking to incorporate the studied inputs of faculty and officer-students at the Naval Postgraduate School, Monterey, along with those of the professional research staff of the Naval Civil Engineering Laboratory, Port Hueneme.

The principal investigator and coordinator for contributed studies is John F. Peel Brahtz, Ph.D., P.E., (Consulting Research Professor, Dept. of Civil Engineering, Stanford University, on temporary assignment to the staff of the Technical Director, NCEL). The investigation is conducted under the joint cognizance of R. N. Storer, Ph.D., P.E., Technical Director, Naval Civil Engineering Laboratory; and J. J. Tritten, Ph.D., Associate Professor, Department of National Security Affairs, Naval Postgraduate School.

The investigation is conducted entirely with facilities, personnel, and support provided by the Naval Civil Engineering Laboratory and the Naval Postgraduate School. 


\subsection{ANALYSIS}

\subsubsection{Security Environment Factors}

The following three categories of security environment factors each include citations from reports by CILTS, the Hudson Institute and the Center for Naval Warfare Studies. This arrangement enables an overview of the national security environment as assessed by these three sources in terms of U.S. national strategy and the forward basing issue. Analysis of the future security environment provides strategic factors which lead to formulation of alternative system concepts and threat factors that describe the environment within which to evaluate and compare alternatives. The impact of security environment factors is reflected in subsequent sections of this report where they are applied according to the flow diagram of Appendix B.

\subsubsection{Political and Strategic}

The report of the President's Commission on Integrated Long-Term Strategy, Discriminate Deterrence, enunciates the United States' grand strategy quite simply: forward deployment of American forces, assigned to oppose invading armies and backed by strong reserves and a capability to use strategic weapons if necessary. The Commission recognizes trends in the nation's security environment which, if allowed to continue without compensatory measures, would place U.S. vital interests in severe jeopardy and eventually threaten national survival.

The doctrine of mobility and flexibility underlies the CILTS report. The following selected citations from that report are descriptive of the future security environment and are germane to justification of requirements for modularized ocean basing functions:

(a) Major U.S. interests will continue to be threatened at fronts much closer to our adversaries than to the United States. Our ability to deter aggression at these distant places will be impaired by uncertainty about allies and friends granting us access to bases and overflight rights, or joining us in defense preparations to respond to ambiguous warning signals. 
(b) We must have militarily effective responses that can limit destruction if we are not to invite destruction of what we are defending.

(c) To help deter nuclear attack and to make it safer to reduce offensive arms we need strategic defense. To deter or respond to conventional aggression we need a capability for conventional counter offensive operations deep into enemy territory.

(d) To help protect U.S. interests and allies in the Third World, we will need more of a national consensus on both means and ends. Our means should include: (among other provisions) versatile, mobile forces, minimally dependent on overseas bases, that can deliver precisely controlled strikes against distant military targets.

(e) The principles above imply change. But, our strategy also includes many things that will not change: We will need forward deployed forces in some critical, threatened areas. seas bases.

(f) The United States must develop alternatives to over-

The Hudson Institute study, "U.S. Global Basing," offered in four separate task reports, was sponsored jointly by the Director of Net Assessment, OSD, and the Director, Strategic Concepts Development Center, the National Defense University. That study, and an ancillary article, ("U.S. Overseas Basing System Faces a Difficult Transition," published in the Armed Forces Journal International of February 1989), both authored by James $R$. Blaker of the Hudson Institute (Appendix $E$, Items 2 and 3 ), set forth the following pertinent security environment factors bearing on the U.S. forward basing situation:

(a) Between now (February 1989) and 1994, the United States will renegotiate base access agreements with Spain, Portugal, Morocco, the Philippines, Kenya, Oman, Greece, and Turkey.

(b) In the late 1970s several interrelated events transformed the dynamics of U.S. overseas basing. The most obvious of these was the shift in U.S. strategy toward the Persian Gulf. The collapse of the U.S.-Iran relationship, followed shortly by the Soviet invasion of Afghanistan, stimulated a series of policy shifts (in support of Carter Doctrine) that committed the U.S. to the direct defense of Western access to Persian Gulf oil, ostensibly against the threat of Soviet aggression. 
(c) The military strategy that emerged -- (in support of Carter Doctrine) -- added new strategic importance to U.S. basing in the Philippines, Spain, Portugal, Greece, and Turkey.

The Center for Naval Warfare Studies, Naval War College, was tasked by the Chief of Naval Operations in December, 1987 to study the effects of a contraction of overseas bases and access on the U.S. Navy. The study, "Overseas Basing: The Impact of Change" (Appendix E, Item 4), was to assume continuity in the U.S. strategy of forward defense. In his tasking, CNO identified two specific areas of interest:

(a) The general implications for naval forces of a loss of U.S. ground and land-based tactical air forces' overseas basing.

(b) The implications for the U.S. Navy of a contraction of its own overseas base support structure.

In view of the present investigation, directed to the feasibility of modularized ocean basing systems as an alternative to overseas base support structure, it should be noted that the Center for Naval Warfare Studies team interpreted their charter to explore the implications of a reduction in the number of bases overseas. In responding to CNO, the NWC study team conceded that "obviously, the simplest method to deal with the loss of a base is to move the functions to alternative sites."

The investigators at the Naval War College identified security environment factors which provided context for their problem situation. Certain of those factors relate significantly to the thrust of the present investigation as follows:

(a) Today, the 'Communist threat' argument has lost much of its strength. ... Indeed, on both sides of the world, the image of the Communist threat is waning in the minds of our hosts, who initially welcomed us. Now, 40 years later, they just tolerate our presence. ... Increasingly, our allies wish to find their own way in the world....

(b) In some countries, there is a growing uneasiness with our continued carrying of nuclear weapons in nonstrategic or marginally strategic platforms. Some of this opposition also spills over to include nuclear-powered ships. 
... Nuclear-free zones would reduce the possibility of accidental release of radioactivity and, perhaps, serve to remove one's homeland from a strategic target list. These movements will continue around the globe.

(c) Today's bases are consolidated, multifunction installations. In some areas, there is no functional redundancy and little reserve capacity. These bases form a transportation and communications network with a number of critical nodes -some patently obvious. The removal of one of the critical nodes leaves a noticeable gap in the network. Some of these nodes are of questionable reliability because of differences of opinion on remuneration and/or uses for the facilities.

(d) That the U.S. needs most of the bases it now possesses is the natural result of our optimizing the worldwide base structure. The facilities that remain are primarily logistical support bases for theater non-nuclear missions. Increasingly, in the 1980s and 1990s, we want to use these facilities for the pursuit of unilateral objectives.

(e) Access to U.S. facilities is becoming increasingly limited. To protect their political options, host nations understandably want consultation when we use bases in their territory to project power. They may withhold agreement when it is U.S. power that is being projected for U.S. purposes alone.

\subsubsection{Technical and Physical Factors}

\subsubsection{The President's Commission on Integrated Long-Term Strategy}

Although, CILTS does not abandon the basic grand strategy of forward deployment, the report critically addresses potential impact of contemporary realities and trends in technological factors. For instance, it is recognized that life-cycle generations in large scale force developments require long-term strategic planning projections of at least two decades. This requirement applies to lead-times for major armaments procurement and warfare systems architecture based on conceivable future developments in technology.

\subsubsection{The Hudson Institute}

(a) Overall, the global basing system has been streamlined and stripped of the redundancy it once had. ...As the 
range of (transport) aircraft increased, it became costeffective to bypass what were once necessary intermediate stops. ... Today's system is optimized for smooth peacetime use; much of what was excess to this has been dismantled.

(c) ...a limited number of base sites have emerged as central nodes in the global system. They are important not only for regional military operations, but for moving men and material to other regions as well. The leaders of the nations in which these key nodes are emerging -- in the Philippines, Spain, Portuga1, Greece, and Turkey -- are aware of the growing dependency of the entire U.S. overseas basing system on the facilities on their territory.

\subsubsection{Cost and Financial}

\subsubsection{The Hudson Institute}

(a) ...there (are) two broad categories of monetary costs associated with overseas basing. One of these can be called the "fixed costs" of basing.... Another cost associated with overseas basing might be calied "permit costs." Permit costs are paid to obtain the privilege and authority to build, improve, and maintain U.S. military facilities on another nation's territory.

(b) It is in the next seven years or so that the basing problem is likely to be most acute, because this is when the most difficult and contentious base access negotiations are to occur.

\subsubsection{The Center for Naval Warfare Studies, MWC}

(c) The cost of bases is increasing coincidentally with a reduction in the resources available to pay the increased cost. ...Our willingness and ability to pay have not kept pace. Even when we achieve mutually agreed terms in base negotiations, often pledged aid has not materialized.

\subsubsection{Strategic Problem Definition}

Part of the thrust of the report of the Commission On Integrated Long Term Strategy, Discriminate Deterrence, can be characterized as long term strategic requirements and problems for which solutions must be sought. The following strategic requirements reflect the security environment factors previously categorized and lead to a definition of effective basing needs: 
(a) Required: A long term (20 years) forward strategy of discriminate deterrence to aggression for the future U.S. security environment.

(b) Required: A strategy synthesized by the integration of new technology with concerns over force structure, basing needs and mobility, including conventional and nuclear arms.

(c) Required: A capability for effective and discriminating military response to a wide range of contingencies over the full spectrum of conflict by engendering a mix of offensive and defensive systems for U.S. conventional and nuclear posture.

(d) Required: A diversified and strengthened ability to bring discriminating, non-nuclear force to bear where needed in time to defeat aggression through exploitation of emerging technologies of precision, control and intelligence, thereby enabling more selective and effective destruction of military targets.

(e) Required: Versatile, mobile-forces, minimally dependent on overseas bases, that can deliver precisely controlled strikes against distant military targets as a means for protecting U.S. interests and allies in the Third World.

(f) Required: Continuously forward deployed U.S. forces in some critical, threatened areas.

(g) Required: Future U.S. defense budgeting guided by the strategic priorities outlined above, permitting economies in some areas and providing needed enhancement in others. Given the future perils and uncertainties facing our nation and our allies, defense and security assistance budgets should grow at a rate commensurate with our growing economy. 


\subsubsection{Effective Needs}

The following statement of effective basing system needs is in response to the strategic problem definition as outlined in Section 2.2.0. The effective needs are distinctly derived from security environment factors (Section 2.1.0) abstracted from items 2, 4, and 6 of Appendix $E$. Since those same environmental factors also circumscribe the generalized scenario (Section 3.0), they provide the context to demonstrate and evaluate the required war-fighting support structure and forward basing functions:

(a) Need: Major innovations in forward basing infrastructure oriented to the future security environment and U.S. strategy of "Discriminate Deterrence." Such a forward basing system would fully complement the vital war-fighting role of the Fleet.

(b) Need: Alternative to fixed land bases which can be deployed on the high seas or in accord with jurisdictional provisions of "Law of the Sea" for waters contiguous to sovereign states, and as a component within an adjustable network of forward bases.

(c) Need: Forward basing alternative to U.S. foreign land bases which provides a full range of basing functions for contemporary WSA\&E including joint multi-service operations and pursuit of U.S. unilateral objectives.

(d) Need: Cost-effective basing alternative which can serve as a mechanism in determining fair and reasonable levels for both fixed and permit costs while negotiating foreign basing assets with host countries.

(e) Need: A U.S. forward basing doctrine during the 1990 s which utilizes advancing technology to accommodate the vicissitudes of foreign relations, a national economy with budget constraints, and a defense strategy of Discriminate Deterrence. 
(f) Need: A modular ocean basing system including both offshore and nearshore elements, characterized by generic mobllity and flexibility, enabling an adjustable network of components for cost-effectiveness and a degree of redundancy for contingencies.

\subsubsection{Applied Value System}

The value system applicable to selection of basing system objectives is a synthesis of qualitative judgments. These judgments are based on analysis of decision factors which are implied in the CILTS report and reflected in the "Strategic Problem Definition" (2.2.0) as well as the statement of "Effective Needs" (2.2.1). The following categories of criteria set system objectives and represent three levels of priority in descending order:

\section{(1) Essential:}

Assured unconstrained access to forward bases

Ful1-spectrum forward basing functions

Survivability of basing functions

Global capacity for contingent early response with

discriminate profiles of deterrent operations (LIC/MIC)

Minimal dependence on foreign land bases

Proximate basing for recognized potential crisis areas

Mobile, deployable support structure

Unconstrained nuclear presence with basing support

Ability to employ basing system for U.S. unilateral objectives Adaptability of basing infrastructure to joint multi-service military operations

\section{(2) Cost-Effective:}

Flexibllity in level of effort for deterrence Versatility in level of support to deterrent operations Universally adjustable basing network for optimal logistic paths 
Avoidance of prohibitive costs for access to foreign base sites

Retention of basing infrastructure on redeployment of forces Enhanced integration of C(3)I advanced technology with basing functions and force deployment

Enhanced cost-effectiveness of forward basing over current budget outlays for foreign basing assets

(3) Desirable:

Optional supplementary utilization of forward basing system as infrastructure for U.S. diplomatic, foreign trade and economic interests and, offshore operations which are directed for preservation of the natural environment and social welfare, e.g., drug interdiction.

\subsubsection{System Objectives}

Setting design/development objectives for the forward basing system requires simultaneous consideration of the Effective Needs (2.2.1) and the selection criteria (Value System, 2.2.2).

1. System Objective (a): Provide platform integrity and support structure for performance of 21 critical forward base functions identified below (Table 1). It is assumed the range of present-day (circa 1990) critical basing functions identified in the referenced source (Appendix G) are applicable to U.S. security environment, circa 2000. This assumption is supported by the consensus that characteristics of Navy force structure will be sustained for three decades, notwithstanding prudent changes in Top Level Warfare Requirements (TLWR) and WSA\&E.

2. System Objective (b): Provide, in theater, all critical forward basing functions for joint land-sea-air war-fighting operations as needed to address the Generalized Scenario (Section 3.0). 
Table 1. Forward Base Functional Matrix

\section{Operationa 1}

Function*

1. SOSUS

2. ASWOC

3. MPA (P3)

4. Radar/IFF

5. Aircraft Weapon

Control

6. Surface-to-Air

Missile

7. Fighter Aircraft

8. Radar

9. Weapon Control

10. Attack Aireraft SAM

11. Terrestrial $C(3)$

12. Ordnance Supply

13. Aircraft Ordnance

Supply

14. Ship Fuel Supply

15. Aircraft Fuel Supply

16. Ration Supply

17. Aircraft Supplies

18. Systems Supplies

19. Aviation MRR

20. Ship, Hull MRR

21. Admin/LOG

Communications

$$
\begin{aligned}
& \text { Mission Area } \\
& \text { Function }
\end{aligned}
$$

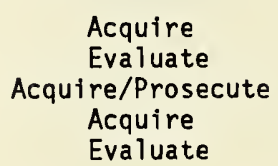

Prosecute

Prosecute

Acquire

Evaluate

Prosecute

Communicate

Sustain

Sustain

Sustain

Sustain

Sustain

Sustain

Sustain

Fix

Fix

Communicate
Mission

Area

ASW

ASW

ASW

AAW

AAW

AAW

AAW

ASUW

ASUW

ASUW

AAW/ASW/ASUN

LOG

LOG

LOG

LOG

LOG

LOG

LOG

LOG

LOG

LOG

*Appendix G: Definitions of Forward Naval Base Functions

3. System Objective (c): Provide and/or maintain a suitable environment for the personnel needs and amenities customarily avallable at major U.S. foreign bases, circa 1990.

4. System Objective (d): Provide integrity of basing functions for maintaining operational mobility and flexibility according to the applied value system. Achieving this design objective leads to realization of uniquely configured systems for cost-effective adaptation to varying conditions of the future security and diplomatic environment. This includes service to U.S peacetime interests such as diplomatic, welfare, economic and foreign trade missions. 


\subsubsection{System Boundary Conditions}

The following system boundary conditions serve as guidelines for formulating MOBS concepts which will serve system objectives.

\subsubsection{Desired Outputs}

The desired outputs of the ocean basing system are those necessary and sufficient for functional performance speciffed in System Objectives (a) $-(d)$.

\subsubsection{Undesired Outputs}

The most undesirable feature of the MOBS concept is sense of isolation for operating cadre not able to participate in the normal experiences of the foreign land base with its nearby urban environments. This deficiency may be ameliorated by provisions for personnel recreation, quarters for visiting dependents and, recreational visits to nearby foreign territories.

There is a problem: that of providing measures to compensate for potential impacts on the natural environment. This is due to the high density population on the MOBS and intense operational activity within restricted ocean areas of neighboring countries. Unless managed, this can have a negative influence on foreign relations. This impact may be more than might be expected from surface craft operating within the territorial waters of nearby foreign countries.

\subsubsection{Purposeful Inputs}

Essential characteristics of a MOBS operating under conditions of Low-Intensity Conflict (LIC) or Mid-Intensity Conflict (MIC), extreme weather conditions of the high seas or, within the constrained Exclusive Economic Zone (EEZ) of a nearby sovereign nation, must accommodate the basing needs previously identified (2.2.1). This requires input for 
system operating characteristics such as mobility over expanded geographical areas, relocation of modules for change of deployment including, minimal disruption of basic support operations, communication, power supply, personnel safety and security. Since MOBS is a major component in a large scale support structure for joint multi-service operations, it must accommodate air, surface and subsurface logistic systems. It must also serve as a repair and refurbishing base for operating forces.

\subsubsection{Incidental Inputs of Physical Environment.}

The environmental inputs which require special accommodation are characterized by unusually high sea states. The basing functions should be made sustainable in all but the most severe environmental circumstances while maintaining survivability of the infrastructure under the severest of conditions.

\subsubsection{Constraints on Outputs, Inputs, System}

Constraints on the system, its inputs and outputs, stem primarily from the physical environment, jurisdictional impacts of Law of The Sea, and the threat of hostile activity.

\subsection{SYNTHESIS}

The synthesis of forward basing concepts which are both physically viable and operationally effective requires consideration of the extremes under which the system would be expected to perform including the boundary conditions cited above. For that reason the system designer is exposed here to a situation scenario with an included crisis alert which typifies the future U.S. security environment. 


\subsubsection{Generalized Scenario}

Introduction: Excerpts from reports of the Commission on Integrated Long Term Strategy, the Hudson Institute, and the Naval War College are combined in the present study (Section 2.0) to provide a credible consensus as to the future U.S. security environment. In this report that consensus has been related to a set of strategic threat factors for hypothesizing a credible potential crisis situation. The scenario provides for a broad spectrum of functional military basing requirements. In this scenario the strategist can demonstrate attributes of alternative war-fighting support structures as instruments of "Discriminate Deterrence" in a typical Third-World environment.

The alternative Basing Systems, I and II, including U.S. Strategy and Crisis scene, are characterized by the deployment of MOBS in the first scenario and alternatively, by projecting current (circa 1990) war-fighting support structure without MOBS into the year 2000 time frame for the second scenario. 


\section{BASING SYSTEM I (MOBS)}

U.S. Strategy: This is the year 2005. Over the past decade the U.S. has been implementing its strategy of "Discriminate Deterrence" by deploying modularized ocean basing system (MOBS) platforms at selected locations in lieu of diminished access to fixed land bases. This reordering of the the U.S forward basing network is still in process. Changes in the economic status of Third World nations has adversely impacted the effectiveness of some vital U.S. foreign bases. This has resulted in diminished utility and increased access costs.

As a consequence of these developments, the U.S: has deployed MOBS outside the EEZ of host countries as a reliable alternative to land bases. In the interest of harmonious foreign relations, MOBS deployments conform to provisions of the Third United Nations Conference on Law of the Sea, 1982, as well as special treaty relationships with concerned sovereign states.

U.S. defense strategists view the deployability of MOBS as compensation for diminished flexibility caused by restricted access to foreign land bases and arbitrary denial of overflight rights.

Crisis Scene: A major Third World crisis has now emerged involving Soviet inspired and supported insurrection in one of the Southwest Asia countries. If the insurgents are allowed to prevail, Soviet influence will dominate the Persian Gulf theater. The Soviet intent is to acquire, by surrogate force, political dominance over the oil-rich countries of the Persian Gulf, thereby gaining control of the region's petroleum resources for Soviet benefit.

The crisis scene involves the United Arab Emirates (UAE), a country lacking sufficient military capability to withstand prolonged conflict against sophisticated guerrilla forces trained and supplied by the Soviets. Five years prior to onset of the insurrection, the U.S. deployed a modularized ocean basing system adjacent to the Gulf of Oman at the periphery of Pakistan's EEZ within 500 miles of the Strait of Hormuz. 
The MOBS is a critical node in a global network of forward bases. Its deployment at the Gulf of Oman was initially a deterrent by providing the needed military support functions should any contingency arise in the Southwest Asia theater. With the onset of organized insurgent activity, the U.S. remains party to a long-standing agreement to provide military assistance when invited by western-oriented countries of the Persian Gulf region including the UAE.

Aside from the deployed MOBS, the only proximate basing assets available to the U.S. are the British Isles in the West and Okinawa in the East. Diego Garcia (previously available to the U.S. as part of British Indian Ocean Territory) has become the subject of counter-claim by India as a regional basing asset for their carriers and nuclear submarines. U.S. access to seaports and airports of debarkation (SPODS/APODS) for military operations near the Persian Gulf is lacking.

Should the current insurrection be allowed to prevail, this situation will present a threat of major confrontation with Soviet forces over control of Persian Gulf oil resources. Early assessments of the situation indicate that U.S. forces in a possible joint multi-service operation must be prepared for mid-intensity conflict (MIC) of 6 to 18 months duration to terminate the insurrection. Immediate and visible resolution by the U.S. is viewed as critical for pre-empting or deterring initial movement by Soviet conventional ground forces supporting the insurgents.

MOBS Characteristics (Section 3.2.1): Substantiating the U.S. strategy of Discriminate Deterrence in the Persian Gulf region, the MOBS represents a capability for credible military response. To facilitate this capability, the deployed MOBS is modularly configured as a threedeck 9,900 - by 1,200-foot airstrip with sizable adjacent areas for the several support functions customarily associated with large land bases, including two covered lower decks.

The top deck serves as industrial plant and parking area including sufficient runway for accommodating fully loaded $\mathrm{C}-5 \mathrm{~B}$ and $\mathrm{C}-17$ heavy transport aircraft in take-off and landing. The MOBS platform lower decks can readily accommodate prepositioned material and equipment for 
one Marine Expeditionary Force (MEF) plus two Army mechanized infantry divisions (MECH + HVY CS). This prepositioning function of the MOBS has been viewed as an essential component of the U.S. Rapid Deployment Force implemented in 1986.

Three basic modules of a Deployable Waterfront (DWF) are prepositioned alongside the MOBS for 6-knot transfer by ocean-going tug to a designated shoreline site. The DWF is designed to operate functionally in concert with the MOBS as an integrated logistic port system to support combat forces ashore.

MOBS is capable of incorporating any or all of the essential basing functions attributable to a major node in the U.S. forward basing network. Combat forces prepositioned on board the MOBS can be in a state of readiness including a Marine Expeditionary Brigade (MEB) with a complement of 15,000 combat troops. Either alongside or in the proximity of the MOBS is a Marine Expeditionary Unit (MEU) consisting of 2,000 amphibious assault troops afloat on Maritime Prepositioning Ships (MPS) with amphibious landing craft, equipment and supplies for 15 days of sustained initial assault. 


\section{BASING SYSTEM II \\ (Comparative Alternative to Basing System I)}

Considering the circumstances depicted in the Generalized Situation Scenario for Basing System I, the likely alternative basing scenario for evaluation in lieu of a prepositioned MOBS in the Gulf of Oman, would be to acquire functionally effective assets ashore through aggressive and overwhelming military action. This would necessarily include initial assault by amphibious expeditionary forces with follow-on reinforcements for expanding control and penetration of forward areas enabling the establishment of forward operating base structure.

To ensure rapid and pre-emptive response required for the crisis situation described, the first phase of the operation would include the commitment of Marine Air-Ground Task Forces (MAGTFs) prepositioned afloat in the mid-Indian 0cean. Initial air cover and surface support would be provided by carrier battle forces also on station in the Indian Ocean at the time of alert. Further, it would be assumed that a Deployable Waterfront Facility (DWF) is prepositioned at Okinawa and intended for logistic support to expeditionary forces responding to any contingency in the Southwest Asia theater. The DWF could be assembled for initial operations at a potential port site in the Gulf of Oman within 15 days of transit at 20 knots by heavy-lift ship from Okinawa. Timed to the arrival of the MAGTF at the assault zone, the attending carrier battle forces will have sought to ensure effective air and offshore control enabling the amphibious operation to proceed.

Assuming the early assault action to have established functional control of the forward area, broadened logistic infrastructure would then become a requirement in addition to that of the advance DWF transported from Okinawa for the expected duration of the campaign. The additional basing facilities would consist of debarkation and cargo handing facilities including SPODs and APODs capable of accommodating major components of sealift and airlift systems as projected for operations in the year 2000 time frame. According to the crisis scenario, it must be assumed that such support facilities would be entirely lacking 
at the time of alert. The special SPODs and APODs would be providing both intra-theater and inter-theater logistic throughput by accepting various surface support craft along with large cargo transport ships and aircraft. These elements of sealift and airlift would be transiting between the CONUS, the nearest remaining U.S. forward land bases and, the special APODS and SPODS estabilshed in-theater.

Although, the MAGTFs are capable of sustained operations of extended duration, U.S. strategy requires that such forces be maintained in a state of standby readiness whenever not actually engaged in an immediate crisis response. Hence, for the extended duration of the insurgency as depicted in the crisis scenario, the MAGTFs would be replaced by up to two Army mechanized light infantry divisions deployed in accordance with 1986 Rapid Deployment Force planning. However, the MAGTFs would be required to maintain the operation pending airlift of the Army Rapid Deployment Forces from CONUS to the battle zone. Moreover, the heavy combat equipment would necessarily be transported either by sealift or transport aircraft capable of accommodating outsize cargo. 


\subsubsection{Formulation of Concepts}

First order formulation of basing system concepts is a creative process leading to large scale innovation while addressing fundamental objectives. The innovative designer generally views the objectives in light of an applied value system providing direction and constraints at this broadly perceived level of conceptualization. The process is designed to develop desired system characteristics. This is done by considering system boundary conditions and the engineering problem situation as it exists within the operational environment. Ensuing phases which are beyond the scope of this feasibility investigation include a sequence of analyses treating design parameters for sensitivity, compatibility, stability and optimization. These considerations are usually addressed in the system preliminary design, which focuses on conclusions reached in a feasibility analysis.

\subsubsection{Modularized Ocean Basing Systems (MOBS)}

As a precursor to formulation of MOBS concepts, system characteristics have been developed for satisfying objectives (2.2.3) while seeking to optimize the application of the value system (2.2.2). In this case the objectives are served by initially perceived deployment requirements for the Generalized Scenario (Section 3.1.0). This scenario depicts a typical threat environment for an operational gaming comparison of technically viable system alternatives. (Refer Appendix B: System Feasibility Logic).

\section{Indicated MOBS Characteristics}

\section{(Per situation scenario, Section 3.1.0)}

- An array of floating modules connected in configuration as a three-deck platform. The top deck would be designed to serve as an operational runway for large military transport aircraft of the $C-5 B$ 
class. The lower two decks would be enclosed and designed for accommodation of personnel, storage of prepositioned equipment and logistic support functions requiring sheltered space. (Note that the runway length is directly a function of the takeoff requirements for fully loaded $C-5 B$ aircraft. Other functional basing requirements may become critical to the MOBS configuration should future heavy lift transport aircraft be designed for significantly shortened takeoff lengths over that provided for C-5 type aircraft.)

- MOBS is conceived as a complete functional alternative to current forward basing infrastructure required for a strategy of "Discriminate Deterrence." For example, in specific situations MOBS could be designed to serve as a repair/rework facility for carrier-based aircraft or, to contain an in-theater dry-docking capability for the carrier battle group. It depends on what emerges as a critical need for achieving strategic objectives in terms of operational readiness and sustainability. The system innovator should not limit his perception of a large scale MOBS to that of a single platform. When designing a MOBS configuration in response to a specified scenario, formulation of first-order concepts should include consideration of a localized and interacting community of platforms, serving as a single major node within the total forward basing network.

- Either a single platform or a community of MOBS-type platforms will be expected to provide berthing and servicing accommodations for small ship-to-shore surface craft as well as normal waterfront requirements (i.e., break-bulk cargo transfer, ammunition and POL handling) as part of the logistic support structure for theater operations. This provision should be designed to enhance the current NCEL concept of a Deployable Waterfront which is viewed as a most likely interfacing subsystem with the MOBS array.

- On the basis of extensive analytical studies including 1/10thscale model testing by NCEL, the basic MOBS building block is seen as a 300- by 300-ft three-deck module constructed of buoyant prestressed 
concrete elements (Appendix C). Individual modules would be fabricated at an appropriate CONUS coastal site where the structural and buoyant elements can be mass produced and assembled into basic modules prior to being launched and moved to a protected offshore area. Here the modules would be joined to constitute mid-sized and towable units for later onsite assembly as a functional MOBS platform. Mid-sized components could be designed to be either self-propelled or towed. In comparison to the basic module, the larger mid-sized units would be joined in final assembly on site in ambient sea-state conditions. The larger unit has additional hydrodynamic stability (pitching, heaving and rolling) afforded by increased mass and larger plan area over that of the smaller basic module.

- The spectrum of logistic and operational support functions to be performed by an ocean basing system in any situation would be accommodated by configuring the MOBS uniquely for its mission. This may be achieved by outfitting each module with subassemblies or components by retrofit prior to combining as mobile or transportable units for later on-site MOBS final assembly.

Early studies reveal three types of floating modules which may be considered candidates for selection as the optimal MOBS component. These types vary in terms of the desired operational characteristics. Studies performed at NCEL in the early 1970s (Appendix C with references), focused on the following three types of floating modules:

(a) COLUMNAR: Single or multi-story decks supported on vertical, hollow buoyant columns (also called legs) or piles.

(b) BARGE: Single or multi-story decks supported on barge-type hulls.

(c) SEMI-SUBMERSIBLE: Single or multi-story decks supported on vertical legs atop submerged horizontal pontoons. 
Conclusions reached in these studies with model experiments iend support to selecting the semi-submersible as the most serviceable. A properly designed semi-submersible module would have the dynamic stability inherent to the columnar platform and the favorable drag characteristics of the barge type for mobility. Unlike the columnar platform, the semisubmersible could be readily constructed with a propulsion system like the barge. All three lend themselves to prestressed concrete construction methods.

An investigation by Bechtel Civil Inc., San Francisco (Appendix E, Item 11) as to the feasibility of Floating Airports, revealed that a steel runway deck with supporting structure of reinforced concrete appeared to be the most acceptable alternative concept, considering cost and operational effectiveness.

Based on the cited investigations of MOBS alternatives, the semisubmersible provides optimal desired system characteristics. This concept is configured by combining three-deck semi-submersible modules ( 300 feet by 300 feet) having the lower two decks and supporting structure composed primarily of prestressed concrete including buoyant vertical legs and horizontal pontoons. The exposed top deck is constructed of steel designed to withstand live runway loads attributed to fully loaded C-5 type aircraft. This alternative also provides a favorable distribution of structural mass within the MOBS platform.

C-5 aircraft, designed for inter-theater strategic airlift, is indicated for deployment along with $\mathrm{C}-17$ aircraft for intra-theater or inter-theater transport in response to the Generalized Crisis Scenario. Assuming the basic module dimensions of 300 feet by 300 feet and the required runway length for fully loaded C-5 aircraft as governing criteria for platform length, the MOBS configuration emerges as a 9,900- by 1,200-foot airport afloat having lateral extensions for other required basing functions.

The architectural renderings (Figures 1 through 5) are representative of the ocean basing system characteristics desirable for military and strategic applications, peacetime diplomatic and, commercial needs. 


\subsection{COMPARATIVE EVALUATION}

In order to assess the relative feasibility of MOBS versus an alternative basing system, the analyst would normally first seek to ensure the technical-viability of each concept before comparing them for operational effectiveness and cost. Since the subject of this investigation involves an innovative approach to forward basing in future time frames, the matter of technical or physical viability must be addressed.

\subsubsection{Physical Viability}

Physical viability of MOBS (Basing System I) is not a matter of exceptional risk if one considers the advanced state of technology for off-shore drilling platforms and reinforced concrete marine structures. The Naval Civil Engineering Laboratory has performed extensive engineering analysis including model testing of the MOBS concept as described in Appendix $C$ of this report. Notwithstanding their positive conclusions as to general technical feasibility of the concept, the investigators were able to isolate certain specific problem areas requiring further analysis and experimental development. However, these problems appear entirely tractable and such as could be readily managed in the normal RDT\&E process.

Basing System II, the most likely comparable alternative to MOBS, is an extension of the current war-fighting support structure for joint multi-service operations as depicted in the Generalized Situation Scenario. Its credibility as an operationally and technically viable system in the year 2000 time frame is established by precedence, assuming only incremental changes attendant to the attrition of U.S. forward basing assets.

In accordance with the logic of this study as set forth in Appendix $B$, it remains to assess and seek to quantify relative costeffectiveness of the two forward basing systems under consideration. 


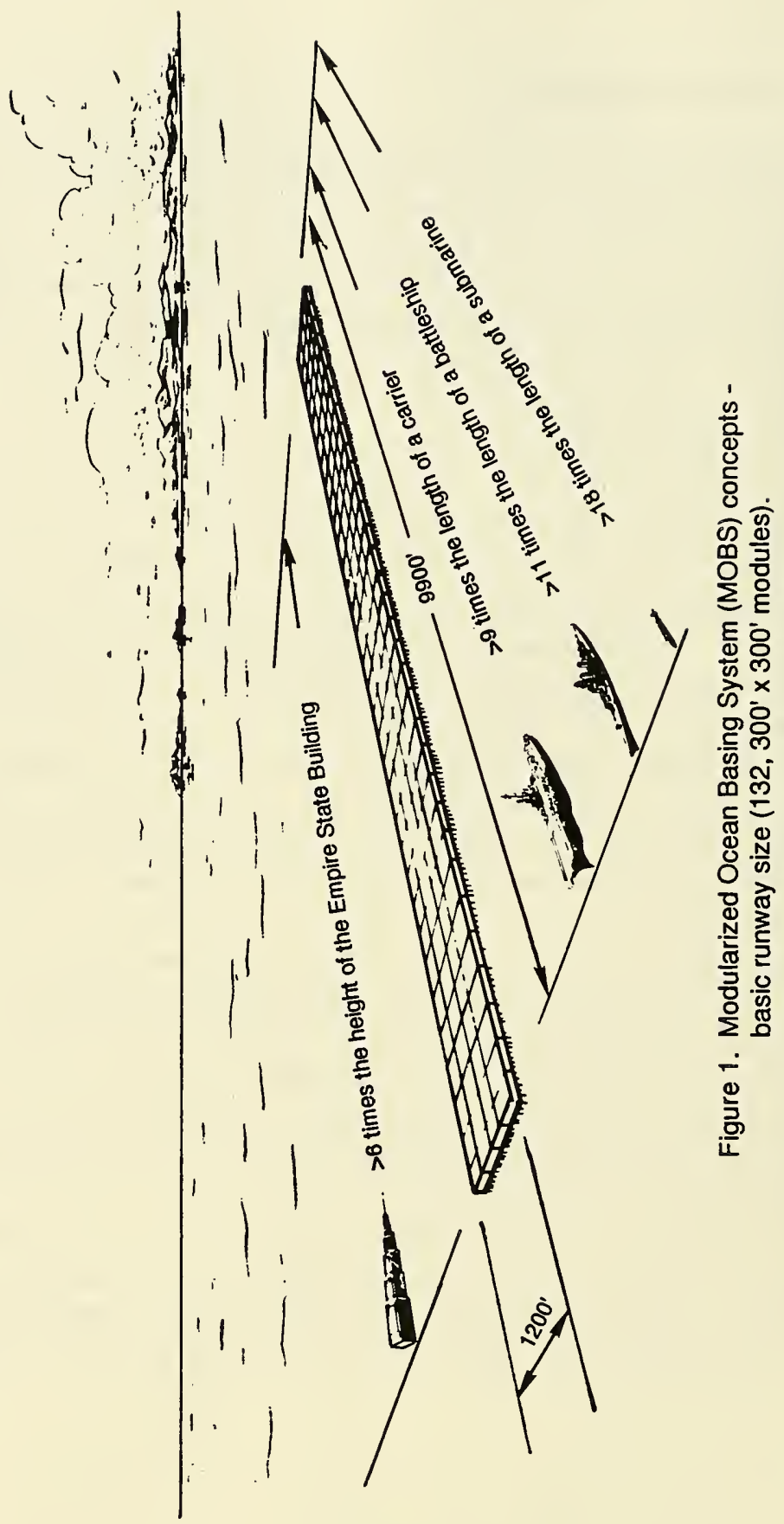




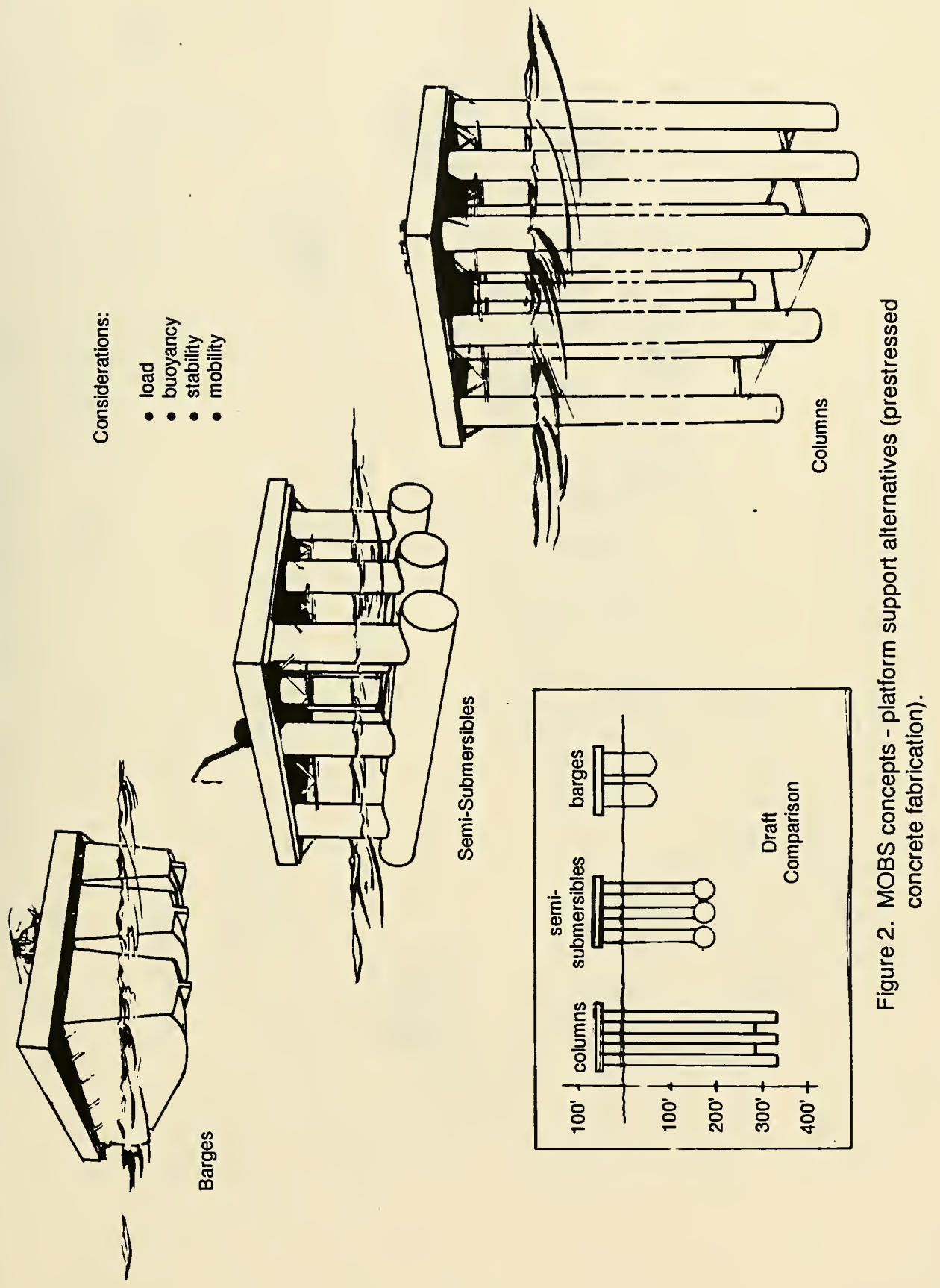




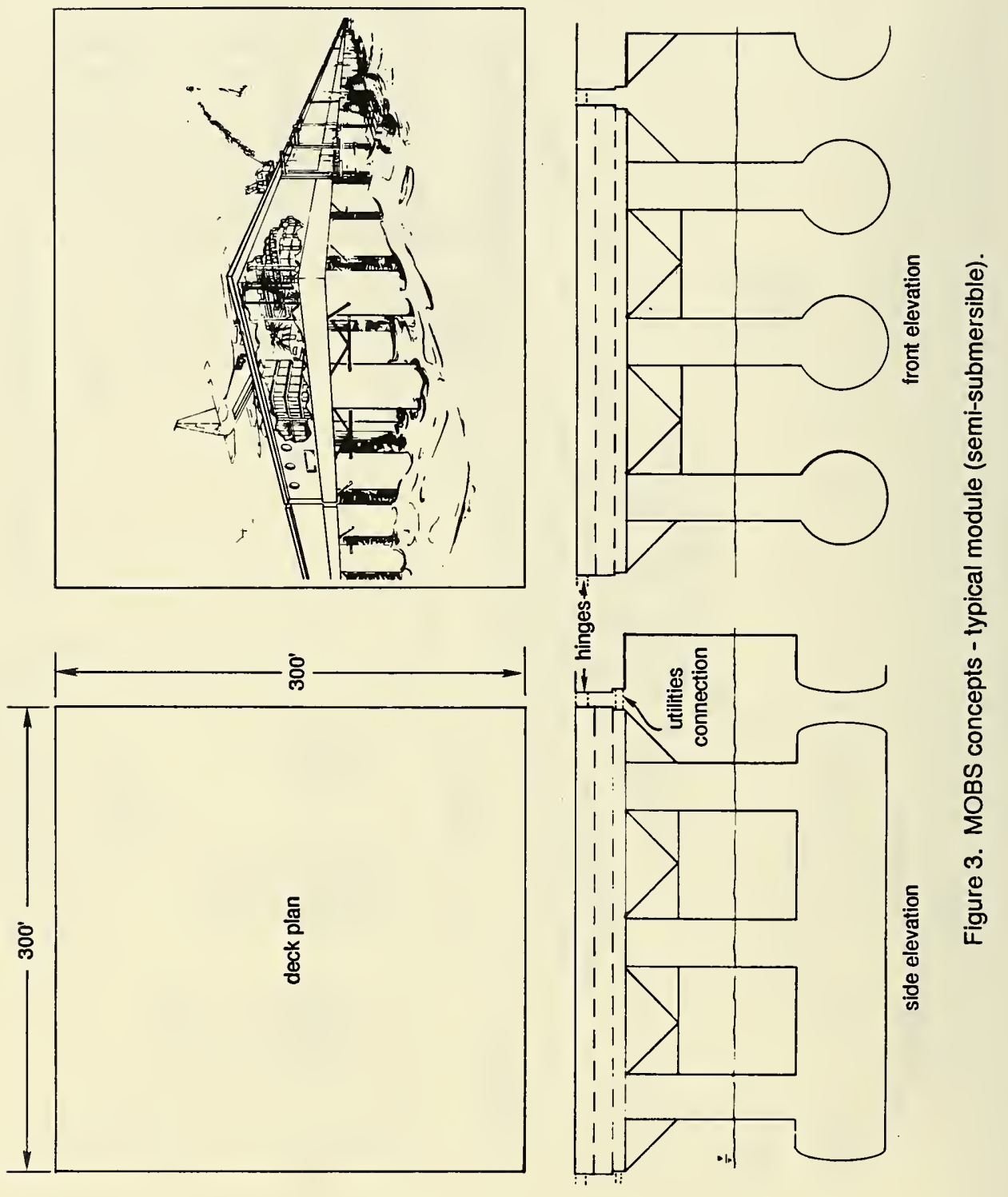




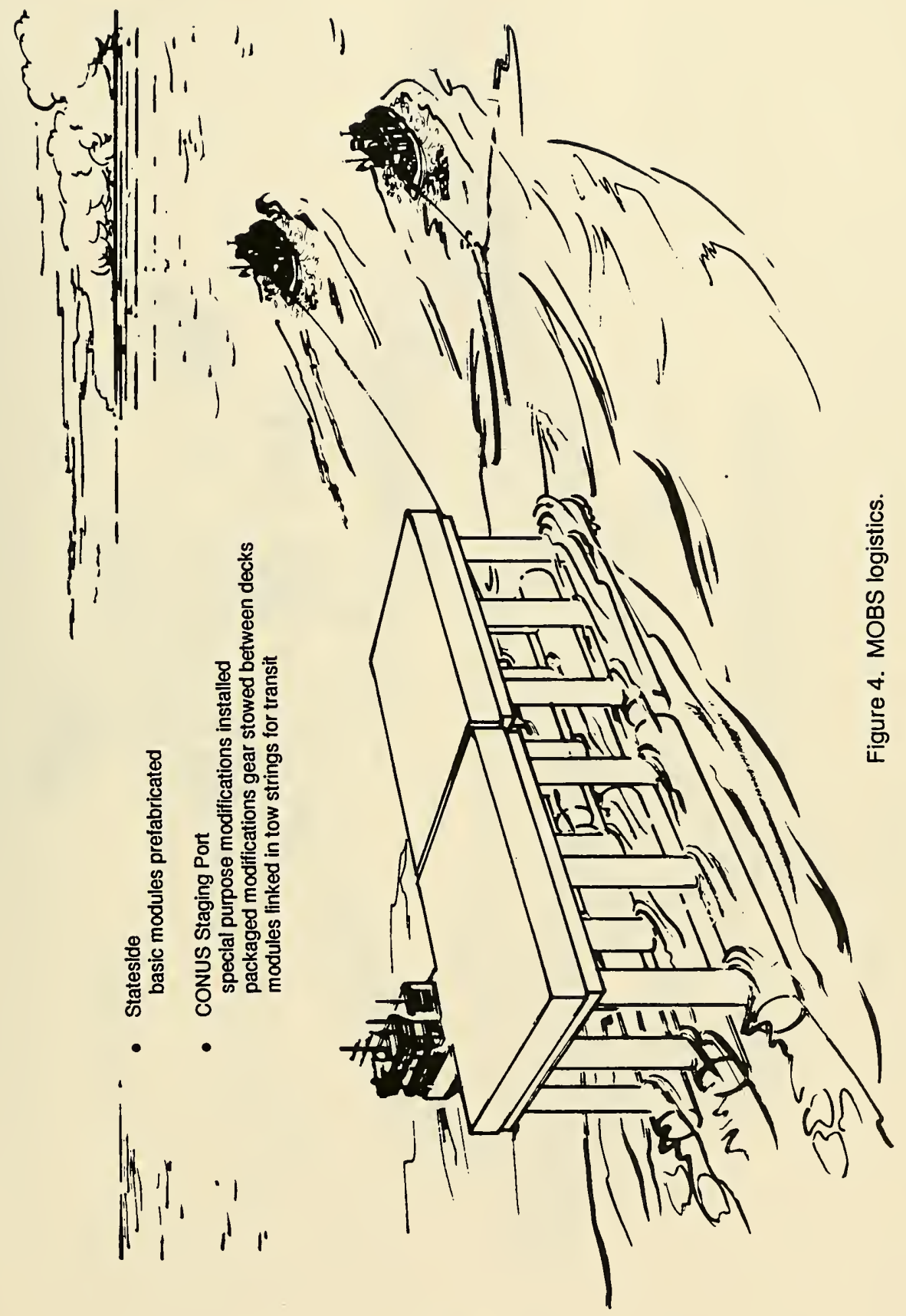




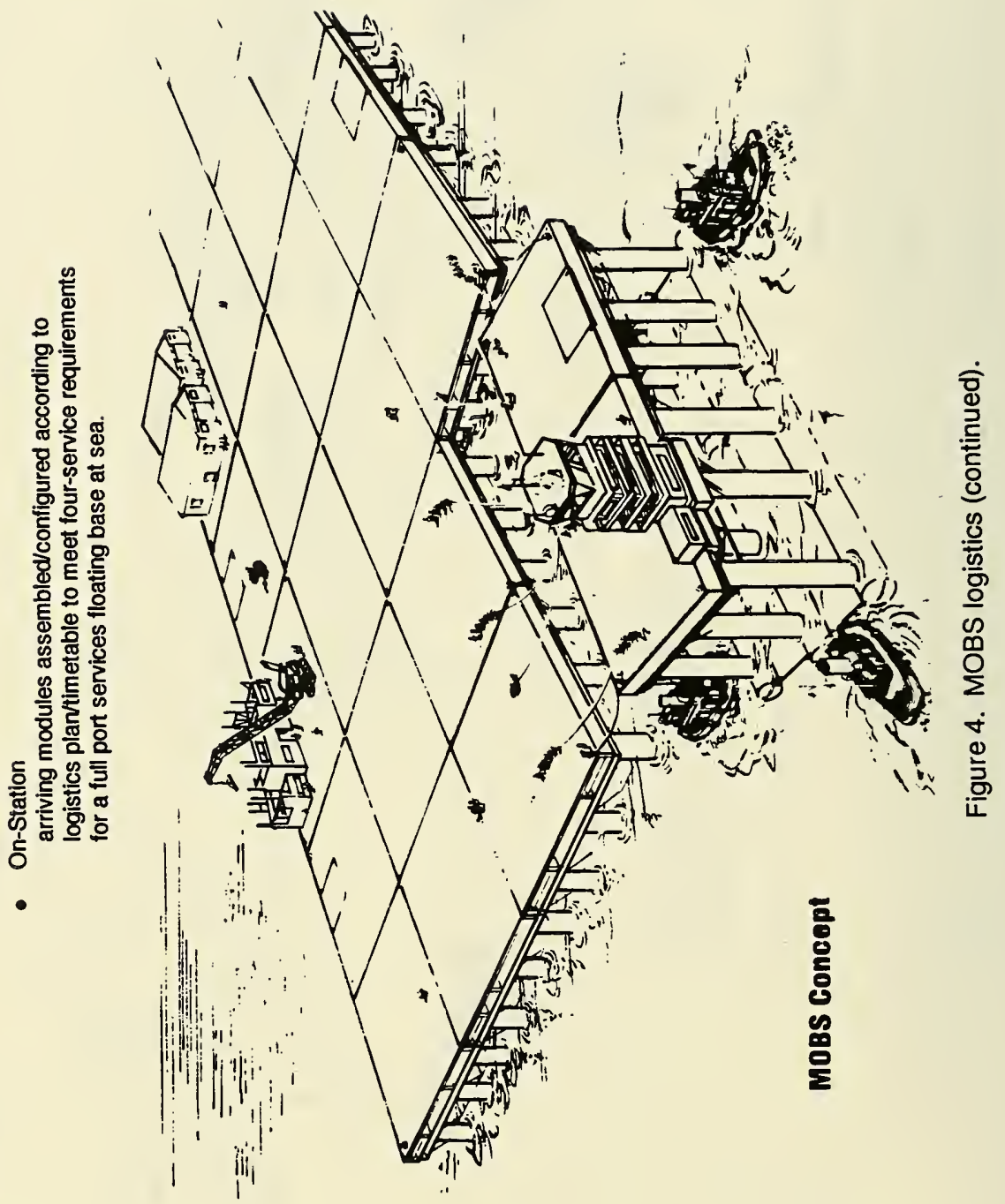




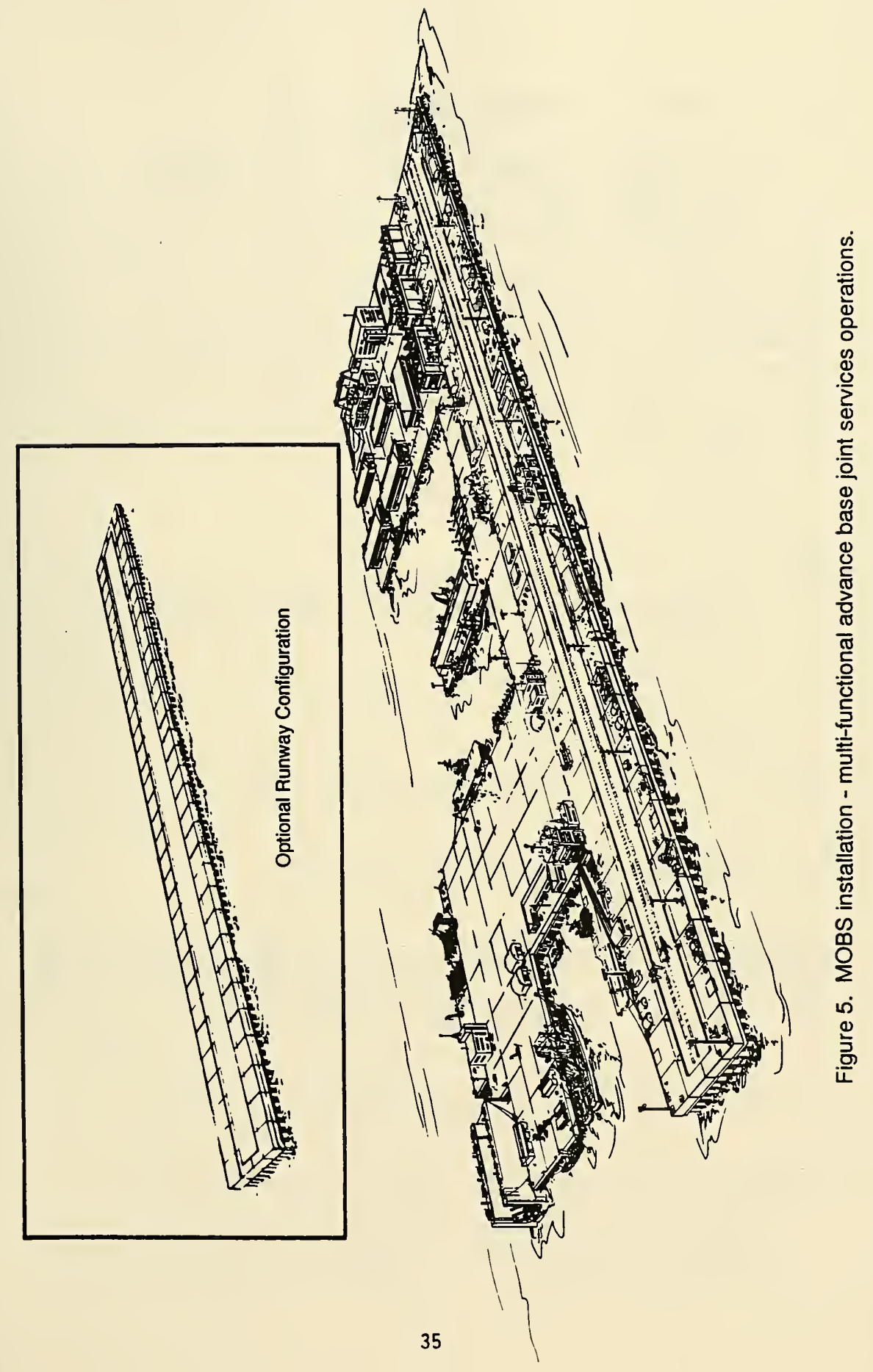




\subsubsection{Performance Effectiveness}

For a definitive assessment of MOBS versus its "NON-MOBS" alternative, both systems should logically be compared for their relative achievement of System Objectives (2.2.3) in terms of required basing functions. This implies a set of measures of effectiveness (MOE) corresponding to the included spectrum of basing functions. Since Basing Systems I and II are compared for operational effectiveness under the specific, however limited, circumstances of a Third World crisis scenario, a single MOE is considered sufficient for the purpose of this investigation. Therefore, the following summary criterion is applied:

$$
N=f(t)
$$

where:

$$
\begin{aligned}
& N=\begin{array}{l}
\text { cumulative tonnage of logistic throughput (available for } \\
\text { useful application) }
\end{array} \\
& t=\text { time (days) } \\
& d(N) / d(t)=f^{\prime}(t)
\end{aligned}
$$

where: $f^{\prime}(t)=$ instantaneous rate of change of $N$ at time, $t=T$.

\subsubsection{Crisis Response: Basing System I (With MOBS)}

The following matrix of time $(T)$ versus participant events is representative of the operational sequence "with MOBS" subsequent to the crisis alert in the Generalized Scenario (3.1.0): 


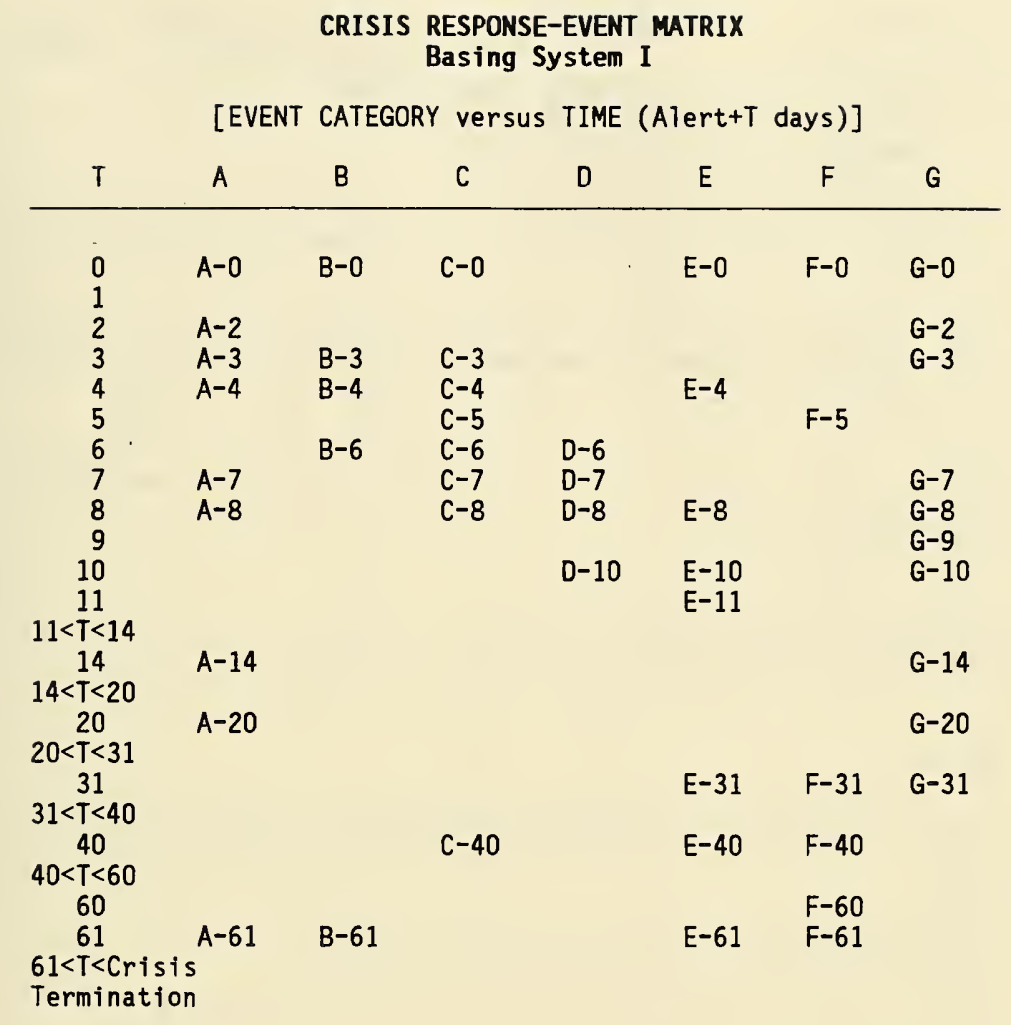

LEGEND:

$T=$ Alert plus days elapsed

$A=$ Modularized Ocean Basing System, Deployable Waterfront, Amphibious Objective Area (MOBS/DWF/AOA)

$B=$ Carrier Battle Force (CVBF)

$C=$ Marine Expeditionary Unit/ Amphibious Construction Battalion (MEU/ACB)

$D=$ Maritime Prepositioning Ship (MPS)

$E=$ Marine Expeditionary Brigade/Marine Expeditionary Force (MEB/MEF)

$F=$ Army Rapid Deployment Force, (LTDIV) and (LTARM + LTCS)

$G=$ Participant as specified in event description

Note: The above matrix representation of transient events in the Basing System I (MOBS) crisis response is open ended beyond the indicated 60 days in order to provide for those continuing and cyclical logistic support events which follow the initial assault. Analysis of the timeextended MOBS response should reveal a near steady-state condition in the cumulative effect of $N=f(t)$ and it first derivative, $N^{\prime}=f^{\prime}(t)$. 


\section{MATRIX EVENT DESCRIPTIONS: Basing System I (With MOBS)}

Category A: Modularized Ocean Basing System (MOBS);

Deployable Waterfront (DWF);

Amphibious Objective Area (AOA)

A-0: Alert! MOBS starts tug-tow ( 4 knots) on $400 \mathrm{mile}$ transit to position 100 miles off-shore of AOA; DWF starts 10-day transit by heavy-lift ship from Okinawa to AOA

A-2: MOBS 300 miles from AOA; advance DWF (3 modules) prepositioned with MOBS embarks from MOBS on independent tug-tow ( 6 knots) to AOA

A-3: $\quad$ MOBS 200 miles from AOA

A-4: MOBS arrives on station 100 miles off-shore of AOA; advance DWF ( 3 modules) arrives $A O A$

A-7: Advance DWF assembled and serviceable at AOA

A-8: Emergency airstrip on captured roadway adjacent to AOA becomes serviceable for helicopter and Harrier aircraft

A-14: DWF (complete version) arrives AOA by heavy-lift ship from Okinawa

A-20: Seaport of Debarkation (SPOD) at AOA becomes serviceable consisting of DWF modules from Okinawa plus advance DWF modules from MOBS

A-61: MOBS continues to serve as in-theater Command Headquarters and central logistic supply node for UAE operation

\section{Category B: Carrier Battie Force (CVBF)}

B-0: Alert! CVBF ordered to proceed to AOA

B-3: CVBF arrives off-shore AOA; commences bombardment

B-4: CVBF achieves air/sea control of $A O A$

B-6: CVBF remains on station in AOA providing continuing air/sea control and selective bombardment

B-61: CVBF stands off $A O A$ pending in-theater contingencies 
Category C: Marine Expeditionary Unit (MEU); Amphibious Construction Battalion (ACB)

C-0: Alert! MEU afloat in Indian Ocean ordered to proceed to AOA

C-3: MEU arrives AOA; stand off pending CVBF bombardment and appropriate aircover for amphibious landing; MEU has maximum 15-day sustainment

C-4: MEU with accompanying ACBs commence amphibious assault on AOA

C-5: MEU secures beach head in AOA including terminal of adjacent crosscountry paved roadway; ACBs commence assembly of advance ( 3 modules) DWF at captured roadway terminal

C-6: MEU advancing inland from secured beach head; combat engineers with MEU clearing emergency airstrip on captured roadway, AOA

C-7: ACBs with MEU complete installation of advance DWF

C-8: Marine combat engineers with MEU complete preparation of emergency airstrip on roadway suitable for helicopter and Harrier aircraft

C-40: MEU and MEB relieved by Army (LT DIV)

\section{Category D: Marine Prepositioning Ships (MPS)}

D-6: Five MPS depart MOBS for AOA

D-7: Five MPS arrive AOA and tie up to advance DWF

D-8: MPS commence down-loading at advance DWF, serving two ships concurrently

D-10: MPS complete off-loading and depart for resupply at MOBS (100 miles off shore)

Category E: Marine Expeditionary Brigade (MEB); Marine Expeditionary Force (MEF)

E-0: Alert! MEF personnel prepare for airlift from CONUS to MOBS; MEF equipment prepositioned on MOBS

E-4: MEB personnel commence arriving from CONUS by airlift as back-up for MEU

E-8: MEB personnel commence moving ashore from MOBS by LCAC and helicopter for marry-up with equipment prepositioned on MOBS

E-10: MEB moving up to reinforce MEU 
E-11: Full complement of 16,500 MEB personnel ashore and reinforcing MEU

E-31: MEB establishes FOB with captured airstrip; insurgents retreat to positions at UAE-Oman border near Straight of Hormuz and villages along coast of Persian Gulf

E-40: MEB combat engineers repair damage to APOD (captured airstrip at FOB) caused by retreating insurgents; MEB relieved by Army (LT DIV)

E-61: MAGTF redeploys to standby positions afloat for future in-theater contingencies

\section{Category F: Army Rapid Deployment Force; (LT DIV), (LT ARM + LT CS)}

F-0: Alert! 7th U.S. Army Infantry (LT DIV) prepares for airlift to MOBS from CONUS; equipment and supplies for $30+$ days of sustainability prepositioned on MOBS

F-5: One additional U.S. Army division (LT ARM + LT CS) prepare for embarkation from CONUS by sealift (Pacific Coast) to MOBS, 6 weeks transit

F-31: U.S. Army (LT DIV) arrives MOBS by C-141 airlift from England

F-40: U.S. Army (LT DIV) moves ashore from MOBS to staging area with equipment prepositioned on MOBS for motorized transit to FOB and selected deployment sites under MEB control

F-60: U.S. Army (LT ARM + LT CS) arrive MOBS/DWF, AOA by sealift from west coast CONUS

F-61: U.S. Army (LT ARM + LIT CS) with (LT DIV) continue UAE operations with required logistic support continuing via MOBS and captured airstrip at FOB

\section{Category G: Miscellaneous Participants as Specified}

G-0: Navy Mobile Construction Battalion (NMCB) prepare for airlift to MOBS from CONUS via England

G-2: Air Detachment (NMCB) departs CONUS for 24-hour transit to MOBS

G-3: Air-Det (NMCB) arrives MOBS

G-7: Air-Det (NMCB) moves ashore from MOBS by shuttle sealift with equipment prepositioned on MOBS to advance DWF

G-8: Air-Det (NMCB) commences final construction of APOD using captured roadway 
G-9: Air Echelon (NMCB) arrive AOA NMCB (Atlantic) Sea Echelon arrive MOBS by airlift from CONUS

G-10: Air-Det completes final construction of APOD for $\mathrm{C}-17$ aircraft

G-14: NMCBs commence assembly of DWF as SPOD with modules from Okinawa

G-20: NMCBs complete assembly of DWF (SPOD)

G-31: U.S. Air Forces squadron of attack bombers and interceptor aircraft arrive MOBS on departure of MAGTF 


\subsubsection{Crisis Response: Basing System II (Without MOBS)}

The following matrix of time $(T)$ versus participant events is representative of the operational sequence "without MOBS" subsequent to the crisis alert in the Generalized Situation Scenario (3.1.0):

\section{CRISIS RESPONSE-EVENT MATRIX \\ Basing System II}

[EVENT CATEGORY versus TIME (Alert+T days]

\begin{tabular}{|c|c|c|c|c|c|c|c|}
\hline$T$ & A & B & $c$ & D & $E$ & $F$ & G \\
\hline Alert +0 & $A-0$ & $B-0$ & $c-0$ & $D-0$ & $E-0$ & $\mathrm{~F}-0$ & $\mathrm{G}-0$ \\
\hline $0<T<3$ & & & & & & & \\
\hline $\begin{array}{l}3 \\
4\end{array}$ & & $\begin{array}{l}B-3 \\
B-4\end{array}$ & $\begin{array}{l}c-3 \\
c-4\end{array}$ & & & & \\
\hline & & B-5 & $\begin{array}{l}c-5 \\
c-6\end{array}$ & $D-6$ & & $F-5$ & G-6 \\
\hline 7 & & & & & & & \\
\hline $\begin{array}{c}8 \\
8<T<11\end{array}$ & & & $C-8$ & $D-8$ & & & \\
\hline 11 & & & $c-11$ & & & & G-11 \\
\hline $\begin{array}{l}13 \\
14\end{array}$ & $A-13$ & & & & $E-13$ & & G-13 \\
\hline $\begin{array}{c}15 \\
15<T<19\end{array}$ & & & & $D-15$ & $E-15$ & & \\
\hline $\begin{array}{c}19 \\
19<T<30\end{array}$ & $A-19$ & & & & $E-19$ & $F-19$ & G-19 \\
\hline $\begin{array}{c}30 \\
30<T<40\end{array}$ & & & & & & & $G-30$ \\
\hline $\begin{array}{c}40 \\
40<T<50\end{array}$ & & & & & $E-40$ & & \\
\hline $\begin{array}{c}50 \\
50<T<54\end{array}$ & & & & & $E-50$ & & \\
\hline $\begin{array}{c}54 \\
54<T<64\end{array}$ & & & & & & $F-54$ & G-54 \\
\hline $\begin{array}{l}64 \\
65\end{array}$ & & & & & $E-64$ & $F-64$ & \\
\hline $\begin{array}{c}66 \\
66<T<75\end{array}$ & & & & & $E-66$ & $F-66$ & \\
\hline $\begin{array}{l}\quad 75 \\
75<T<\text { Crisis } \\
\text { Termination }\end{array}$ & $A-75$ & $B-75$ & $c-75$ & $D-75$ & $E-75$ & $F-75$ & G-75 \\
\hline
\end{tabular}

LEGEND: (Refer Matrix 4.2.1 for category descriptions except, delete MOBS from Category A). 
MATRIX EVENT DESCRIPTIONS: Basing System II (Without MOBS)

Category A: Deployable Waterfront (DWF);

Amphibious Objective Area (AOA)

A-0: Alert! Prepositioned DWF starts 12-day transit by heavy-lift ship from Okinawa to $A O A$

A-13: DWF arrives AOA by heavy-lift ship from Okinawa

A-19: DWF (SPOD) in place and serviceable

A-75: Logistic throughput continues in steady state with SPOD pending termination of crisis

\section{Category B: Carrier Battle Force (CVBF)}

B-0: Alert! CVBF proceeds from Mid-Indian Ocean patrol toward AOA; 3-day transit

B-3: CVBF arrives offshore AOA; commence reconnaissance and bombardment of enemy positions

B-4: CVBF achieves air/sea control of AOA

B-5: CVBF remains on station offshore $A O A$ for air cover to amphibious assault

B-75: CVBF stands off pending further in-theater contingencies

Category C: Marine Expeditionary Unit (MEU); Amphibious Construction Battalion (ACBs afloat with MEU)

C-0: Alert! MEU proceeds to AOA from position afloat in Mid-Indian Ocean; 3-day transit

C-3: MEU arrives AOA, stands off pending achievement of air/sea control by CVBF

C-4: MEU commences amphibious landings

C-5: MEU continues with amphibious landings

C-6: MEU advances inland securing roadway for 3 miles from beach head; combat engineers with MEU prepare emergency airstrip on captured roadway

C-8: Emergency airstrip becomes serviceable for helicopter and Harrier aircraft on temporary basis 
C-11: Emergency airstrip upgraded to accept C-130, C-17 type aircraft on temporary basis

C-75: MEU/ACBs redeploy afloat pending further contingencies

\section{Category D: Maritime Prepositioning Ships (MPS)}

D-0: Alert! Five MPS units on station afloat in Mid-Indian Ocean; 4-day transit to $A O A$

D-6: Five MPS arrive AOA with on-board support equipment for MEU/MEB/MEF; MPS move inshore to commence down-loading with on-board lighterage

D-8: MPS continue down-loading with on-board lighterage

D-15: MPS complete down-loading

D-75: MPS acquire resupply from nearest U.S. land base and redeploy afloat for future contingencies

Category E: Marine Expeditionary Brigade (MEB); Marine Expeditionary Force (MEF)

E-0: Alert! MEF prepares for airlift from CONUS to crisis zone; equipment prepositioned on Okinawa and MPS; MEB forces on Okinawa depart for AOA; 12-day transit on amphibious ships

E-13: MEB forces arrive $A O A$ from Okinawa

E-15: MEB forces from Okinawa prepare to reinforce MEU with men and equipment

E-19: MEB amphibious ships from Okinawa continue off-load of equipment and supplies for MEB at DWF (SPOD)

E-40: MEB advances to capture major airport and establish FOB; insurgent forces retreat and regroup at Oman/UAE border near Straight of Hormuz and along shore of Persian Gulf

E-50: MEB combat engineers and NMCBs complete damage repair to captured airport facilities; APOD becomes serviceable for $\mathrm{C}-17$ and other aircraft; FOB becomes Command Headquarters for in-theater operations

E-64: MEB being relieved by Army (LIT DIV)

E-75: MEB/MEF return to home bases pending future contingencies 
Category F: Army Rapid Deployment Forces, Light Infantry (LIT DIV) and Light Armored (LIT ARM + LIT CS)

F-0: Alert! One U.S. Army Light Infantry Division (LIT DIV) prepares for C-141 airlift to in-theater APOD upon securing of such by MEB after amphibious deployment

F-5: U.S. Army Light Armored Infantry Division (LIT ARM + Lit CS) prepare for sealift from CONUS to AOA; 6 weeks transit

F-19: Army (LIT ARM + LIT CS) embark from CONUS for AOA by sealift

F-54: First contingents of Army (LIT DIV) arrive APOD/FOB by C-141 aireraft

F-64: Army (LIT DIV) move up to relieve MEB forces

F-66: Army (LIT ARM + LIT CS) begin arrival at SPOD from CONUS

F-75: Army (LIT DIV) and (LIT ARM + LIT CS) continue prosecuting operations against insurgents to termination of crisis

\section{Category G: Miscellaneous Participants as Specified}

G-0: Alert! Naval Mobile Construction Battalion (NMCB-Atlantic) prepares for combined air/sea lift to AOA

G-6: Air-Detachment (Air-Det) of NMCB prepares to embark on 48-hour transit to crisis zone; C-130 aircraft to follow-on with airmatting and equipment for preparation of airstrips

G-11: NMCB Air-Det and Air Echelon arrive in-theater

G-13: NMCB arrive AOA; NMCBs and ACBs with MEB commence installation of DWF

G-19: NMCBs and ACBs complete installation of DWF (SPOD)

G-30: NMCB Sea Echelon arrives $A O A$

G-54: U.S. Air Force squadron of attack bombers and interceptors arrive for deployment as needed out of APOD/FOB

G-75: U.S. Air Force squadron remains in-theater to provide air support as needed for prosecution of operation 


\subsubsection{Crisis Response Comparison: Basing Systems I and II}

The relative performance effectiveness of Basing System I versus Basing System II is shown here in Figures 6 and 7 for LOGISTIC THROUGHPUT based on the CRISIS RESPONSE-EVENT matrices displayed in Sections 4.2.1 and 4.2.2 and the quantities indicated in Tables 2, 3, 4, and 5.

\subsubsection{Cost}

It is beyond the scope and charter of this investigation to provide definitive cost analysis and comparisons of projected costs for constructing and maintaining alternative basing systems over the ensuing decade. Because of this limitation, it is also impossible to discuss the relative cost-benefit ratios for the alternatives. However, it is interesting to note that U.S. overseas basing costs projected to the year 2000 are expected to reach an annual level of $\$ 11$ billion with $\$ 7.5$ billion of this amount attributable to leasing and access costs alone. Based on comparisons of studies by the RAND Corporation, Bechtel, and the Hudson Institute one can reasonably place the cost of a 10,000- by 1,200-foot floating airstrip (3 decks) such as discussed herein as not exceeding the projected year 2000 cost for leasing and access rights. Because of the immaturity of construction technology for very large ocean bases one can expect long term costs to decrease measurably over that of the above short term comparison.

\subsubsection{Financial Feasibility}

Financial analysis is beyond the scope and charter of this investigation. However, it should be observed as a basic premise of the study that the cost of large offshore bases will be justified as displacing the excessive cost of foreign land bases. Although, this matter will require thorough investigation, the present U.S. financial commitment for supporting a vast network of foreign bases will assuredly be sufficient to accommodate the incremental and selective displacement of fixed 
land bases with positionable and undeniably accessible forward off shore bases. Beyond this, the concept of burden sharing by U.S. allies should be included as a possibility where such alliances derive mutual benefit from nearby U.S. military presence on offshore bases.

Table 2. Logistic Throughput: Basing System I (With MOBS)

\begin{tabular}{|l|l|r|c|}
\hline Event & \multicolumn{1}{|c|}{ Type } & $\begin{array}{c}\text { Event } \\
\text { Tonnage }\end{array}$ & $\begin{array}{c}\text { Cumulative } \\
\text { Tonnage }\end{array}$ \\
\hline C-4 & MEU/ACBs & 11,123 & 11,123 \\
G-7 & NMCB-AirDet & 412 & 11,535 \\
G-9 & NMCB-AirEch & 2,271 & --- \\
& NMCB-SeaEch(air) & 1,136 & 14,942 \\
D-10 & MPS & 45,452 & 60,394 \\
E-11 & MPF-MEB/ACBs & 96,571 & 156,965 \\
F-40 & Army (LT DIV) & 40,887 & 197,852 \\
F-60 & Army (LTARM+LTCS) & 47,487 & 245,339 \\
\hline
\end{tabular}


Table 3. Logistic Throughput: Basing System II (No MOBS)

\begin{tabular}{|l|l|c|c|}
\hline Event & \multicolumn{1}{|c|}{ Type } & $\begin{array}{c}\text { Event } \\
\text { Tonnage }\end{array}$ & $\begin{array}{c}\text { Cumulative } \\
\text { Tonnage }\end{array}$ \\
\hline C-5 & MEU/ACBs & 11,123 & 11,123 \\
G-13 & $\begin{array}{l}\text { NMCB-AirDet } \\
\text { NMCB-AirEch }\end{array}$ & 2,683 & 13,806 \\
E-15 & MEB/ACBs & 1,702 & \\
D-15 & MPS & 45,452 & 60,960 \\
E-19 & MEB (Amph Ships) & 94,869 & 155,829 \\
G-30 & NMCB-SeaEch & 1,136 & 156,965 \\
F-64 & Army (LT DIV) & 40,887 & 197,852 \\
F-75 & Army (LTARM+LTCS) & 47,487 & 245,339 \\
\hline
\end{tabular}

Table 4. Logistic Throughput Availability: Basing System I (With MOBS)

\begin{tabular}{|c|r|}
\hline $\begin{array}{c}\text { Alert + T Days } \\
\text { (Ton-Days) }\end{array}$ & $\begin{array}{r}\text { Throughput } \\
\text { Availability, } \\
\text { P }\end{array}$ \\
\hline & \\
4 & 0 \\
7 & 33,369 \\
9 & 56,439 \\
10 & 71,381 \\
11 & 131,775 \\
40 & $4,683,760$ \\
60 & $8,640,800$ \\
90 & $16,000,970$ \\
\hline
\end{tabular}


Table 5. Logistic Throughput Availability: Basing System II (NO MOBS)

\begin{tabular}{|c|r|}
\hline $\begin{array}{c}\text { Alert }+ \text { T Days } \\
\text { (Ton-Days) }\end{array}$ & $\begin{array}{r}\text { Throughput } \\
\text { Availability, } \\
\text { P }\end{array}$ \\
\hline & \\
5 & 0 \\
13 & 88,984 \\
15 & 116,596 \\
19 & 360,436 \\
30 & $2,074,555$ \\
64 & $7,411,365$ \\
75 & $9,587,737$ \\
90 & $13,267,822$ \\
\hline
\end{tabular}




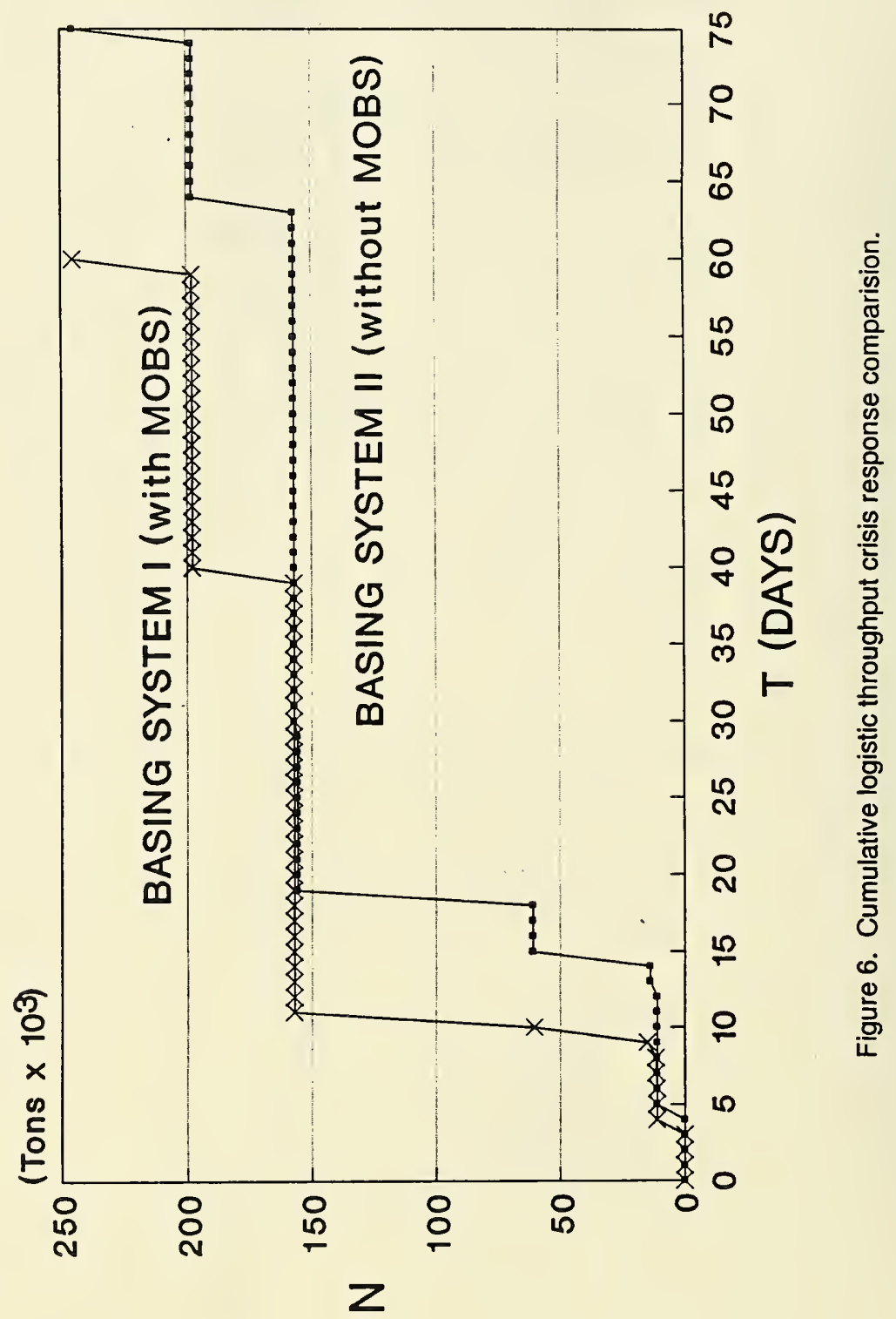




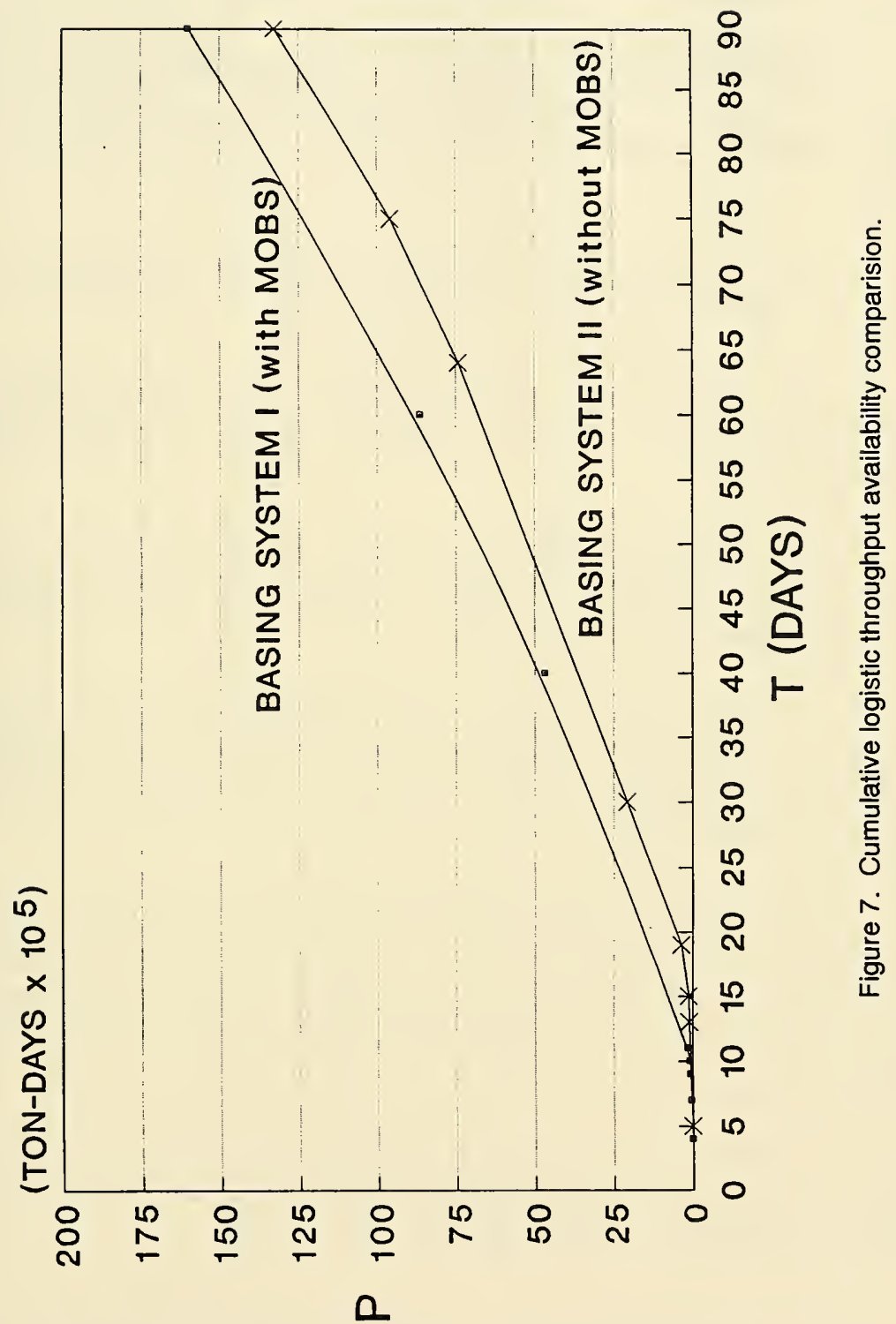




\subsection{CONCLUSIONS}

In serving the study objectives for this investigation, clearly defined conclusions can be justified on the basis of system feasibility logic (Appendix D) which has been applied consistently throughout the study.

1. The U.S. Will remain committed to a forward strategy of discriminate deterrence for the long term (20 years).

2. In support of a forward strategy the U.S. must anticipate future diminished foreign basing assets by seeking to develop viable alternatives.

3. The most likely viable concept for addressing effective basing needs in the year-2000 time frame is a large scale floating structure with specified ancillary facilities.

4. The technology of enduring and sustainable marine structures indicates a modularized floating platform of large scale constructed primarily of prestressed concrete elements and configured for hydrodynamic stability within a wide range of sea states.

5. The concept of modularized ocean basing systems can be demonstrated as significantly superior in terms of cumulative logistic throughput on a daily basis over that of present U.S. capabilities for projecting military force assuming a dearth of proximate foreign basing assets.

6. The cost of a modularized ocean basing system, pending definitive cost analysis, is of the same order of magnitude as the access costs attributable to foreign bases in the year-2000.

7. Financing a MOBS can be viewed as effectively transferring the displaced funds for foreign base lease/access thereby, eliminating added financial burden. 
8. Significant technical issues, al though considered readily tractable within the normal RDT\&E process, will need to be addressed in near-term budget programming in order to realize system acquisition of the MOBS concept in a timely and realistic manner. 
Appendix A

SUPPORTING EXHIBITS

A-1 


$$
\text { . }
$$

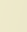

-

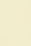




\author{
DFPARTMENT OF THE NAVY \\ orpice of rme cMIEF of MaVAL OPERATIONe \\ WASMINGTON. DE 80350.8000
}

In SePLY AENG To

Ber $00 / 90500103$

22 Mny $1989^{\circ}$

MAMORANTIM TOA PIBTRIBUTIOA

SUbF, LAROE OFTBHORE PLATFORMS

1. There 1s a growing consensus among some of the nation'.

leseing technologists that large flasting offehore platforme are both technlcally feesible and offordable, and that they may be a viable alternative to overcas U.8. Iand bases.

2. Mille Iurther developmint. and applieation of this toohnology could go forward Independent of the v.8. Havy, it is likely that

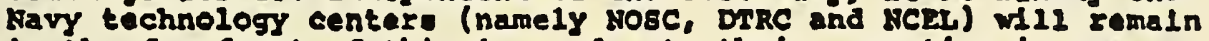
in the forefront of this issue due to thelr expertive in ocean and civil engineering.

3. In.order to be en informed partiolpant in any endeavor to Eurther develop large ofeshore platform for mllitary applicatione, an Information CEB on the technleal fuesibility. coets. otatus of U.S. Mavy technology. and Implementation plane, will be cheduled for early JuIy 1989. OP-04 and MAV8EA ara to take the lead with support provlded by NAVAC and DKR.

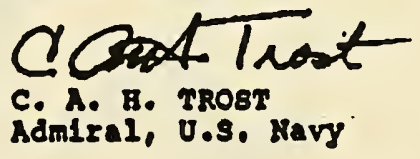

DLetr1but1ons

0Pa-04,08,098

COMNAVSEASYSCOY .

mirac

DIRECTOR mVY LABE

Copy to:

veito

OF $900,09,06,07,001$, UUH

COMHAVAIRAYSCOY

mMEDAWRA

ockr 


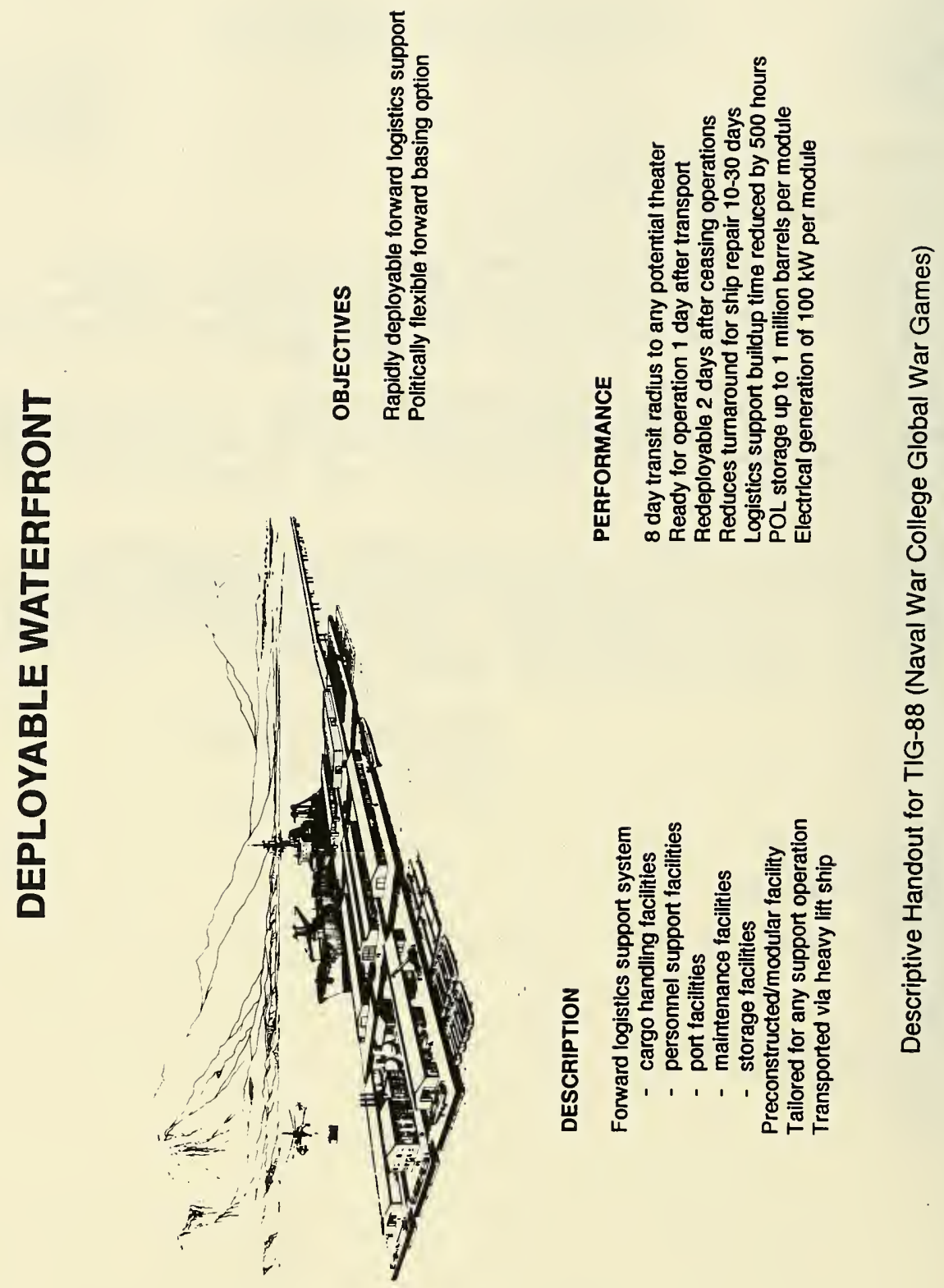




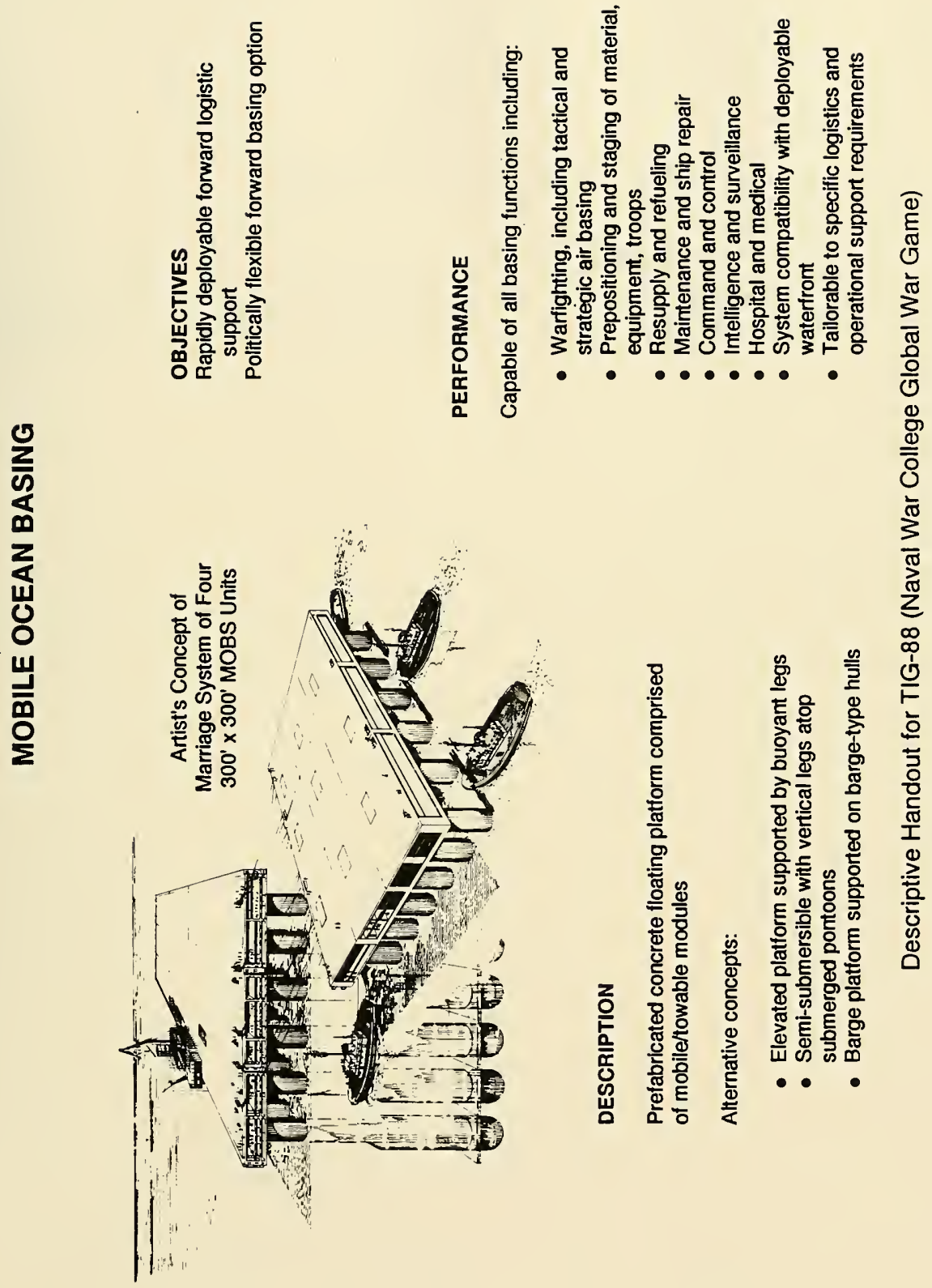




\section{Appendix B}

\section{SYSTEM FEASIBILITY LOGIC}

This diagram is from the MOBS Feasibility Study performed by the Naval Civil Engineering Laboratory and the National Security Affairs Department of the Naval Postgraduate School, Monterey, California. 
(System Feasibility Logic)

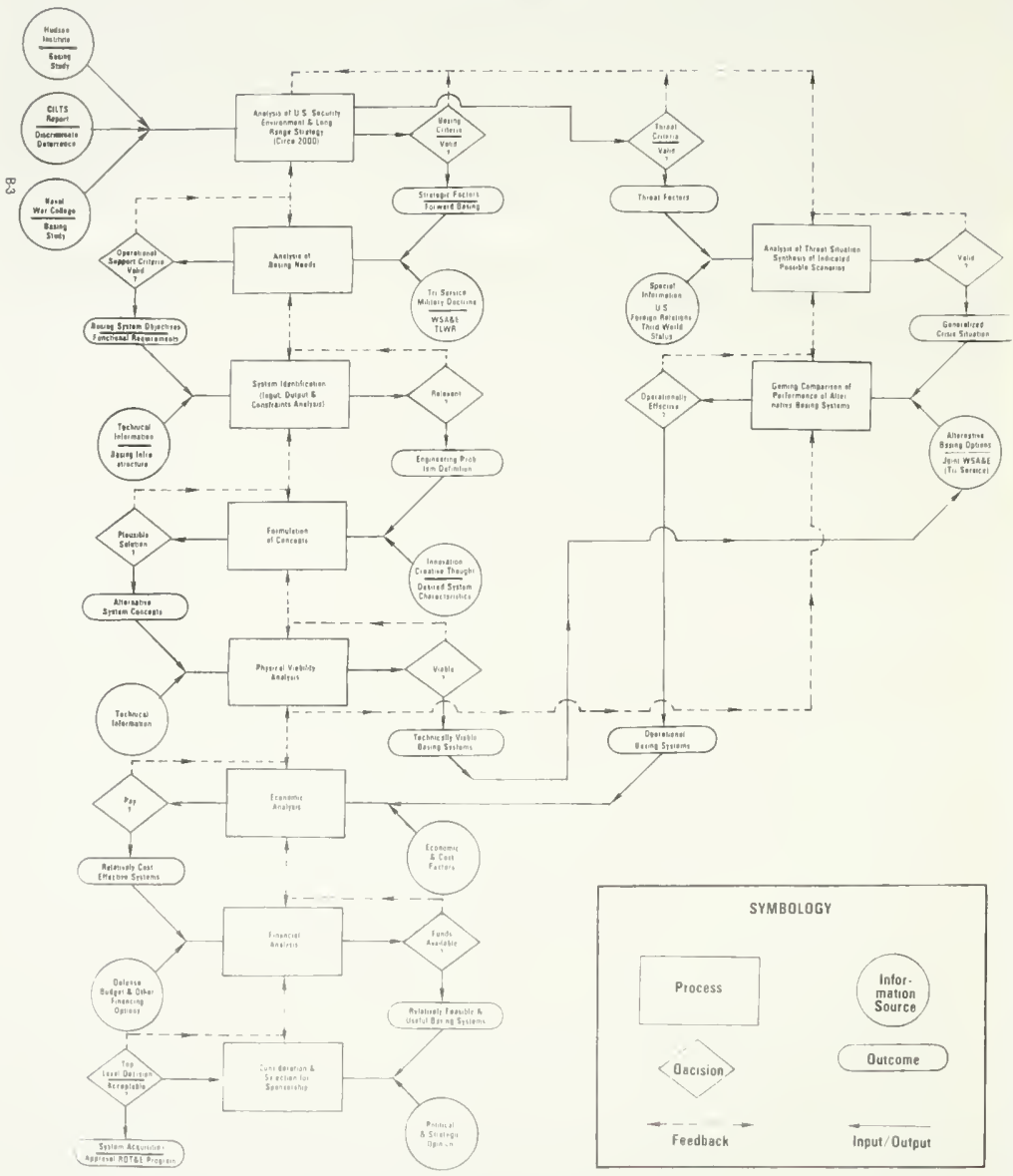





\title{
Appendix C \\ MOBILE OCEAN BASING SYSTEM
}

by

\author{
D. A. Davis and J. J. Hromadik \\ Naval Civil Engineering Laboratory
}

Presented at the First International Conference on Offshore Airport Technology, Bethesda, Maryland; April 29-May 2, 1973. "Mobile," as represented in the acronym, "MOBS," for this 1973 paper has been replaced in the basic 1989 study by "Modularized" as being more applicable to large scale MOBS concepts envisioned for a Strategy of Discriminate Deterrence, circa 2000.) 


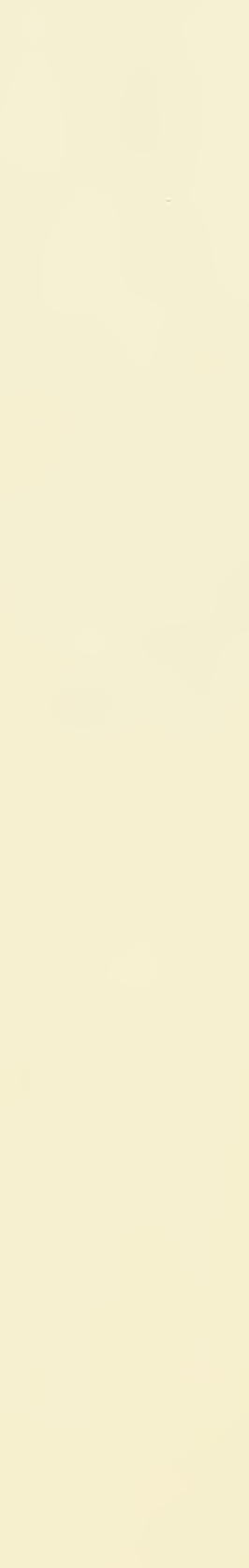

.
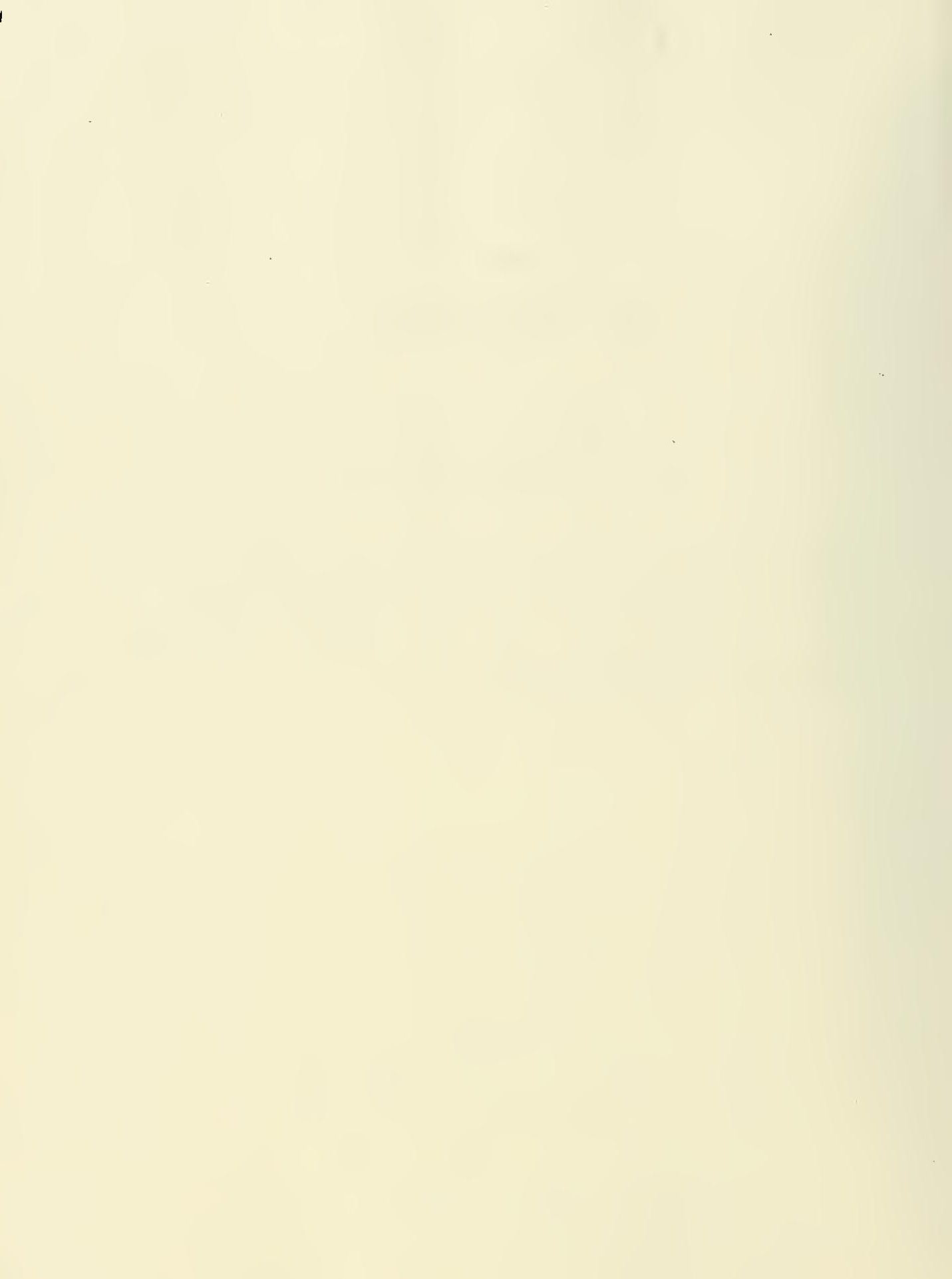
D. A. Davis and J. J. Hromadik

Neval Civil Engineering Laboratory Port Hueneme, California

\section{Abstract}

This paper deals with an investigation into the feasibility and practicability of concrete as the conatruction material for large ocean platforms which are envialoned as satisfying basing requirements of the Navy in the mid $80^{\prime} \mathrm{s}$. The floating platforms would consist of structural components mass-produced asbore, constructed into modules, lsunched, towed to the site and assembled into platforms. Three platform sizes were investigated: $300 \times 300,400 \times 1200$, and $1000 \times 4000$, with dimensions given in feet. Various conflgurations of three basic types were considered: (a) elevated decks on columnar, vertical supports for providing buoyancy, (b) elevated decks with semi-submersible type horizontal hulls and (c) elevated decks with barge-type hulls for floatation. Concrete production quantities and costs are estimated for all platforms investigated. The construction, assembly, launch and testing of a 1/10 acale model twin hull, semi-submersible plat form is also described. The model was constructed to verify the findings of the platform feasibility study.

\section{Introduction}

A vast real estate potential exists in Mobile Ocean Basing Systems (MOBS); large floating platforms that can essentially occupy any ocean site. The floating platforms are seen as consisting of components mass produced ashore, constructed in modules, launched, towed to the site and assembled.

Such a capability to support occupsncy of a particular ocean region for the performance of specified operational tasks exists. It does not appear to require major scientific discoveries or technical breakthroughs; it does require systematic development with accompanying RDT\&E to update and extend current technology. While avallable materials of construction provide designers with a chotce, concrete does appear to stand out. It is readily available, economical, can be mass produced and lends itself to repetitive large-scale conatructions. With concrete, it is not necessary to bring the project to the industrial plant, the production processes can go to the site. Moreover, the history of concrete in a marine environment speaks for itself.

Concrete is an exotic material, not by itself, but through applications that have evolved as a result of recent developments ... improvements in handling and placing, and in the design and control of concrete mirtures ... higher atrengths with improved cement formulations and reinforcing techniques ... innovations in thin-shell construction, longer spans, and now entirely precast ayatems. These developments are leading not only to improvements in quality, but 8180 to techniques that are ever broadening the applications, enabling an efficiency in modern concrete structures never before realized.
The use of large floeting concrete platforms to satisfy basing requirements of the Navy in the mid $80^{\prime} \mathrm{s}$ has been under investigation at the Naval Civil Engineering Laboratory since 1970. $(1,2)$ Th1s paper summarizes investigations into the feasibility of the MOBS concept and concludes with a deacription of the deaign, construction and teating of a $1 / 10$ scale twin-hull concrete aemi-aubmersIble platform.

\section{Description of Concepts}

Candidates are classifled according to their buoyancy elements into the three basic types defined below.

\begin{tabular}{|c|c|}
\hline Platform & Definition \\
\hline Columar & $\begin{array}{l}\text { aingle or multi-story decks } \\
\text { supported on vertical, } \\
\text { hollow buoyant colums (also } \\
\text { called legs) or piles. }\end{array}$ \\
\hline Barge & $\begin{array}{l}\text { single or multi-story decks } \\
\text { supported on barge-type } \\
\text { hulls. }\end{array}$ \\
\hline Semt-Submersible & $\begin{array}{l}\text { single or multi-story decks } \\
\text { aupported on vertical legs } \\
\text { atop submerged horizontal } \\
\text { pontoons. }\end{array}$ \\
\hline
\end{tabular}

All suggested configurations not falling into one of the above were grouped into a separate classification, which is beyond the scope of this presentation.

\section{Columar Plat forms}

The most obvious feature of the columnar concept (Figure 1) is the many possible geometries of the vertical buoyant elements for aupporting the deck. De-coupling from the sea is achleved by reduction of the water plane area relative to the mass of the platform. This Idea is not new. In 1924 Armstrong patented a concept for a floating alrdrome that he envistoned as a refueling station for trans-Atlantic aircraft. (3) His platform, conatructed of steel, resembled that depicted in FIgure 1.

An elevated columar platform can be designed to have a minimum heave, pitch, and roll response for practically any sea condition. For a platform having cylindrical legs of constant diameter and length, and uniform spacing in both plan dimensions, the natural heave period is:

$$
\mathrm{T}_{\mathrm{H}}=1.11 \sqrt{\mathrm{S}_{\mathrm{L}}}
$$

where $S_{1}$ is the wetted length of one of the legs. Thus, an elevated columar platform with a draft of 330 -feet would have a natural heave period of 20 
seconds, which insures that the platform wi11 exhlbit little heave motion in, say, a sea state 7 .

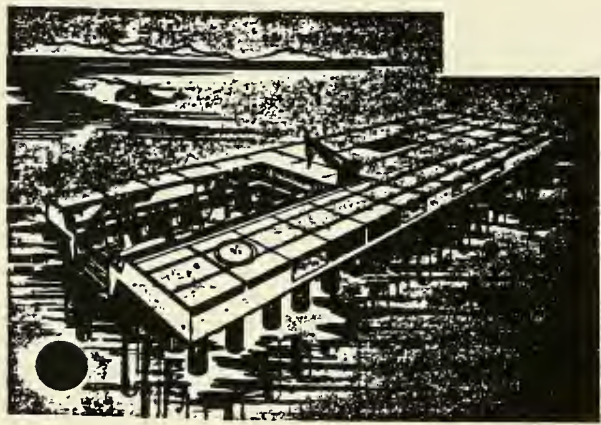

Figure 1. Elevated platform with circular cylindrical legs.

The advantages of a hydrodynamically atable elevated platform are manifold. Firstly, because of atability, alrcraft take-offs and landings are facilitated. This becomes an especially important consideration for handling large, heavily laden cargo afrcraft that are designed to operate from terreatrial alr terminals.

Since elevated sections of modest plan dimensions are themselves hydrodynamically stable, the assembly of much larger floating units from these sections will be a simpler procedure than w111 be the care with the dynamically leas atable shallowdraft aections.

Habitation aboard the platform will be enhanced if it is hydrodynamically stable. The large platform may require the presence of considerable number of support personnel, having little or no nautical experlence, wo may be susceptible to motion sickness. Certainly, life will be more pleasant for everyone aboard a stable platform.

Another advantage mentioned by proponents of elevated platforms is the favorable station-keeping propertles of floating atructures having minimal water plan, and aall area.

The elevated columar platform could be designed so that damaged legs could be removed wthout recourse to dry-docking. Pumps could handle minor leaks wich might develop from timeto-time, while water-tight compartments would laolate flooding due to localized fallure to a leg.

The princlpal disadvantage of this type of platform is its inherent lack of atatic stability.
A positive restoring moment can be assured only if enough ballast Is added at the base of the legs (or If the length and breadth of the platform is increased, thereby increasing the water plane restoring moment). Depending on the pletform size and the weight distribution of the atructural and buoyant elements, the ballast can assume an appreclable percentage of the toral weight.

Compared with the more conventional shallowdraft configurations, additional diadvantages of the columner platform include (1) restriction to sites having a water depth greater than 300-400 feet because of the platform's large draft, and (2) high rowing drag.

\section{Barge Platforms}

Barge platforms have several inherent attributes which commend them for consideration in the MOBS program. It is apparent, for example, that there is a long and succesaful record established In the construction of ocean going concrete barges, shtps and dry-docks. A 300 $300-$ foot or even a 400x1200-foot barge platform is certainly not beyond today's state-of-the-art in floating concrete a tructures.

A $300 \times 300-$ foot barge MOBS can be constructed which has a considerable degree of positfve static stability without the need of ballast, whereas the aemi-submersfble and elevated platforms must be ballasted to prevent capsizing.

The shallow draft of the barge, and the use of falrings fore and aft, will result in a comparative1y low hydrodynamic drag. Thts becomes an important consideration if the platform must be moved rapidly or for appreclable distances. The shallow draft will also allow operations at near-shore sites that are not posstble with deeper draft configurations.

The barge may also be an effective breakwater. It has been demonstrated, both analytically and experimentally, that a large, floating slab is an effective wave attenuator. One can conceive a sheltered area in the lee of the platform which could be used for docking all types of vessels, large and small. The relative motion between the barge-type platform and the vessels would be minimal and, as a result, cargo could be eastly transferred.

Compared to a $300 \times 300$-foot columar platform, a barge platform of the same size will tend to respond readily to the seaway. Helicopters can tolerate some deck movement - operation from aircraft carrlers are routine - and future VTOL afrcraft may eventually achieve a similar tolerance to deck movement. It is questionable, therefore, whether the stabllity afforded by a semi-submersible or a columnar platform is really necessary for operations envolving these types of aircraft.

\section{Semi-Submersible Platform}

An early example of a semi-submersible platform was the steel structure designed (but never built) for use in Project MOHOLE. The MOHOLE platform was to consist of twin submerstble hulls, measuring 350feet in length, which were to support an elevated deck atructure upon aix large diameter, vertical cylinders. Today, there are many semi-submeratbles serving the offshore o11 induatry as exploration, development and work platforms. 
During tow (the platform could be $8 \mathrm{elf}$ propelled) the semi-submersible rides high out of the water in a ahallow draft condition thus reducing hydrodynamic drag to a minimum. On atation the platform is bellasted into a atable, deep-draft mode. Hydrodynamic stability on station reaulta from (1) the relatively low wer plane area of the vertical cupporte, (2) the large added-mas reaulting from oscilletion of the horizontal pontoons, and (3) fluld drag on the pontoons and connecting struts.

The semi-cubmersible shares some of the best features of the other two concepts. A properly designed semi-sumbersible has the dynamic stability of the columar platform and the favorable drag characteriatics of the barge. Conceivably, like the barge, a ami-submersible could be constructed with a propulsion system. It is difficult to imagine any type of columar platform having this cspability.

Figure 2 pictures a possible semi-submeraible configuration. The platform has horizontal pontoons that aupport a multi-level deck. The vertical cupports could be circular in cross-section as shown, or they could be streamlined for reducing the form and wave drag during tow or cruiae. Several platforms like the one depicted could be joined to form large floating complexes.

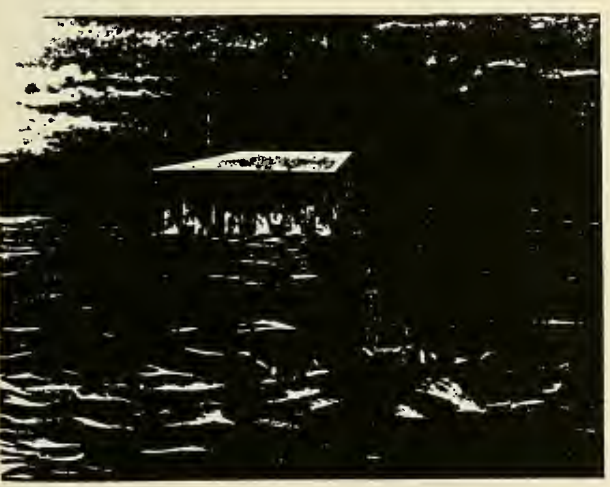

Figure 2. $300 \times 300$ semi-submersible platform section.

If the ballast penalty for static stability is not considered excessive, if the design and sssembly complexities involved in forming this type of platform from concrete can be resolved, and if a propulsion system is determined to be compatible with a aubmerged concrete hull, then a semi-submersible platform can be considered a strong contender in the MOBS program.

\section{Preliminary Design}

Several candidate platform configurations vere considered in the baaic atudy with particular. emphasis on the columar, semi-submersible and barge type platforms. Optinization was found to depend primarily on considerations of static and dynamic stability, material requirements, and design complexity.

This section summarizes the resulting estimates of candidate platform size, weight and hydrodynamic response. It is emphasized that the results are preliminary eatimates. However, auch approximations are sufficiently accurate for relative comparisons and determining the order of magnitude of concrete qualities involved.

\section{Structural Design Assumptions snd Criteria}

The design calculations were based on simplified geometries of each basic configuration (Table 1). In addition the following assumptions were applied:

1. Both the single slab and multi-level decka for the columnar and semi-aubmersible platforms were considered as aeparate structural components resting on buoyant support elements.

2. The vertical legs for both the columnar and semi-submersible platform were considered to have sufficient lateral bracing to prevent failure due to buckling.

3. All structural elements were designed according to ACI standards for reinforced concrete constructions.

\section{Design live loads for the platforms}

were:

(a) with multiple decks

flight deck.......... 250 psf aircraft storage deck . . . . 250 psf personnel deck ....... 100 psf

(b) with single slab deck

flight/storage deck . . . . . 400 psf

5. Design live load was considered distributed uniformly throught; no allowance was made for partlal loading.

6. Concrete having a density of $150 \mathrm{lb} / \mathrm{ft}^{3}$ and a compressive strength of 6,000 psi was used in all design estimates.

7. All columnar and semi-submersible platforms were held to a minimum clearance of 50 feet between the bottom deck slab and the mean water surface when the platform was losded with the full design dead load plus live load. This specification insured thst wsve uplift on the deck will be prevented in all but exceptionally high sea ststes.

8. All platforms were designed with a minimum free-board of 60 feet to insure that deck washing does not impede aircraft landings/take-offs as well as cargo transfer and storage operations. 
Table 1. Typical Simplified Geometry Used in Preliminary Design Calculations

\begin{tabular}{|c|c|}
\hline$\therefore \quad$ Element & Description \\
\hline $\begin{array}{l}\text { Single } \\
\text { Multiple }\end{array}$ & $\begin{array}{l}\text { Solid, two way alab atructurally adequate to } \\
\text { span apacing between supports. } \\
\text { Three deck levels consisting of flight deck } \\
\text { plus two lower-level decks with } 20-\mathrm{ft} \text { clearance } \\
\text { for middle deck and } 8-\mathrm{ft} \text { clearance for bottom } \\
\text { deck. }\end{array}$ \\
\hline Barge-type hull & $\begin{array}{l}\text { 100-ft besm with 50-ft clear span between hulls; } \\
\text { U-shaped cross section. }\end{array}$ \\
\hline $\begin{array}{l}\text { Elevated platform columns } \\
\text { or legs }\end{array}$ & $\begin{array}{l}\text { 25-ft diameter, cylindrical, spaced at } 50-\mathrm{ft} \\
\text { and } 43-\mathrm{ft} \text { centers each way respectively for } \\
\text { the single and multi-level decks. }\end{array}$ \\
\hline $\begin{array}{l}\text { Semi-aubmersible with } 36-\mathrm{ft} \\
\text { diameter hulls and column } \\
\text { supports }\end{array}$ & $\begin{array}{l}\text { 26-ft diameter, cylindrical columns, spaced as } \\
\text { for the elevated platform, atop horizontal } \\
\text { cylindrical hulls transveraely spaced to match } \\
50-\mathrm{ft} \text { or } 43-\mathrm{ft} \text { apacing of colums. }\end{array}$ \\
\hline
\end{tabular}

\section{Results}

Size and Weight. Preliminary design specifications for five types of the $1000 \times 4000-\mathrm{ft}$ platforms are presented in Table 2.

Table 2. Preliminary Design Weights (LT) for the 1000x4000-ft Platforms

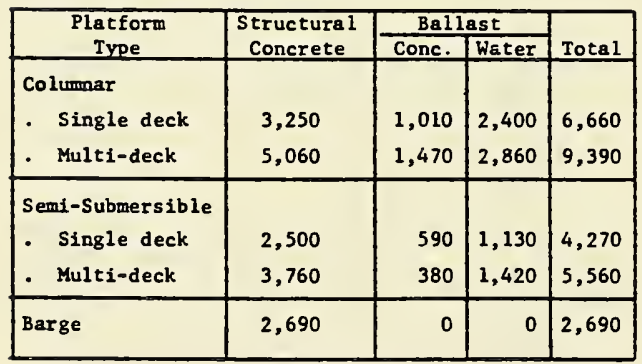

The tabulations for the columnar platform and the semi-submersible platform are given for both single and multiple decks. These values represent the extremes, oince in all probability the optimized designs for apecific missions will have combinations of single and multiple decks; the weights of such platforms will lie between these extremes. The barge-hull platform has interior decks; the single deck did not appear practical for structural reasons. Thus, only one tabulation for the barge is given.

Figure 3 illustrates the relative size of the three MOBS base concepts while the freeboard and plan dimensions are identical for each platform.
The principal difference lies in the draft for each candidate, the elevated platform having a loaded draft more than five times that of the barge.

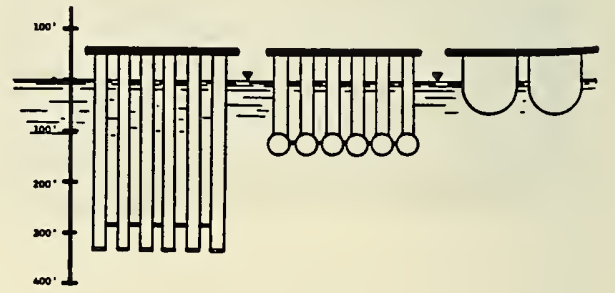

Figure 3. Elevation views of the three MOBS base concepts. 
Dyanic Reaponse. The natural heave perlods for three selected $300 \times 300$ plat forms are preaented in Table 3. The estimates for the columar and seni-subaraible platforms were determined from the following expression:

$$
T_{H}=\frac{2 \pi}{\frac{k}{M}}
$$

where $T_{H}$ is the natural period in heave, $k$ is the restoring force per foot of submergence and $M$ is the totsl 188 of the platform (including the of the live load and the added-mass).

Table 3. Estimated Heave Periods for Selected MOBS Candidates

\begin{tabular}{|l|c|}
\hline \multicolumn{1}{|c|}{ Platform Type } & $\begin{array}{c}\text { Natural Period } \\
\text { in Hesve (sec) }\end{array}$ \\
\hline $\begin{array}{l}\text { (1) Columar (330 ft-draft } \\
\text { mlti-deck) }\end{array}$ & 20 \\
$\begin{array}{l}\text { (2) } \begin{array}{l}\text { Semi-submersible } \\
\text { (multi-deck) }\end{array} \\
\text { (3) Barge }\end{array}$ & 20 \\
\hline
\end{tabular}

The added-mass for the columnar platform was assumed to be negligible and was neglected in arriving at the estimates in Table 3. This assumption makes sense only if the legs are slender, constant diameter cylinders without inter-connecting structural support. The addition of supports between legs and the inclusion, especially, of damping plates at the base of the legs will add considerably to the vitural mass of the elevated platform. The heave period, in this case, would be greater than that shown in the Table. The added mass for the semi-submersible platform was assumed equal to the mass of the water displaced by the horizontal floats. The barge natural heave period is a gross estimate based upon the response of conventional ships with comparable displscement.

For a platform to be considered "stable" in heave, it should have a natural heave period of at least 20 seconds. A natural period of this magnitude is insurance against high platform response for all but extreme storm wave and swell conditions.

\section{Construction Quantities, Time and Cost}

Concrete quantities for the various platforms are given in Table 4. From the standpoint of volume, one may compare a large platform to that of a medium size dam. Mass concrete of 2,000,000 cubic yards or more will be required. Currently there are 17 plants routinely producing in excess of 500,000 cubic yards per year. Any number and/or combination of similar plants can be assembled at the construction site to obtain virtually any production rate - and the rate can be scaled up or down to meet demands. The only restriction appears to be the problem of adequate manpower for exceptlonally rapid construction.
Table 4. Concrete Quantities (in million cu yds) for Type of Pletform Indicated ${ }^{2}$.

\begin{tabular}{|l|c|c|c|c|c|}
\hline $\begin{array}{l}\text { Platform } \\
\text { Size (ft) }\end{array}$ & $\begin{array}{c}\text { Single } \\
\text { deck }\end{array}$ & $\begin{array}{c}\text { Multiple } \\
\text { deck }\end{array}$ & $\begin{array}{c}\text { Single } \\
\text { deck }\end{array}$ & $\begin{array}{c}\text { Multiple } \\
\text { deck }\end{array}$ & Barge \\
\hline $300 \times 300$ & 0.05 & 0.08 & 0.04 & 0.04 & 0.03 \\
$400 \times 1200$ & 0.28 & 0.42 & 0.21 & 0.27 & 0.18 \\
$1000 \times 4000$ & 2.34 & 3.59 & 1.73 & 2.28 & 1.48 \\
\hline
\end{tabular}

The table values also represent time in years when production rate is one million cubic yards per year.

Cost estimates for bare hull structures at or near the assembly/launch site are given in Table 5 . These are based on the calt per cubic yard of concrete required for construction. Conservative eatimates of $\$ 150 / c u b i c$ yard for 8 tructural concrete and $\$ 75 /$ cubic yard for ballast concrete were used in the calculations. The $\$ 150$ per cubic yard chosen for MOBS is about $50 \%$ greater than the national average for buildings and $25 \%$ greater than the prevalent estimate of $\$ 120 /$ cubic yard for floating concrete airports.

Table 5. Estimated Bare-Hul1 $\stackrel{\text { a/ }}{\text { Construction }}$ Costs (In millions of dollars)

\begin{tabular}{|l|c|c|c|c|c|}
\hline $\begin{array}{l}\text { Plat form } \\
\text { Size (ft) }\end{array}$ & $\begin{array}{c}\text { Single } \\
\text { deck }\end{array}$ & $\begin{array}{c}\text { Multiple } \\
\text { deck }\end{array}$ & $\begin{array}{c}\text { Single } \\
\text { deck }\end{array}$ & $\begin{array}{c}\text { Multiple } \\
\text { deck }\end{array}$ & Barge \\
\hline $300 \times 300$ & 7.0 & 10.7 & 5.3 & 7.4 & 5.0 \\
$400 \times 1200$ & 37.0 & 57.5 & 28.3 & 30.2 & 26.7 \\
$1000 \times 4000$ & 312 & 481 & 236 & 328 & 223 \\
\hline
\end{tabular}

a/

Excludes such itema as power systems, machinery, mission equipment and personnel support facilities.

\section{Semi-Submersible Scsle Mode1}

The model, hown in Figure 4 , is a $1 / 10$ th scale twin-hull semi-submersible plstform with hulls spaced on 20-foot centers. The model was constructed to demonstrate the feasibility of assemblying svailable concrete products elements into a platform, to evaluate construction techniques, and to study means of linking the platform modules together to form large platforms.

The bssic elements of the hull and columns are precast pipe sections conforming to ASTM Designation c76-69. They were fabricated by the Ameron Pipe Products Division of South Gste, California. The deck is of steel, consisting of open floor gratiog supported by 8-inch channels that slso serve as the main deck beams. The deck in plan is 27 feet by 32 feet. 


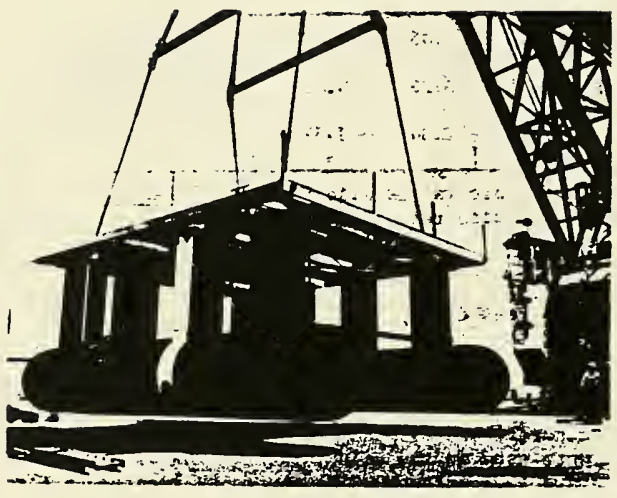

Figure 4. Model twin-hull semi-submersible plat form.

\section{Fabrication of Pipe Sections"}

All pipe elements were centrifugally cast by Ameron Pipe Products at South Gate, California. A minimm concrete cylinder strength of 5,000 psi was specified. The actual strength was nominally 6,300 psi at 7 days. Standard 7-sack concrete mix and curing procedures were used to produce the pipe. All pipe ends were square and plain.

The $66 \frac{1}{2}$-inch OD cylinder of a hull was made up of four 8-foot long pipeswith a 4-inch wall. Eight longitudinal 1 -Inch ducts were provided through the center of the wall and at equal circumferential spacing to accommodate prestressing strands. The wall was reinforced with two circular cages, one on each side of the ducts. A cage consisted of $5 \frac{1}{2}$ coils of $3 / 8$-inch bars per foot and nominal longitudinals.

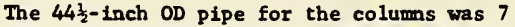
feet long with a 3 -inch wall. Eight longitudinal 3/4-inch ducts at equal spacing were provided in the wall center for prestressing. The wall was reinforced with $5 \frac{1}{2}$ coils of $3 / 8$-inch bars per foot on the outside of the ducts.

Since joints in the hull cylinder were vertical, it was convanient to use non-slumping and fast-curing joining material that would stick to vertical concrete surfaces and flow into joint irregularities when compressed. Nukem No. 109 epoxy filler compound manufactured by Ameron's Corrosion Control Division was selected. The cured epoxy joint was reported to be stronger than the concrete of the pipe.$$
\bar{\hbar}
$$

As reported by A. B. Szulc, Project Engineer, Ameron Corporate Research and Development Department.
Prior to fointing the hull sections, all joint surfaces were sandblasted and sealed with primer. The four pipe sections were then aligned in a horizontal position; about a 3/4-inch thick layer of filler compound was applied to one surface of each joint; and the pipe sections were then posttensioned together. Excess compound wich squeezed out was removed, and paper tape was bonded over the joints to confine the materinl during cure.

Steel and rings, 3/4-inch thick, were also bonded with the epoxy compound to the ends of the 32-foot long cylinder (Figure 5). The rings served as anchor plates for distribution of lontigudinal prestressing forces to the concrete, and provided attachment for the concrete bemispheres over the ends.

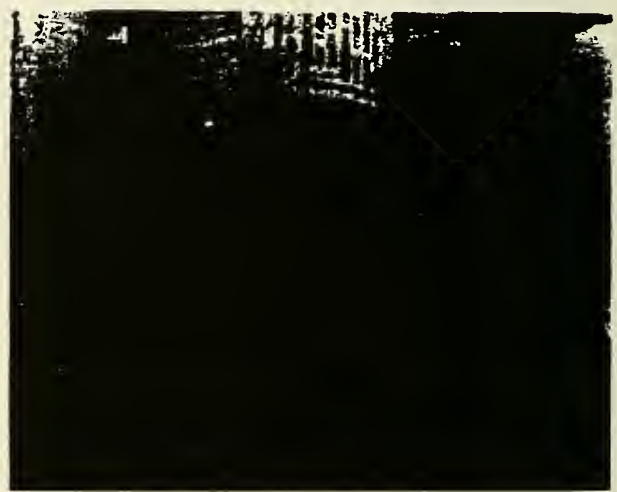

Figure 5. Detall of columm/hull intersection and hul1 end rings.

The hull was prestressed with eight $\frac{1}{2}$-inch, Grade 270 strands to 250 psi resultant concrete compression. The strands passed through the ducts In the wall and their ends were anchored with individual chucks against the steel end rings. Four symetrically located strands were stressed at a time to produce uniform compression. After completion of prestressing, all ducts were pressure grouted with cement mortar mainly to protect the strands against corrosion.

For pipe columns with square, plain ends, special concrete saddles, as may be noted in Figure 5 , and anchor blocks were required to at tach and prestress them to the hull cylinder. During model construction, it was more economical to cast concrete ring saddles directly on the hull than to precast or integrally cast the saddles with the cylinder or colums. The ring saddles were reinforced and tied to the cylinder wall with eight pipe ducts passing through holes drilled through the hull wall, and with $\frac{1}{2}$-Inch bar hoops. 
The pipe ducts were welded to steel anchor plates placed at the inside urface of the hull. Spaces between the plates and the bull surface were drypacked with cement mortar.

The columes were joined to the saddles with Nukem epoxy compound. Steel plate rings, $\frac{1}{2}$-inch thick and with holes for attaching the platform deck, were bonded to the upper ends of the columns. The columns were prestressed to 290 psi resultant compression and tied to the hull cylinder with eight $\frac{1}{2}$-inch, Grade 270 strands located in the ducts. Strand ends were anchored with chucks on the end ring plate and plates on the inside of the hull wall (Figure 6). The ducts were pressures grouted with cement mortar.

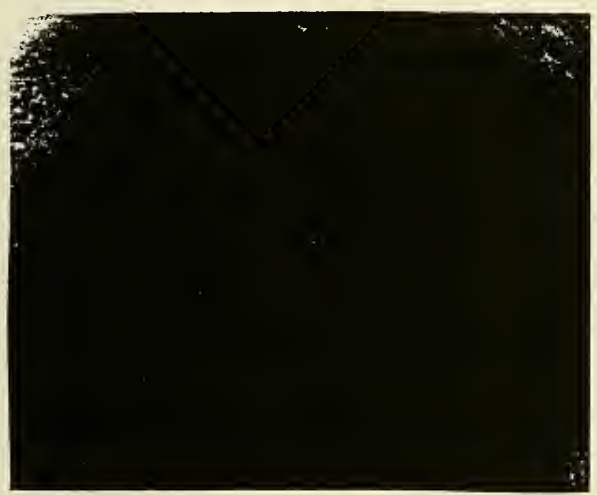

Figure 6. Interior view of hull showing colum anchors and anchor blocks.

\section{Assembly to Launch}

The fabricated units were truck delivered to NCEL in two sections, each consisting of the $32-\mathrm{ft}$ hull with colums attached. Weight of each section was approximately 44,000 Ibs. These were subsequently aligned and plumbed, ready to receive the deck.

The main deck beams, shown in Figure 7 , consisted of pairs of 8-inch channels spanning transversely column to column; the channels were welded to the top column plated ring. Open floor grating ( $1 \frac{1}{2} \times 1 / 8$ bars (a $1-3 / 16$ incihes on center) was used for the deck.

Three steel ballast tanks were installed in each hull, fore, aft and amidship. Each tank had a nominal capacity of taking on 5,000 lbs of sea water ballast. Individual fill/suction lines were plumbed to each tank from a control point in the deck. Access to each hull through a corner column was provided by drilling/coring an 18-inch opening in the hull. The structure was cross braced transversely fore and aft with $\frac{1}{2}$-inch wire rope. A 3-inch steel pipe was used for the horizontal strut at the base of the columns.

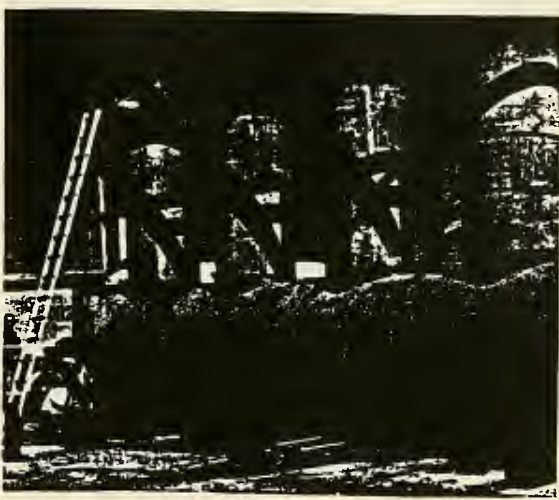

Figure 7. Welding of deck frame components.

The hulls were closed off with steel bulkheads of 5/8-inch plate attached with cap screws to the hull end plate rings; a neoprene gasket was used in between for water tightness. Sixty-six (66)inch concrete hemispheres were attached in turn to the bulkheads that were strengthened with eight radial stiffeners for this purpose. The hemispheres were seated on the stiffeners and secured by a 1inch diameter rod at the center.

After assembly the structure was sandblasted and painted. For evaluation four different antifouling coatings were applied to different exterior portions of the concrete. Three coatings were rubber-base compounds (DEVCON, Phenoline 300 and rubber adhesive), each with 10 percent tributyl tin oxide as the toxic agent to discourage growth. The fourth coating was a two-part urethane base impregnated with very fine specially-cut polyester fibers; this non-toxic coating derives its effectiveness for anti-fouling by providing a non-attractive surface to growth. A portion of the concrete was left uncoated for reference. The steel deck was coated with a primer paint.

As a convenience to launching the structure was assembled on the dock. Launching consisted of hoisting the model with a YD-193 floating crane and setting it in the water as shown in Figure 8 . The lift lines were attached to the top plate rings of the corner columns. The structure, according to the crane load Indicator, weighed 119,000 lbs. of this, approximately 100,000 lbs was concrete. 
assurance that the structures under study can be built. It appears likely that the final selection of $\mathrm{a}$ platform will be more dependent upon stability, ease of assembly, station-keeping, and other factors related to design and cost rather than to feasibility vis-a-vis the state-of-the-art in concrete construction.

\section{References}

1. Hromadik, J. J., et. al. (1971), "Mob1le Ocean Basing Systems - A Concrete Concept," Navsl Civil Engineer ing Laboratory, Technical Note N-1144. Port Hueneme, Cslifornia, January 1971.

2. Dsvis, D. A. (1973), "Mobile Ocean Basing Systems - The Concrete Semi-Submersible Platform," Nsval Civil Engineering Laboratory, Technical Note $\mathrm{N}-$ , Port Hueneme, California. (In preparation)

3. Engineering News-Record (1946), "Army Engineering Finish Successful Tests of Flosting Seadrome Model Design," Vol. 131, No. 13, March 28, 1946, p. 449 .

Figure 8. Leunching of model platform.

Tests

Testing of the model was not completed at this writing. Results of preliminary tests indicate that a full-scale structure in the unballssted stste will have the following naturs 1 periods:

heave - greater than 20 seconds pitch and roll - grester than 25 seconds

After nine months of submergence, the hulls were dry on the inside with no trace of leakage or permeating seawater.

\section{Conclusions}

It was concluded from the study that concrete is a feasible and practical construction material for large ocean platforms. It seems clear that existing construction technolog can be successfully applied to the fabrication through an orderly process of development. Raw material quantities, even for the largest platform studied at $3 \frac{1}{2}$ million cubic yards, are not excessive. Cement requirement is nominally 7 million barrels, less than $2 \%$ of the 1968 production of 400 million barrels. Also, the aggregate production of one million tons per year can be readily accomplished. The success ful construction and launch of a 1/10 scale concrete platform supports the conclusion that neither the size nor shape of the components presents unusual construction requirements. The experience gained in the concrete ship building program is also indicative of the suitability of applying tried and proven techniques to the construction of concrete vessels. The success of these vessels, com$b$ ined with substantial progress in concrete techniques during the intervening years, offers 


\section{Appendix D \\ SYSTEM REQUIREMENTS AND DESIGN CRITERIA FOR FLOATING DEPLOYABLE WATERFRONT FACILITIES ON EXPOSED COASTLINES}

by

Glenwood Bretz

August 1989

NAVAL CIVIL ENGINEERING LABORATORY

Port Hueneme, CA 93043 



\section{CONTENTS}

Page

1.0 INTRODUCTION . . . . . . . . . . . . . . . . . D-1

1.1 Purpose . . . . . . . . . . . . . . . . . . . D-1

1.2 Background . . . . . . . . . . . . . . . . . D-1

1.3 Scope . . . . . . . . . . . . . . . . D-2

1.4 Methodology . . . . . . . . . . . . . . . D-2

1.5 Installation Sequence . . . . . . . . . . . D-2

2.0 DESIGN CRITERIA . . . . . . . . . . . . . . D-2

2.1 Major Requirements . . . . . . . . . . . . D-2

2.2 Design Loads and Forces . . . . . . . . . . . . D-3

2.3 Pier Construction . . . . . . . . . . . . . . D-6

2.4 Mooring System . . . . . . . . . . . . . . . . D-8

2.5 Approachway Design . . . . . . . . . . . . . . . . . . D-9

2.6 Offloading Cranes . . . . . . . . . . . . D-10

3.0 SYSTEM REQUIREMENTS . . . . . . . . . . . . . . . D-10

3.1 Transportation to the Site . . . . . . . . . D-10

3.2 Installation Equipment ............. . . . . . . . . .

3.3 Installation Time . . . . . . . . . . . . . . D-11

3.4 System Life . . . . . . . . . . . . . . . . D-11

3.5 Safety Factor Requirements . . . . . . . . . . D-11

3.6 Reliability, Availability and Maintainability . . . . . D-11

4.0 RECOMMENDATIONS . . . . . . . . . . . . . . . . . D-12

5.0 REFERENCES . . . . . . . . . . . D-12 



\subsection{INTRODUCTION}

\subsection{Purpose}

The purpose of this document is to present proposed system requirements and design criteria for the installation of a Deployable Waterfront Facility (DWF) on an exposed coastline and to identify research necessary to improve the rationale on which these criteria are based. The requirement to install a DWF occurs when supplies and equipment are needed at locations which have no port. The system may be used in either sheltered water or on an exposed coastline. For purposes of this document, deployable waterfont facility is taken to mean a floating facility for ship berthing and cargo discharge. A DWF generally consists of, at minimum, a floating pier and an approachway.

\subsection{Background}

The simplest floating pier is the common barge seen at most small passenger terminals around the world. The barge is moored and access is provided to land through a bridge. Some of the more complex and outstanding examples of floating piers can be seen at: the passenger wharf at Liverpool, England, built in 1874; the oil and container ports at Valdez, Alaska, the port of Iquitos, Peru and the Flexiport in the Falkland Is lands.

\subsection{Scope}

This document reflects a review of the literature on floating piers and the literature and work done on installation of military structures on exposed coastlines (Ref 1 through 5 ). The results of this information 
have been synthesized into a set of proposed design criteria and requirements for construction and installation of a DWF suitable for offloading containerized and roll-on roll-off (RO/RO) cargo from a modern cargo ship. Where requirements are known they have been specified. These specified requirements are intended to be used as guidance and may be changed as more information on the proposed system is gathered. Where requirements are either not known or are uncertain a discussion of the uncertainty is included.

\subsection{Methodology}

The DWF concept will allow construction in a modular or building block approach. Many simplifying assumptions have been made to allow this modularity and to permit simple adaptation of the modules to a specific site. The assumptions have been made on the side of conservatism. Exceptions to this are noted in the text.

\subsection{Installation Sequence}

The DWF scenario begins with Figure 1, loading of equipment aboard the barges. Figure 2 depicts the transfer of the barges to the heavy lift ship. In Figure 3, the heavy lift ship has been ballasted down and the barges are being loaded aboard. Figure 4 shows the heavy lift ship fully loaded with 3 barges and their equipment, ready for transport. Upon reaching the forward site the ship is ballasted down and the barges floated off, see Figure 5 . Construction of the facility may proceed either parallel to the beach as in Figure 6 or perpendicular to the beach as in Figure 7 .

\subsection{DESIGN CRITERIA}

\subsection{Major Requirements}

Major DWF requirements include: 
a. Provisions for berthing of large cargo and military ships, with a total uninterrupted berth length of at least 1,000 feet.

b. The floating pier must be capable of supporting operations in water depths of 50 to 150 feet while supporting off-loading equipment for 40 -foot containers $(67,200$ pounds) and live loads of 1,000 psf.

c. The floating pier and off-loading equipment must be designed for quick erection time. Complete installation of the pier and approachway shall be accomplished in less than 30 days. Initial offload capability shall be achieved in as little as 5 days.

d. The off-loading equipment must be capable of nominally 20 pickups per hour.

e. Floating piers must have the capability of being retrieved and relocated.

f. Provisions for a container storage and marshalling areas, with up to 20 acres per berth. This storage area may be floating or shore based depending on specific site requirements.

g. Provisions for the transport of containers off the floating pier to shore and eventual loading on line haul vehicles.

h. Provisions for the offloading and transit of RO/RO vehicles to the shore.

i. Materials Handling Equipment (MHE) at container storage and marshalling areas.

\subsection{Design Loads and Forces}

2.2.1 Ship Size. The DWF shall be capable of mooring all ships listed in the Mllitary Sealift Command register including, but not limited to the following types and sizes: 
Types

Container ships

Lash/Seabee ships

LHA

$\mathrm{RO} / \mathrm{RO}$

Breakbulk
Length Overall

$(\mathrm{ft})$

$600-1000$

800

820

950

$<600$

2.2.2 Water Depth. The water depth for installation and operation shall range from 50 to 150 feet at the pierhead.

2.2.3 Wind. Prevalling wind speed and directions affect the generation of local waves and at times can be a determining factor in berth orientation (especially in areas of low current). Two cases need to be considered in establishing wind design criteria. First is the facility alone. This should be designed for a 100-mph wind for all components which must remain in place above sea state 8 . The second design case is operation. Wind speed with ships in the berth and offloading in progress should be taken as steady $30-\mathrm{mph}$ wind speed in a direction broadside to the moored vessels.

2.2.4 Current. Currents are of two basic types: unidirectional, resulting from a river or marine stream; and reversing, such as a tidal current. In general the most important would be the tidal current. It is recommended that installation not be attempted in areas with tidal currents exceeding 4 knots maximum.

2.2.5 Tides. Tides affect the length of the approachway which must extend from the pier to shore. Tides also affect operations from decks at fixed elevations. Tide data indicate that 8-foot tides are rarely exceeded, and this value is recommended for establishing the length of the approachway.

2.2.6 Waves. The wave regime in the vicinity of the pier is the most import determinant of the usefulness of the pier as an offloading facility. Ship motions and mooring stresses are affected by the following: 
- Wave period, height and direction

- Stiffness and geometry of moorings

- Mass of the vesse 1

- Water Depth

- Draft of the vessel (in shallow water)

The floating pier should be operable in sea state 4 and be capable of survival in sea state 6 . The characteristics of sea states are defined as follows:

$\begin{array}{llllllll}\text { SEA STATE } & \underline{1} & \underline{2} & \underline{3} & \underline{4} & \underline{5} & \underline{6}\end{array}$

$\begin{array}{lllllll}\text { Wind Velocity (kts) } & 7 & 10 & 16 & 18 & 23 & 30 \\ \text { Wave Height * (ft) } & 1 & 2-3 & 3-6 & 4-8 & 6-13 & 11-23 \\ \begin{array}{l}\text { Wave Period (sec) } \\ \text { Period of Maximum }\end{array} & 3 & 1-6 & 2-8.8 & 2.5-10 & 3.4-12.2 & 4.7-16.7 \\ \quad \text { Energy (sec) } & & 4.0 & 6.0 & 7.2 & 8.9 & 11.3\end{array}$

*Average of the highest $1 / 3$ of the waves

For a facility used to offload large cargo vessels, consideration must be given to the effect of long period waves. The facility should be capable of operation in the following conditions:

$\begin{array}{lrr}\text { Wavelength }(\mathrm{ft}) & 1,300 & 1,000 \\ \text { Wave Period (sec) } & 16 & 14 \\ \text { Wave Height }(\mathrm{ft}) & 3 & 5\end{array}$

The short period sea generated by a local storm can produce waves which are disruptive to small boat or even small ship operations but which do not effect cargo operations. Long period swells produced by distant storms can have a profound effect on both the floating pier and the large cargo ships that are berthed at the pier. These swells may produce extremely large mooring forces and excessive ship motions.

2.2.7 Ice. Consideration must be given to the possibility of pier use in areas where severe ice loads occur. Ice control may be performed by icebreaking, ice suppression, prevention of ice formation or ice diversion. Load calculation must include static and dynamic ice loading. 
2.2.8 Vertical Loads. Vertical loads are those imposed by the weight of the structure (dead load) and by the weight of cranes, cargo, MHE and other equipment (live load). The uniform live load varies, but is usually assumed to be $1,000 \mathrm{bb} / \mathrm{ft}^{2}$ for container cargo facilities. Concentrated wheel loads should be designed in accordance with the American Association of State Highway Officials (AASHO) and Military Load Classifications (MLC) (Ref 6). Vehicle loads are listed below. Uniform live load generally governs pile sizing and wheel loads govern design of deck slab and beams.

\section{Vehicle Loads}

$\begin{array}{ll}\text { Wheeled Vehicles } & \text { HS 20-44 (MLC 60) } \\ \text { Forklifts } & 20 \text { ton } \\ \text { Straddle Carriers } & 30 \text { ton } \\ \text { Cranes } & 300-\text { ton truck crane } \\ \text { Tracked Vehicles } & \text { MLC } 70\end{array}$

2.2.9 Temperature. The facility shall be able to endure a temperature range of -28 to $65^{\circ} \mathrm{C}\left(-18\right.$ to $\left.149{ }^{\circ} \mathrm{F}\right)$ under storage conditions. During operations, the facility shall be able to operate and provide cargo transfer in both polar and tropical temperature extremes.

\subsection{Pier Construction}

2.3.1 Materials of Construction. A major issue which needs to be resolved in pier construction is the choice of material of construction. Timber, steel and concrete are all materials that have a historical basis in pier construction, however, timber has been eliminated because of its low load capacity.

a. Concrete - Reinforced concrete has reduced maintenance costs compared with steel and has the ability to support large loads. Concrete pilings are difficult to splice. On the other hand, prestressed pilings are now produced in long lengths, so splicing requirements would be reduced. As an alternative, steel piling could be used with a concrete structure. Construction times may be greater with concrete structures. 
b. Steel - Steel has a high strength-to-weight ratio, and can be fabricated into almost any shape. Construction and repair techniques are well understood. The only real disadvantage of steel is its tendency to corrode, requiring increased maintenance or careful engineering of corrosion protection features.

2.3.2 Pier Configuration. Two pier configurations have been studied; a standard single deck and a double deck design. Pier length has been set at a nominal 1,000 feet. This will accommodate two berths for Navy vessels or two berths for cargo carriers. Because of transportability limitations and requirements for on site towing, the nominal module length has been chosen as 330 feet. This means three modules would be connected to form a pier.

Port systems studies (Ref 7) on pier width have concluded that for single deck piers the minimum width should be 98 feet and for double deck piers 74 feet. Pier elevation for the top deck should be nominally 13 feet above designed load waterline (DWL) for single deck and 20 feet above DWL for double deck. Draft should be less than 26 feet.

2.3.3 Structural Design. The pier structure can be designed in two ways. Either as a rigid structure in which the lateral forces are absorbed by batter piles or rigid frame action, or as a flexible structure in which the deflections allow the structure to absorb a portion of the impact of berthing ships. The four principal structural schemes for a floating pier are:

- One long pontoon

- Several large pontoons joined by pivots

- A series of small pontoons spanned by a number of single span decks

- A series of small pontoons spanned by a continuous deck

The last two alternatives are the least preferred because of the extra deck weight that must be borne by the pontoons. 
2.3.4 Stability. The floating pier must be capable of carrying all design loads while undergoing a minimal vertical displacement. The pier must be stable in all design environmental and applied loading conditions and must provide reserve buoyancy for damage control and survival. The transverse stability of the pier (as indicated by the distance between the center of gravity and the metacenter) and the overall buoyancy must be sufficient to compensate for flooding of two adjacent compartments.

\subsection{Mooring System}

2.4.1 Mooring System Design. A general requirement for the floating pier mooring system is to provide safe and efficient dock operations. Environmental and ship impact forces must be considered. In general, the mooring system may be composed of both onshore and offshore portions. The onshore moorings terminate at deadmen and the offshore moorings terminate at anchors. The design of the moorings must assure the safe operation of the approachways for all possible environmental loadings.

2.4.2 Fenders. The fender system protects both the vessel and the docking facility from damage resulting from relative motions between the two. Berthing forces are usually the most critical because loading is concentrated on the fender and its footprint, which represents a fairly small portion of the facility. The major factors involved in selecting the fender system are as follows:

- Energy absorption of the fender

- Reaction force exerted on both the pier and hull during impact

- Pressure exerted on the ships hull by the fender

- Size and berthing velocities of ships

- Magnitude of surge and wave action

- Capital and maintenance costs 
In addition to these factors a number of others influence fender design: tidal variations, velocity and direction of winds and currents, types of ships, availability of tugs, difficulty of approach, amount of list in vessels, and design life of facility.

2.4.3 Mooring Dolphins. As part of the pier mooring system, separate mooring dolphins may be installed to absorb the lateral loads from the ship thus reducing berthing loads imposed on the pier. They can be designed either as piled, tension-leg or gravity type structures. The simplest form is a piled or flexible dolphin, which consists of a number of wood, steel or concrete piles. The number and type of piles are dependent on bottom soil conditions, height of the dolphin, and magnitude of the forces acting on the dolphin. Tension leg dolphins rely on the horizontal component of the force in the anchor legs to provide restoring force. Gravity dolphins are usualiy designed in the form of cribs or cells filled with granular material or rock. Gravity dolphins may also be constructed using seawater ballast in conjunction with a structure to resist movement.

\subsection{Approachway Design}

The approachway is the link between the floating pier structure and

the shore. As such, the approachway must provide effective movement of cargo and material handling equipment and personnel. Typical schemes for constructing an approachway include:

- Access bridges

- Floating bridges

- Pile-founded causeway systems

The approachway may be the extension of a causeway system installed during the Assault Follow On phase of an amphibious operation or it may be purposely built to coincide with the installation of the floating pier structure. In either case this is viewed as an undertaking which 
can be done using either current techniques and facilities, such as the Elevated Causeway (Ref 8), or the Modular Causeway System (Ref 9) or technology developed under the Advanced Cargo Transfer Facilities Project (Ref 10 ) such as the folding spans on jackup foundations.

\subsection{Offloading Cranes}

The offloading crane must reflect the nature of the port operations. For example, huge gantry cranes may not be appropriate for military operations in sensitive areas because of the target offered. Four major alternatives are possible in the choice of offloading cranes:

- Container gantry cranes

- Mobile truck or crawler mounted cranes

- Fixed, stiffleg or pedestal cranes

- Barge or ship cranes

Mobile cranes are discussed at some length in Reference 11. A crane ship has been developed by the U.S. Navy and would be available for use at a floating pier. The additional berthing load imposed on the pier by nested ships must be considered in the design calculations.

\subsection{SYSTEM REQUIREMENTS}

\subsection{Transportation to the Site}

Transportation to the site may be accomplished using ocean tow where transport time is not critical. Heavy lift ship transport can be used for transport speeds of up to 16 knots. See Reference 12 for further information on transportability.

\subsection{Installation Equipment}

The primary equipment needed to install the DWF is a minimum of two harbor tugs and a heavy lift crane. The tugs should be capable of open 
ocean operations and should be rated at the thrust required to move the modules in sea state 3 with 4 knots of current. The heavy lift crane shall be rated in accordance with installation $11 \mathrm{ft}$ requirements. The use of the offload crane to meet the installation requirements should be considered.

\subsection{Installation Time}

The DWF shall be installed in stages. The facility could be ready to transfer cargo at reduced rates in as little as 5 days. Full offload capacity shall be achleved in 30 days.

\subsection{System Life}

The service life of the DWF shall be based on 20 years of operation in a seawater environment.

\subsection{Safety Factor Requirements}

Facility modules and appurtenances shall be designed in accordance with governing US Navy and American Bureau of Shipping codes and regulations for the design of structures and the safety factors of those codes and regulations shall be considered adequate.

\subsection{Reliability, Availability and Maintainability}

During the first 90 days of operation the facility shall have an availability of 0.99 . After the initial 90-day period, the facility components shall not have more than 48 hours of down time within a 15day period. During the time the facility is in operation, routine maintenance shall not interfere with ship operations. After any system breakdown, the system shall be capable being repaired within a period not to exceed 24 hours. 


\subsection{RECOMENDATIONS}

The use of a floating pier on an exposed coastline will require some significant advances in the state of our current technology. This operation has never been undertaken before. We have only the experience of floating piers in protected waters from which to draw. Research will be required in the areas of port operations in sea state 4 and development of a breakwater to reduce the effects of high sea states.

\subsection{REFERENCES}

1. Giannotti and Associates Inc. Planning and design criteria for deployable port facilities pier. Ventura, CA, Mar 1987 (N00123-84-D-0235ZZ11).

2. Waterways Experiment Station. TR H-73-9: Port construction in the theater of operations, by A.A. Clark et al., Vicksburg, MS, Jun 1973.

3.

ACN 20382: Container port construction, by Frank B. Cox, vol 9, Vicksburg, MS, no date.

4. Naval Facilities Engineering Command. Systems for mobile piers and causeways for expeditionary logistics facilities, by Fredrick R. Harris, and PRC System Sciences Co., Alexandria, VA, Jun 1973 (N00025-70-C-0004).

5. Gregory P. Tsinker. Floating ports - Design and construction practices, Houston, TX, Gulf Publishing Co., 1986.

6. Belvoir Research and Development Center. Trilateral design and Test code for military bridging and gap-crossing equipment. Fort Belvoir, VA, Jan 1984.

7. Naval Civil Engineering Laboratory. UG 0007: Advanced pier concepts user's guide, by D. Davis. Port Hueneme, CA, Oct 1985. 
8. Naval Facilities Engineering Command. NAVFAC P-460: Elevated causeway facility, vol. 1, Alexandria, VA 22332.

9. MAR, Incorporated. Technical Report No. 748: Transportation and installation scenario for the $\operatorname{ELCAS}(m)$. Severna Park, MD, April 1988 (N00167-86-D-0119).

10. Naval Civil Engineering Laboratory. Technical Note N-1738: Concepts for improving logistic capabilities over the shore, by M. Atturio, J. Miller, S. McCarel, and G. Bretz. Port Hueneme, CA, Nov 1985.

11. Commercial mobile crane handbook for expedient cargo handling operations. Port Hueneme, CA, VSE Corporation, Dec 1983 (N00123-81-D-0173).

12. . Contract Report CR 88.004: Deployable waterfront transportability study using heavy lift submersible ships. Severna Park, MD., Final report, MAR Inc., Dec 1987 (N00167-86-D-0119). 

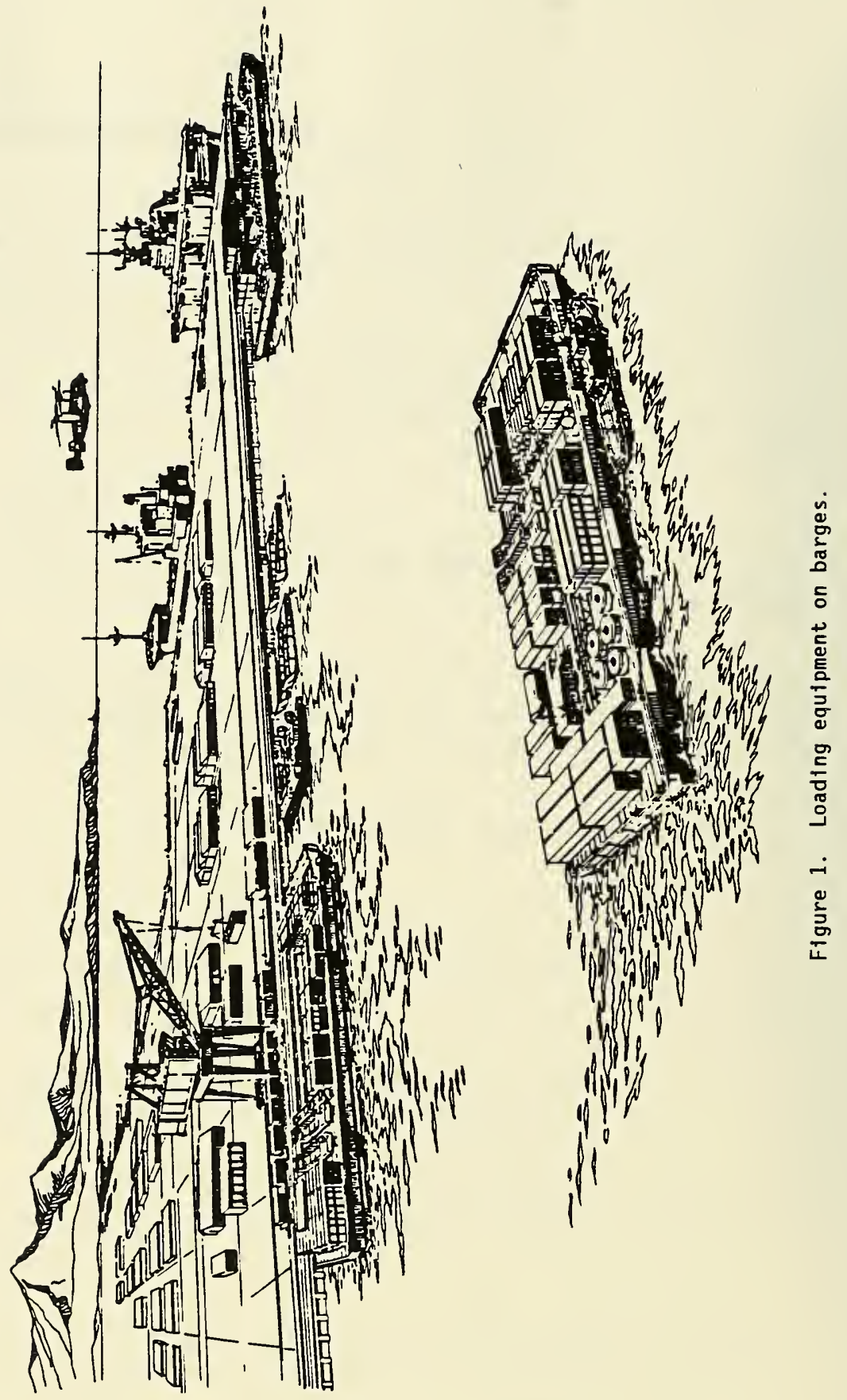


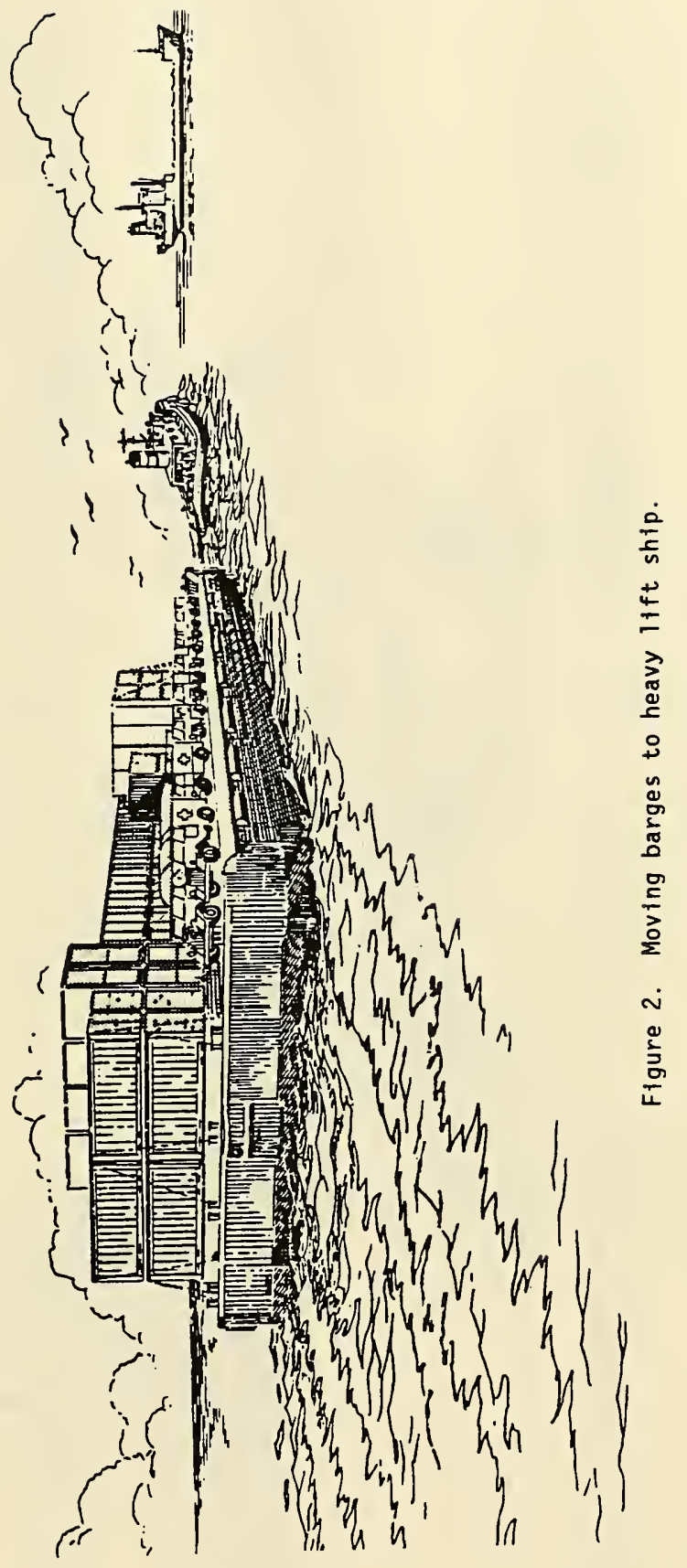




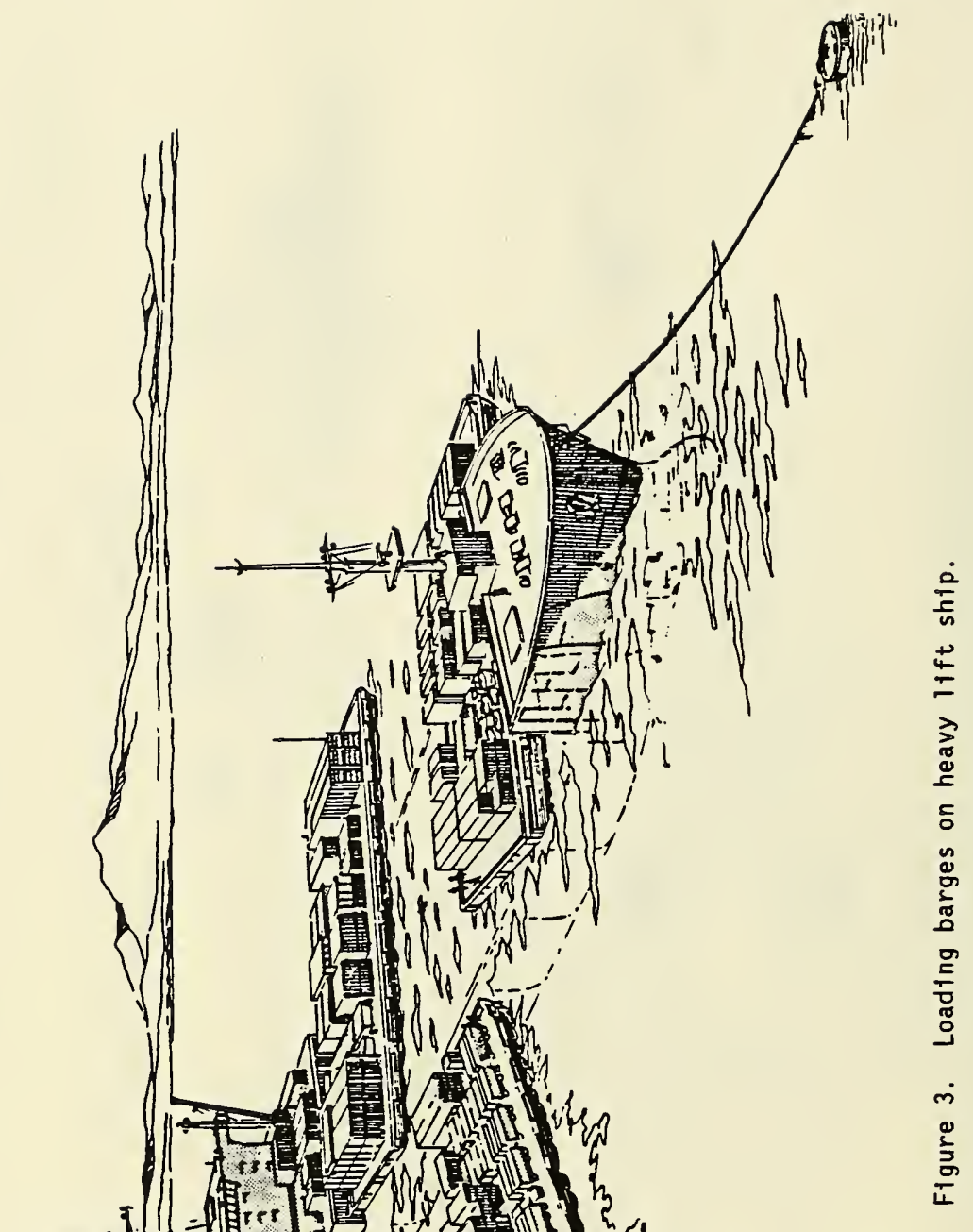




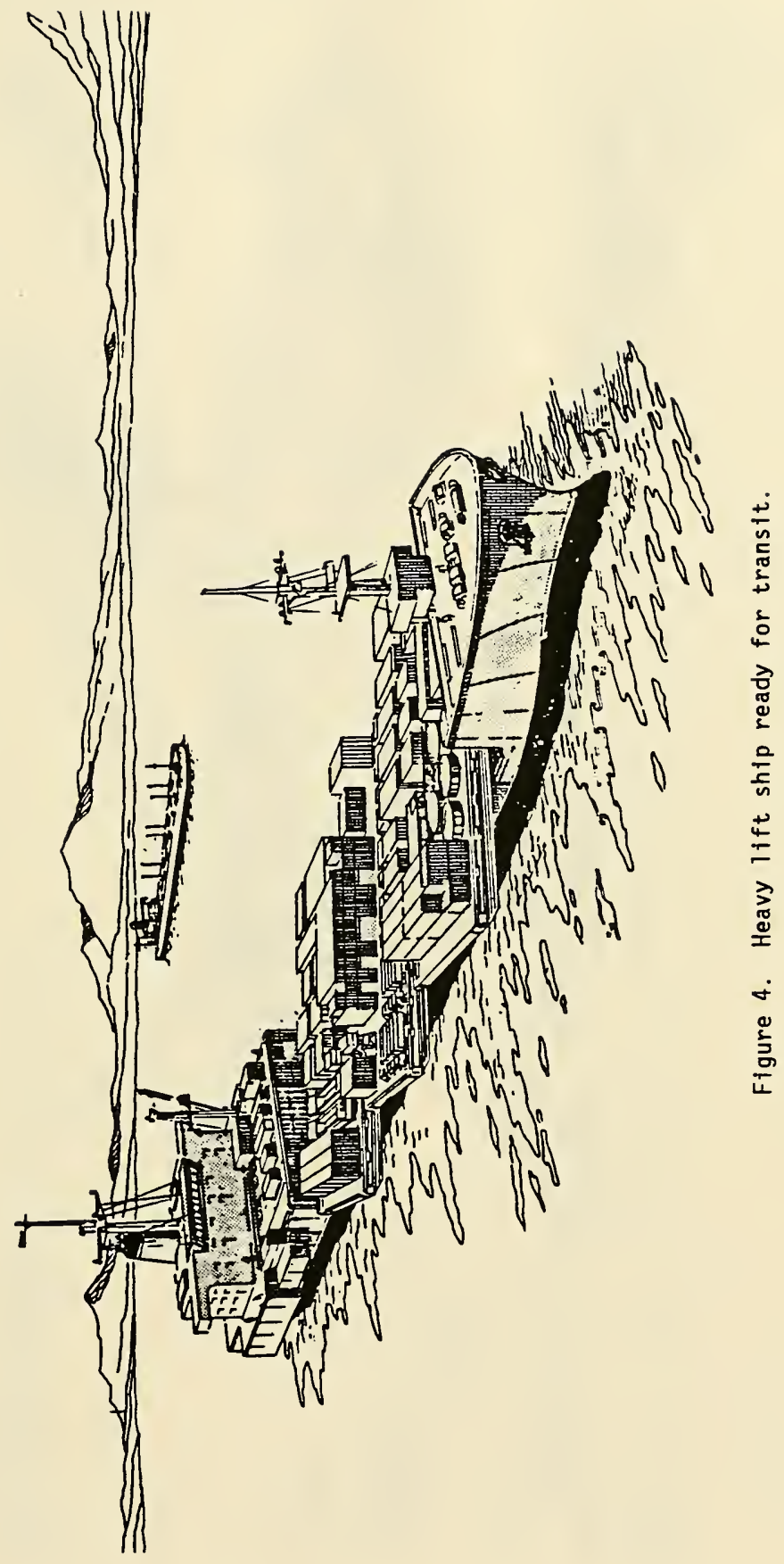




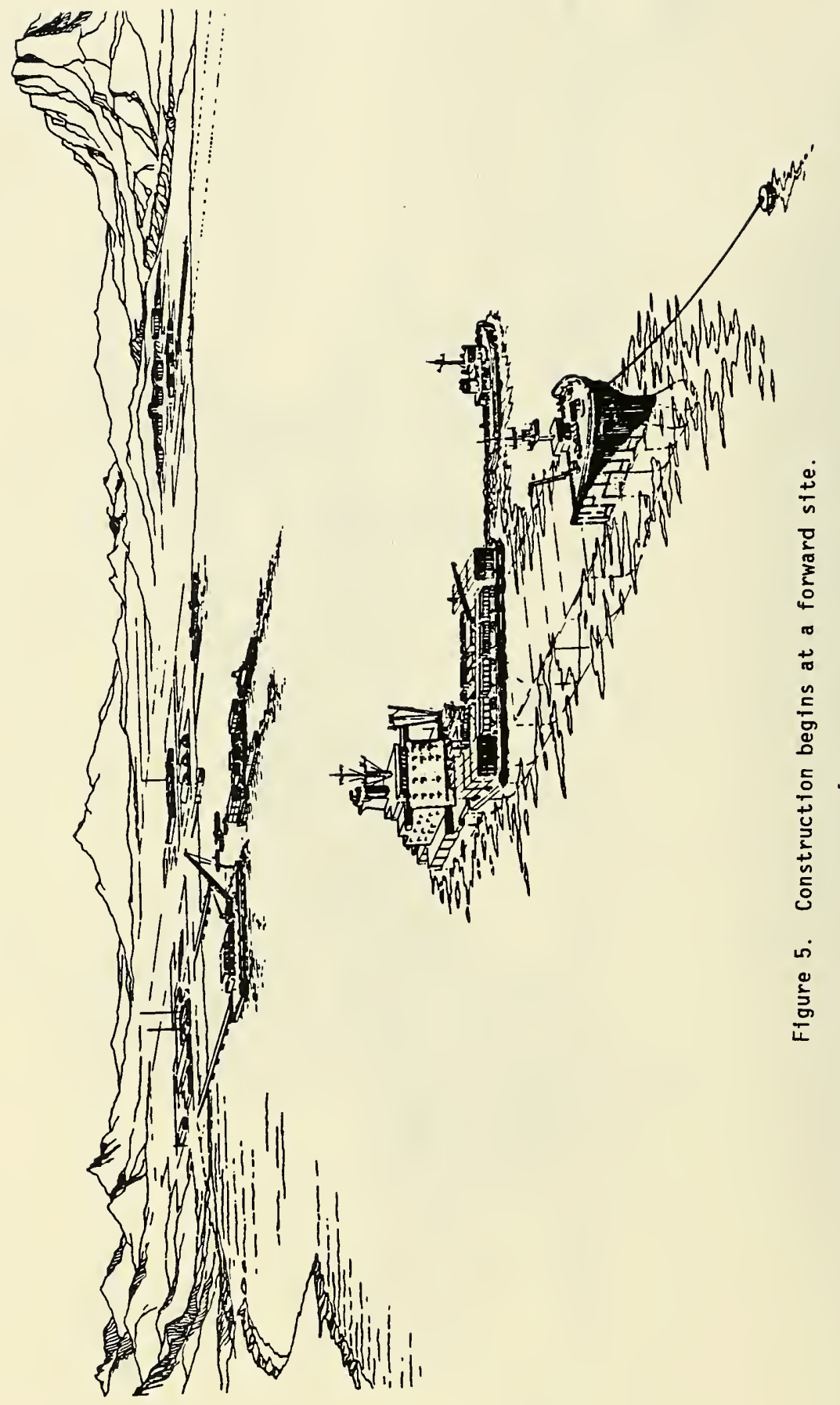




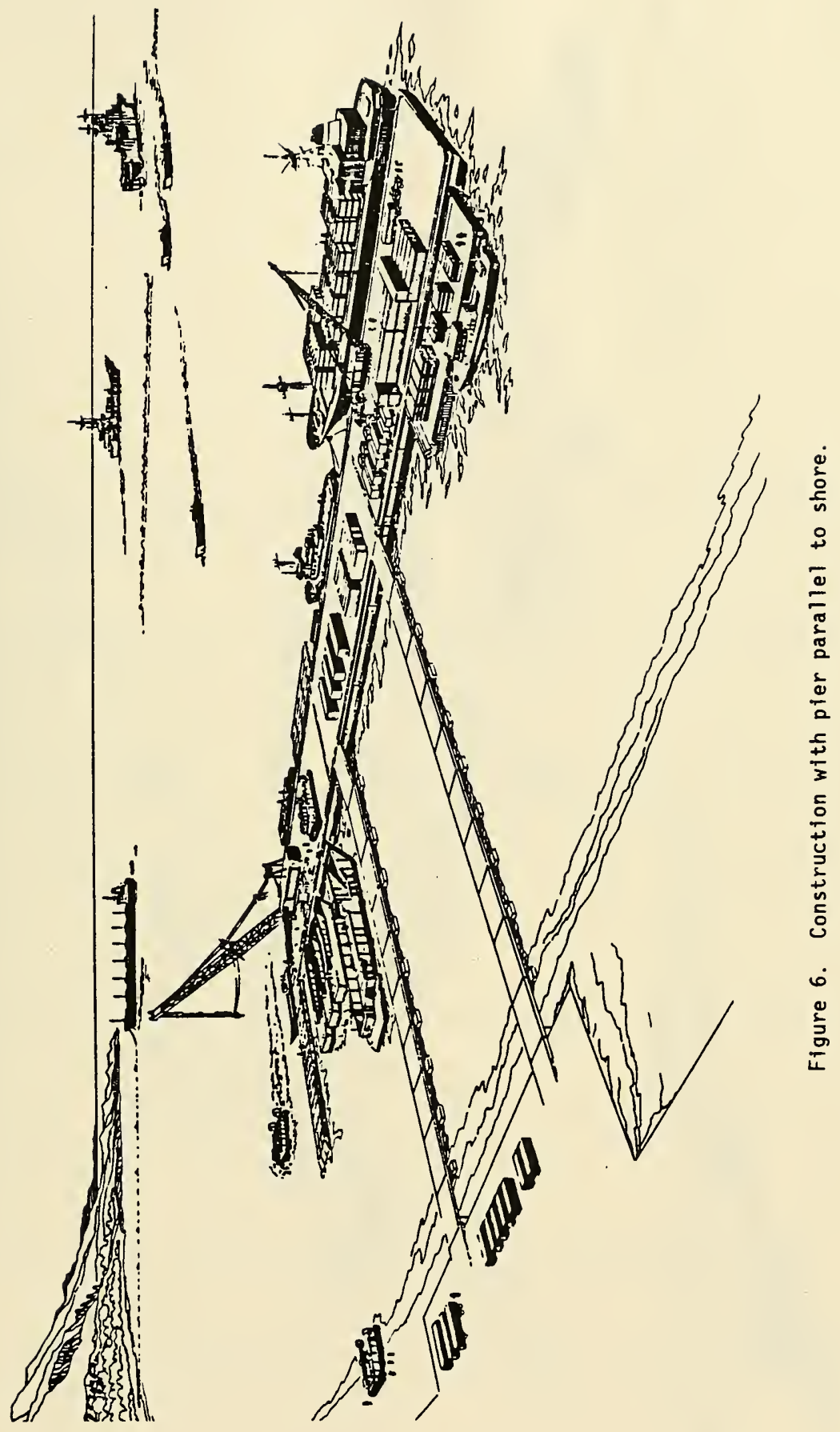




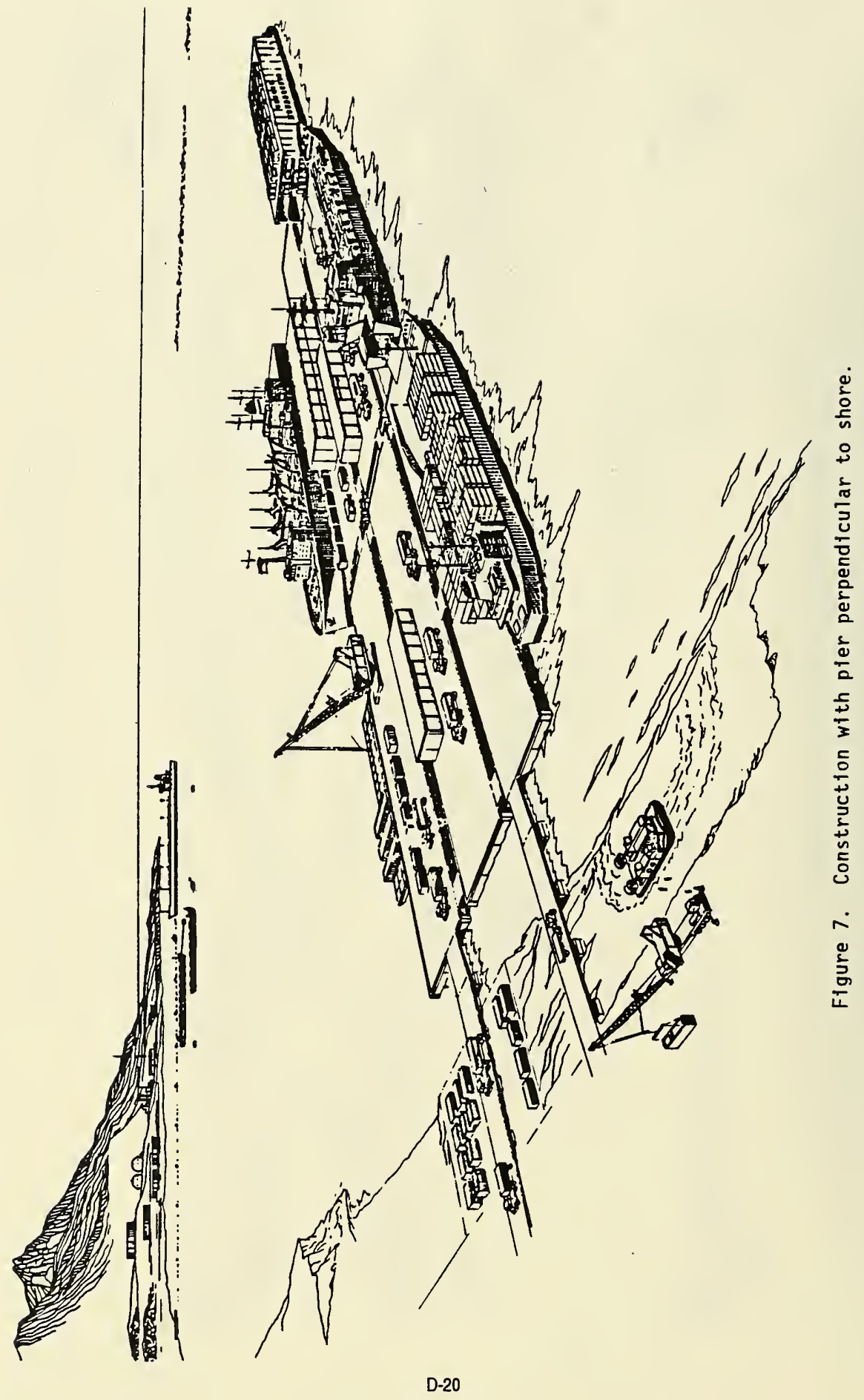




\section{Appendix E}

\section{BIBLIOGRAPHY}

1. Blaker, James R., et al.: "U.S. Global Basing: Historical Overview of the U.S. Overseas Basing System", (Task 1 Report), Hudson Institute, Inc., Alexandria, Virginia, August 1987.

2. Blaker, James R., et al.: "U.S. Global Basing: U.S. Basing Options", (Task 4 Report), Hudson Institute, Inc., Alexandria, Virginia, October 1987.

3. Blaker, James R.: "U.S. Overseas Basing System Faces a Difficult Transition", Armed Forces Journal International, February 1989.

4. Center for Naval Warfare Studies: "Overseas Basing: The Impact of Change", Vol. 1 \& 2 (SECRET), Naval War College, February 1989.

5. Dadant, P.M., et al: "A Comparison of Methods for Improving U.S. Capability to Project Ground Forces to Southwest Asia in the $1990 \mathrm{~s}^{\prime \prime}$, RAND Corp., R-2963-AF, November 1984.

6. Commission on Integrated Long-Term Strategy: "Discriminate Deterrence", The White House, January 1988.

7. Department of Defense: "Soviet Military Power: An Assessment of the Threat-1988", Superintendent of Documents, 008-000-00488-9, April 1988.

8. Headquarters United States Marine Corps: "Marine Air-Ground Task Forces (MAGTFs)", NAVMC 2710, Washington, DC, 28 May 1985. 
9. Hromadik, J.J.: "Mobile Ocean Basing Systems: A Concrete Concept", Naval Civil Engineering Laboratory, Port Hueneme, TN N-1144, January 1971.

10. Joint Chiefs of Staff: "Doctrine For Amphibious Operations", JCS Pub 3-02 (Change 5), Departments of the Army, Navy, Air Force, May 1988.

11. Lemcke, Eberhard: "Floating Airports", Concrete International, May 1987.

12. Marine Corps Development and Education Command: "Maritime Prepositioning Force (MPF) Operations", TACMEMO PZ 0022-1-87, June 1987.

13. Sohn, Louis B., et al.: "The Law of the Sea", West Publishing Co., April 1984.

14. U.S. Army War College: "Forces/Capabilities Handbook", Volumes I and II, Department of Military Strategy, Planning and Operations, September 1988. 


\title{
Appendix F
}

\section{ABRIDGED ACCOUNT OF EVENTS RELATING TO THE JOINT NCEL/NSA FEASIBILITY STUDY OF A MODULARIZED OCEAN BASING SYSTEM}

\author{
by
}

\author{
John F. Peel Brahtz, Ph.D.
}

The earlier contributions to Mobile Ocean Basing Systems (MOBS)* of the past 20 years have come primarily from such activities as University of California, Scripps Institution of Oceanography, Naval Civil Engineering Laboratory (NCEL), and a few other isolated groups. NCEL Technical Note, N-1144: Mobile Ocean Basing Systems - A Concrete Concept, dated January 1971 and authored by J.J. Hromadik, Duane Davis, D.F. Griffin, W.R. Lorman, M.J. Wolfe and H.S. Zwibel offers the most comprehensive insight to the earlier state of the art.

The following items offer a profile of significant MOBS-related activity during the recent past at various agencies of government, industry, and academe.

- The Naval War College at Providence, Rhode Island, at the direction of the Chief of Naval Operations, completed a 1988 study, OVERSEAS BASING: THE IMPACT OF CHANGE. The Naval War College study provides a partial, however, significant premise for the Modularized Ocean Basing System study by NCEL/NSA(NPS). Admiral C.A.H. Trost, USN, Chief of Naval

\footnotetext{
*Note: Early usage (1971-1988) of the acronym "MOBS" by NCEL, designated "Mobile Ocean Basing System". Current usage of the same acronym, as in the present NCEL/NSA study, designates "Modularized Ocean Basing System" or "MOBS, Circa 2000".
} 
Operations, in ordering the 'Overseas Basing' study, included in his Memorandum of 4 December 1987 to the President, Naval War College, the following stipulations for scope of investigation:

"In order to scope the issues and key implications for the Navy of a contraction of the U.S. overseas 10gistic and warfighting support structure, I would like the Center for Naval Warfare Studies to conduct a study of this important potential change in the future security environment. Such a study should address, at a minimum, the following aspects of the problem:

a. The general implications of a loss of U.S. ground and land based tactical air forces' overseas basing and access on mobile, flexible and relatively self-sufficient naval forces.

b. The implications for Navy of a contraction in the Navy's overseas logistic and warfighting support structure e.g., are there any changes in the fundamental way we support naval forces, or in future Navy force structure, that should be anticipated in the near term?" July 1988."

"The requested Study should be completed if possible by

During progress on the Naval War College study, the Navy's David Taylor Research Center (DTRC) hosted a workshop with Naval War College representatives on 28 February 1988 to address the full range of technological alternatives for reducing U.S. dependence on overseas basing. Floating islands of the MOBS type was an included topic of consideration. The workshop focused on the ongoing Naval War College study on "Overseas Basing." This workshop was a follow-on to a 8-9 February 1988 (DTRC) Pilot Decision Conference on Logistic Systems Concepts For The Year 2010. Nine candidate systems were identified and discussed. The pilot conference participants chose six of the nine futuristic logistic systems concepts to analyze, one of which was "Floating and/or Submersible Mobile Base."

- DTRC hosted a conference and workshop on 16-17 August 1988 focusing on Future Logistic Concepts. This workshop was a follow-on to the 28 February 1988 workshop. As a result of the 16-17 August workshop, 
there were five concepts established for primary consideration, one of which was representative of the MOBS concept. Information on MOBS was provided to DTRC by NCEL in order to enable a briefing on the concept to the study group.

- DARPA sponsored the BDM Corporation of Mc Lean, Virginia in 1988 to perform an evaluation study of Technological Alternatives to Bases Overseas (TABO). The BDM study concluded with a set of prioritized recommendations, the first of which was for a "modularized airfield at sea." Soon after BDM briefed DARPA in May 1988 on the results of their TABO study, BDM's consultant, General Paul F. Gorman, USA, Ret., similarly briefed the Commission on the Merchant Marine and Defense. Previous to the TABO study, General Gorman was designated as Working Group Chairman for the White House Commission On Integrated Long-Term Strategy (CILTS). The Commission's report, DISCRIMINATE DETERRENCE, including General Gorman's inputs, made the following significant observations:

a. "One long-term trend unfavorable to the U.S. concerns our diminishing ability to gain agreement for timely access, including bases and overflight rights, to areas threatened by Soviet aggression." ..."We will continue to need bases to deter or defeat aggressors at distant points overseas."

b. "The U.S. must develop alternatives to overseas bases." ..."We should not ordinarily be dependent on bases in defending our interests in the Third World. We have found it increasingly difficult, and politically costly, to maintain bases there."

- Bechtel Civil, Inc. of San Francisco, in early 1987, completed an extensive design study to evaluate the technical feasibility of floating structures suitable for aircraft operations and industrial uses, such as for warehousing or fishing industries. The owner is Kumagai Gumi Co., Ltd. of Tokyo, Japan. Specifically, the study focuses on the feasibility of a floating airport having 10,000 feet of runway to be installed in Tokyo Bay. Intended for use by commerclal aircraft, the strip would be single-point moored in order to allow alignment with wind 
direction. The contractor has determined the optimal design to consist of steel decking with prestressed concrete supporting structure configured to provide buoyancy.

- The RAND Corporation, Santa Monica, California, under the aegis of PROJECT AIR FORCE, conducted a comparison investigation of Methods for Improving U.S. Capability to Project Ground Forces to Southwest Asia in the 1990s. The RAND study results were briefed to the U.S. Air Force, the Military Airlift Command, and to Defense Department personnel by P.M. Dadant in February 1983. RAND concluded in their study that the most favorable system for projecting ground forces ashore included a Mobile Operational Large Island (MOLI) as a floating airbase for accepting large C5A military transport aircraft.

- Defense Advance Research Projects Agency (DARPA), previously known as ARPA, has entertained a prevailing interest over the years in buoyant ocean structures. One of DARPA's earlier projects (1970) was an Engineering Analysis of the Feasibility of a Stable Floating Platform, performed by Scripps Institution of Oceanography at La Jolla. The study was instigated by Dr. William Nierenberg, then Director of Scripps and a respected advisor to the Department of Defense on scientific and oceanographic matters. 


\section{Appendix G}

\section{DEFINITIONS OF FORWARD NAVAL BASE FUNCTIONS}

1. SOSUS (Sound Surveillance System). The SOSUS terminal functions that support ASW acquisition by locating submarine threats beyond the range of the sensors organic to Fleet forces.

2. ASWOC (Anti-Submarine Warfare Operational Center). Functions that support ASW evaluation by analyzing received ASW data, reporting SOSUS track data, and controlling and coordinating ASW functions under the Area ASW Commander.

3. MPA (Maritime Patrol Aircraft) Squadron. The U.S. P3 aircraft and cooperating NATO patrol squadron functions that support ASW acquisition and prosecution, both within and outside of the Naval force area of ASW responsibility, and the associated airfield facilities and assets to include airstrip, taxiways, parking aprons, and protective shelters for aircraft launch and recovery, maintenance, and protection.

4. Radar/IFF (Identification - Friend or Foe). Functions that support AAW acquisition, both within and outside of the Naval force capabilities.

5. Aircraft Control/Warning. Functions that support AAW evaluation and weapons assignment under the direction of the Area AAW Commander.

6. SAM (Surface-to-Air Missile). Functions that support AAW prosecution under the direction of the area AAW Commander. 
7. Fighter Aircraft. Fighter/interceptor aircraft (F-4, F-14, F/A-18) functions that support AAW prosecution.

8. Radar/IFF. Functions that support ASUW acquisition, both within and outside of the Naval force capabilities.

9. Weapon Control. Functions that support ASUW evaluation under the direction of the Area Commander.

10. Attack Aircraft (with SAM). Aircraft (A-6, A-7, $F / A-18)$ functions that support ASUW prosecution.

11. Terrestrial C(3)I. Naval Communications Station functions that provide over-the-horizon tactical target data, and operational low and high frequency circuits for communication and intelligence information.

12. Ordnance Supply. Naval Magazine or Naval Ammunition Depot functions that provide for the replenishment of expended missiles, projectiles, torpedoes, sonobuoys, powder, and fixed ammunition for ship weapons systems.

13. Aircraft Ordnance Supply. Naval Magazine or Naval Ammunition Depot functions that provide for the replenishment of expended missiles, projectiles, torpedoes, sonobuoys, powder, and fixed ammunition for aircraft weapons systems.

14. Ship Fuel Supply. Naval Fuel Depot functions that provide for the resupply of fast combat support ships (AOE) fuel supply via underway replenishment.

15. Aircraft Fuel Supply. Naval Fuel Depot functions that provide for the resupply of fast combat support ships (AOE) aircraft fuel supply via underway replenishment. 
16. Ration Supply. Naval Supply Depot functions that provide for the resupply of combat stores ships (AFS) rations stores via underway replenishment.

17. Aircraft Stores Supply. Naval Aviation Supply Depot functions that provide for the resupply of aviation stores to AFS ships via underway replenishment.

18. Systems Stores Supply. Naval Supply Depot functions that provide for the resupply of combat stores ships (AFS) system stores via underway replenishment.

19. Aviation Maintenance, Repair, Rework (MRR). Naval Avionics Repair Facility or Naval Air Rework Facility functions that maintain, repatr or replace failed or damaged aircraft systems beyond the Naval force capabilities, to include the delivery of critical avionics repair parts via Carrier-on-Board (COD) delivery.

20. Ship, Hull (MRR). Naval Ship Repair Facility functions to maintain, repair or replace failed or damaged ship systems to include weapons, hull, propulsion, and electronics systems, beyond Naval force capabilities.

21. Admin/LOG Communications. Functions that provide nontactical communications for Logistical and administrative operations. 



\section{Appendix H}

\section{GLOSSARY OF TERMINOLOGY}

ACB Amphiblous Construction Battalion

AOA Amphibious Objective Area

APODS Airports of Debarkation

CILTS Commission on Integrated Long-Term Strategy

CVBF Carrier Battle Force

DWF Deployable Waterfront

EE7 Exclusive Economic Zone

LIC Low-Intensity Conflict

MAGTFs Marine Air-Ground Task Forces

MEB Marine Expeditionary Brigade

MEF Marine Expeditionary Force

MEU Marine Expeditionary Unit

MIC Mid-Intensity Conflict 
MOBS As of 1989, Modularized Ocean Basing System; formerly Mobile Ocean Basing System

MOE Measures of Effectiveness

MPS Maritime Prepositioning Ship

NSAD National Security Affairs Department, Naval Postgraduate School

OSP Ocean Station Project

SPODS Seaports of Debarkation

TLWR Top Level Warfare Requirements

WSARE Warfare Systems Architecture and Engineering 


\section{DISTRIBUTION LIST}

ARMY HQDA (DAEN-ZCM), Washington, DC

CBC Library, Davisville, RI

CG FMF Lant, SCE, Norfolk, VA; Pac, SCIAD (G5) Camp HM Smith, HI

CINCLANTFLT Norfolk, Va

CINCPACFLT Code 442, Pearl Harbor, HI; Pearl Harbor, HI

CINCUSNAVEUR London, UK

CNA Tech Library, Alexandria, VA

CNO Code OP603E, Washington, D.C.; DCNO, Logs, OP-424C, Washington, DC

COMDT COGARD Library, Washington, DC

COMNAVAIRSYSCOM Code 41712A, Washington, DC; Code 422, Washington, DC

COMNAVLOGPAC Pearl Harbor, HI

COMNAVSURF Pac, Code N-4, San Diego, CA

COMSURFWARDEVGRU CO, Norfolk, VA

DIRSSP Tech Lib, Washington, DC

DOE Wind/Ocean Tech Div, Tobacco, MD

DTIC Alexandria, VA

FAA Code APM-740 (Tomita), Washington, DC

NSAP Science Advisor SCIAD (G5), Camp HM Smith, HI

LIBRARY OF CONGRESS Sci \& Tech Div, Washington, DC

MARITIME ADMIN R\&D, Washington, DC

MCRDAC Dep. CG, Quantico, VA ; M \& L Div Quantico, VA; RD, Quantico, VA

NAVFACENGCOM Code 00, Alexandria, VA; Code 03, Alexandria, VA; Code 03T (Essoglou), Alexandria,

VA; Code 04A, Alexandria, VA; Code 04A1, Alexandria, VA; Code 06, Alexandria, VA; Code 07,

Alexandria, VA; Code 09M124 (Lib), Alexandria, VA

NAVFACENGCOM - PAC DIV. Library, Pearl Harbor, HI

NAVFACENGCOM - WEST DIV. Code 04A2.2 (Lib), San Bruno, CA

NAVOCEANSYSCEN Code 94, San Diego, CA; Code 9642B, San Diego, CA

NAVPGSCOL Bruneau, Monterey, CA; Code 012, Dir. of Research, Monterey, CA; Code 56 TR, Tritten.

Monterey, CA; Code 68 (C.S. Wu), Monterey, CA; Code 68WY (Wyland), Monterey, CA; DEPT Nat'1 Sec

Affairs, Monterey, CA; E. Thornton, Monterey, CA

NAVSCOLCECOFF Code C35, Port Hueneme, CA

NAVSEASYSCOM Code 05M3, Washington, DC

NAVSWC Code E21I (Miller), Dahigren, VA

NAVWARCOL Code 24, Newport, RI; Lib Serials, Newport, RI

NOAA Joseph Vadus, Rockville, MD

NRL Code 2511, Washington, DC

OCNR Code I12I (EA Silva), Arlington, VA

SUPSHIP Tech Library, Newport News, VA

USCINCPAC Code J44, Camp HM Smith, HI

USNA Ocean Engrg Dept (McCormick), Annapolis, MD

JOHNS HOPKINS UNIV Ches Bay Rsch Inst, Rsch Lib, Shady Side, MD

NATL ACADEMY OF SCIENCES NRC, Dr. Chung, Washington, DC; NRC, Naval Studies Bd, Washington,

DC

WOODS HOLE OCEANOGRAPHIC INST Doc Lib, Woods Hole, MA

BATTELLE New Eng Marine Rsch Lab, Lib, Duxbury, MA

NATL ACADEMY OF ENGRG Alexandria, VA 

The Naval Civil Engineering Laboratory has revised its primary distribution lists. The bottom of the label on the reverse side has several numbers listed. These numbers correspond to numbers assigned to the list of Subject Categories. Numbers on the label corresponding to those on the list indicate the subject category and type of documents you are presently receiving. If you are satisfied, throw this card away (or file it for later reference).

If you want to change what you are presently receiving:

- Delete - mark off number on bottom of label.

- Add - circle number on list.

- Remove my name from all your lists - check box on list.

- Change my address - line out incorrect line and write in correction (DO NOT REMOVE LABEL).

- Number of copies should be entered after the title of the subject categories you select.

Fold on line below and drop in the mail.

Note: Numbers on label but not listed on questionnaire are for NCEL use only, please ignore them.

NO POSTAGE NECESSARY

IF MAILED IN THE UNITED STATES

Commanding Officer

Code L34

Naval Civil Engineering Laboratory

Port Hueneme. California 93043-5003 


\section{DISTRIBUTION QUESTIONNAIRE}

The Naval Civil Engineering Laboratory Is revising Its Primary distribution llsts.

\section{SUBJECT CATEGORIES}

\section{SHORE FACILITIES}

2 Construction methods and materials (including corrosion control, coatings)

Waterfront structures (maintenance/deterioratior, control) Utilities (including power conditioning)

Exploslves safety

Avlation Engineering Test Facllities

Fire prevention and control

Antenna technology

Structural analysis and design (Including numerical and computer technlques)

10 Protective constructlon (including hardened shelters, shock and vibration studies)

11 Soll/rock mechanics

14 Airflelds and pavements

15 ADVANCED BASE AND AMPHIBIOUS FACILITIES

16 Base facilities (including shelters, power generation, water supplies)

97 Expedient roads/alrflelds/bridges

18 Amphlbious operations (including breakwaters, wave forces)

19 Over-the-Beach operations (Includlng containerization, material transfer, lighterage and cranes)

20 POL storage, transfer and dlstrlbution
28 ENERGYIPOWER GENERATION

29 Thermal conservation (thermal engineering of buildings. HVAC systems, energy loss measurement, power generation)

30 Controls and electrical conservation (electrical systems. energy monitoring and control systems)

31 Fuel flexibility (liquid fuels, coal utillzation, energy from solid waste)

32 Alternate energy source (geothermal power, photovoltaic power systems, solar systems, wind systems, energy storage systems)

33 Site data and systems Integration (energy resource data. energy consumption data, integrating energy systems)

34 ENVIRONMENTAL PROTECTION

35 Hazardous waste minimization

36 Restoration of Installations (hazardous waste)

37 Waste water management and sanitary engineering

38 Oil pollution removal and recovery

39 Air pollution

\section{OCEAN ENGINEERING}

45 Seafloor solis and foundations

46 Seafloor construction systems and operatlons (including diver and manipulator tools)

47 Undersea structures and materials

48 Anchors and moorings

49 Undersea power systems, electromechanical cables. and connectors

50 Pressure vessel facillties

51 Physical environment (including site surveying)

52 Ocean-based concrete structures

54 Undersea cable dynamics

82 NCEL Guides \& Abstracts

91 Physical Security
None-

remove my name
65 Techdata Sheets 86 Technlcal Reports and Technical Notes 83 Table of Contents \& Index to TDS 


\section{NCEL DOCUMENT EVALUATION}

You are number one with us; how do we rate with you?

We at NCEL want to provide you our customer the best possible reports but we need your hetp. Therefore, I ask you to please take the time from your busy schedule to fill out this questionnaire. Your response will assist us in providing the best reports possible for our users. I wish to thank you in advance for your assistance. I assure you that the information you provide will help us to be more responsive to your future needs.

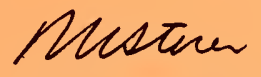

R. N. STORER, Ph.D, P.E.

Technical Director

DOCUMENT NO.

TITLE OF DOCUMENT:

Date: Respondent Organization :

Name:

Phone:

Category (please check):

Sponsor

User

Proponent
Activity Code:

Grade/Rank:

Please answer on your behalf only; not on your organization's. Please check (use an $X$ ) only the block that most closely describes your attitude or feeling toward that statement:
SA Strongly Agree
A. Agree
o Neutral
D Disagree
SD Strongly Disagree

\section{SA A N D SD}

1. The technical quality of the report is comparable to most of my other sources of technical information.

2. The report will make significant improvements in the cost and or performance of my operation.

3. The report acknowledges related work accomplished by others.

4. The report is well formatted.

5. The report is clearly written.
()( )( ()()
() () () () ()
() ()()( () ()

()( )( ()( )

()( )( ) () ()
SA A N D SD

6. The conclusions and recommendations are clear and directly supported by the contents of the report.

7. The graphics, tables, and photographs are well done.

( ) ( ) ( ) ( )

Do you wish to continue getting NCEL reports?

Please add any comments (e.g., in what ways can we improve the quality of our reports?) on the back of this form. 


\section{Comments:}

Please fold on line and staple

DEPARTMENT OF THE NAY

Naval Clvil Engineering Laboratory Port Hueneme. CA 93043-5003

\section{Official Businese}

Penalty for Private Use $\mathbf{s 3 0 0}$

Code LO3B

NAVAL CIVIL ENGINEERING LABORATORY

PORT HUENEME, CA 93043-5003 


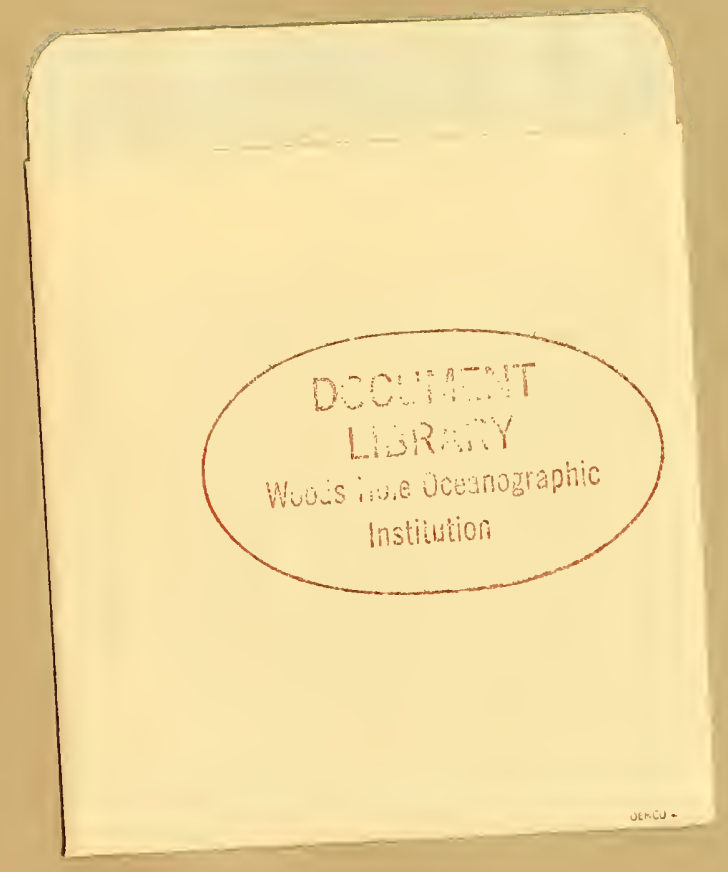




\section{Official Business \\ Penalty for Private Use $\$ 300$}

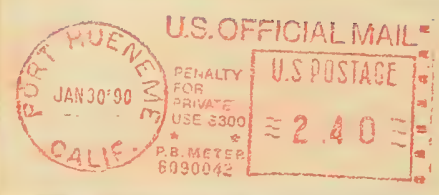

$648-823.001-3$

Document Library LO-206

Hoods Hole Oceanographic Ins?

Woods Hole, MA 02543-0000 